\title{
Analysis of the World Design Organization 'World Design Challenge' Program: Participant Insights for an Improved Process
}

By

Angela Fahlman

A thesis submitted to the Faculty of Graduate and Postdoctoral Affairs in partial fulfillment of the requirements for the degree of

Master of Design

In

Industrial Design

Carleton University

Ottawa, Canada

(C) 2021 Angela Fahlman 


\begin{abstract}
This thesis analyses the World Design Organization (WDO) World Design Challenge program through participant insights to improve the process. The demand for well-thought-out design solutions for complex problems drives industry, governments and educational institutions to seek more efficient and effective ways to generate creative out-of-the-box results. To meet the request for unique, positive user-based approaches, the WDO expands on traditional methods and leans on virtual remote practices that produce robust options to enhance sustainability. The WDO World Design Challenge program is a new strategically designed remote design process that offers possibilities to generate such results. The research analyses a series of World Design Challenge programs through observation, participation and research participant feedback. This thesis documented the researcher's participation and observation of three World Design Challenges and thirteen research participant insights which were obtained through surveys, questionnaires, and interviews. The research explored team dynamics, online and remote obstacles, phase sequence and content, plus process structure and procedures. The research discovered how the WDO World Design Challenge program can be improved to increase user experience and maintain participant retention.
\end{abstract}

Key Words: World Design Organization, Design Challenges, Design Thinking, Virtual Design Process 


\section{ACKNOWLEDGEMENTS}

A special thanks to the powers that be for giving me the ability to learn and remain healthy during my academic journey. Many thanks to my children Stasia and Declan, for enduring the long hours, their support and love, and being selfless while I focus on my studies. To my two closest friends and most prominent cheerleaders, Christine and Elise, for their continued understanding and laughter.

I want to take this opportunity to thank Professor Thomas Garvey, my thesis supervisor, and Professor Mugendi M'Rithaa, my co-supervisor, for providing outstanding guidance, feedback and contributing to unearthing a greater understanding of the design process. It was a pleasure to be enriched by my supervisors and their vast network within industrial design. I would also like to thank Professor Stephen Fai, Professor WonJoon Chung for their valuable time, reading my thesis and offering their advice. A special thank you to Professor Chung for seeing my potential and granted me entrance into the program.

Thank you to all my brilliant professors at Carleton University for leading me in the right direction by providing the necessary knowledge to continue on a productive path. My gratitude goes out to the support staff at Carleton University for their dedication to student success. Thank you, Carleton University and The School of Industrial Design, for moving mountains to allow me to have a customized learner experience that permitted me to grow and transcend academically.

Thank you, to the World Design Organization for allowing me to participate and in the World Design Challenge programs that fostered social and sustainable change. To Bertrand Derome, Andréa Springer, Natalie Dutil, Jessica Hanson and the WDO Secretariat for their outstanding dedication and permitting me to gain insight into their virtual design process structure.

Thank you to the UN Women Asia and the Pacific and Wenny Kusuma and Melissa Alvarado for their research participation and insights. Thank you, Susan Garvey and Lyndsay McLean, for helping educate and guide all the participants on Violence Against Women and Girls (VAWG) content. Thank you to Christine Kretz and Miki Sode of the International Space Station National Laboratories for their endless dedication to understanding design thinking. 
Thank you, Amed Asfand, for your assistance and providing guidance. Thank you, Jed Looker, for introducing me to the program. Finally, thank you to my classmates, Amira Ashraf, Carla Ayukawa, and Maryam Atteff, for the enriching, nonjudgmental and collaborative discussions. 


\section{GLOSSARY of TERMS}

\section{World Design Organization (WDO) World Design Challenge program}

World Design Challenge program is a proprietary programme by the World Design Organization, which is a virtual workshop experience where groups of voluntary participants are guided through facilitated sessions to address issues through the lens of design to propose relevant and impactful solutions. The World Design Challenges exist under the World Design Challenge program umbrella.

\section{Design Process}

A series of steps, actions and constructs that a designer uses to generate creative solutions. The design process usually dictates that a set of structures with various tasks will produce the building blocks for a finished tangible/intangible product or prototype.

\section{Design Sprints}

The series of steps, actions and constructs that a designer uses to generate or brainstorm multiple creative solutions within a short time interval.

\section{Design Creators}

Employees at the World Design Organization (WDO) who created the World Design Challenge program process.

\section{Design Contributors}

Individuals who contributed and participated at various levels in any World Design Organization (WDO) World Design Challenge program.

\section{Phase Zero}

Phase Zero is the initial stage prior to Phase One that includes building the World Design Challenge program and its process. The pre-phase includes all the construction, considerations, and organization of the World Design Challenge program. 


\section{Phase One}

Phase One is the first stage of the World Design Challenge program. It is the brainstorming and ideation stage.

\section{Phase Two}

Phase Two is the second portion of the World Design Challenge program.

It includes the feasibility stage.

Individuals who contributed and participated at various levels in any World Design Organization (WDO) World Design Challenge program.

\section{Research Participants}

Individuals who participated in the research for this thesis. 


\section{TABLE OF CONTENTS}

$\begin{array}{lr}\text { Abstract } & \text { i } \\ \text { Acknowledgements } & \text { ii } \\ \text { Glossary of Terms } & \text { iii } \\ \text { Table of Contents } & \text { iv } \\ \text { List of Figures } & \text { v } \\ \text { List of Appendices } & \text { vi }\end{array}$

\section{INTRODUCTION}

1.0 Background and Scope of Work

1.1 Purpose of Thesis ___ 3

\section{LITERATURE REVIEW}

2.0 Introduction

2.1 1967 Lateral Thinking ___ 5

2.21971 Responsible Thinking ___ 6

2.31978 Human-Centered Thinking ___ 6

2.42005 Socially Responsible Thinking ___ 7

2.5 2009 Business Management Thinking ___ 7

2.6 2020 Virtual Global Thinking ___ 7

2.7 Contribution __ 8

2.8 Conclusion 8

\section{METHODS}

3.0 Introduction and Research Overview ___ 9

3.1 Triangulation Approach

3.2 Delphi Method Approach ___ 9

3.3 Research Procedure $\quad 10$

3.4 Part One-Participant Observation

3.5 Part Two-Survey ___ 14 
3.6 Part Three-Questionnaire and Interview

\section{DATA COLLECTION AND ANALYSIS}

4.0 Introduction to Participant Observation 17

4.1 Participant Observation Results __ 18

4.2 Introduction to Survey ___ 22

4.3 Survey Analysis __ 23

4.4 Introduction to Questionnaire and Interviews __ 32

4.5 WDO Questionnaire and Interview Results and Analysis___ 35

4.6 UN Women and ISS NL Questionnaire and Interview Results and Analysis ___ 40

4.7 Key Findings _ 49

\section{CONCLUSION}

5.0 Summary of Results and Recommendation ___ 53

5.1 The Adjusted World Design Challenge program Structure___ 58

5.2 Limitation of Thesis

5.3 Contributions

5.4 Further Research

\section{REFERENCES}

\section{APPENDICES}




\section{LIST OF FIGURES}

Figure 1. ICSID and WDO Timeline

Figure 2. Research Procedure Illustration

Figure 3. Three Part Research Approach Illustration

Figure 4. Survey Question Responses Diagram

Figure 5. Questionnaire and Results Diagram

Figure 6. Questionnaire Results Diagram

\section{LIST OF APPENDICES}

Appendix A. Email to World Design Organization and Participants

Appendix B. Consent Form

Appendix C. Research Package - Introduction

Appendix D. Research Package - Survey

Appendix E. Research Package - Interview Questions

Appendix F. Supervise Signature Form

Appendix G. Survey Documentation

Appendix H. WDO Interview and Questionnaire Documentation

Appendix I. UN WOMEN and ISS NL Interview and Questionnaire Documentation

Appendix J. Generation Equality Asia Pacific Design Challenge

Appendix K. Design In Space For Life On Earth Design Challenge 


\section{CHAPTER 1: INTRODUCTION}

\subsection{Background Scope of Work}

The International Council of Societies of Industrial Designers (Icsid) was established in 1953.

The intent of the organization was to be an international presence that would represent and showcase the progression of industrial design. In 1959, the name was transitioned to the International Council of Societies of Industrial Design. Icsid officially became the World Design Organization (WDO) in 2017.

\section{Icsid and WDO Timeline}

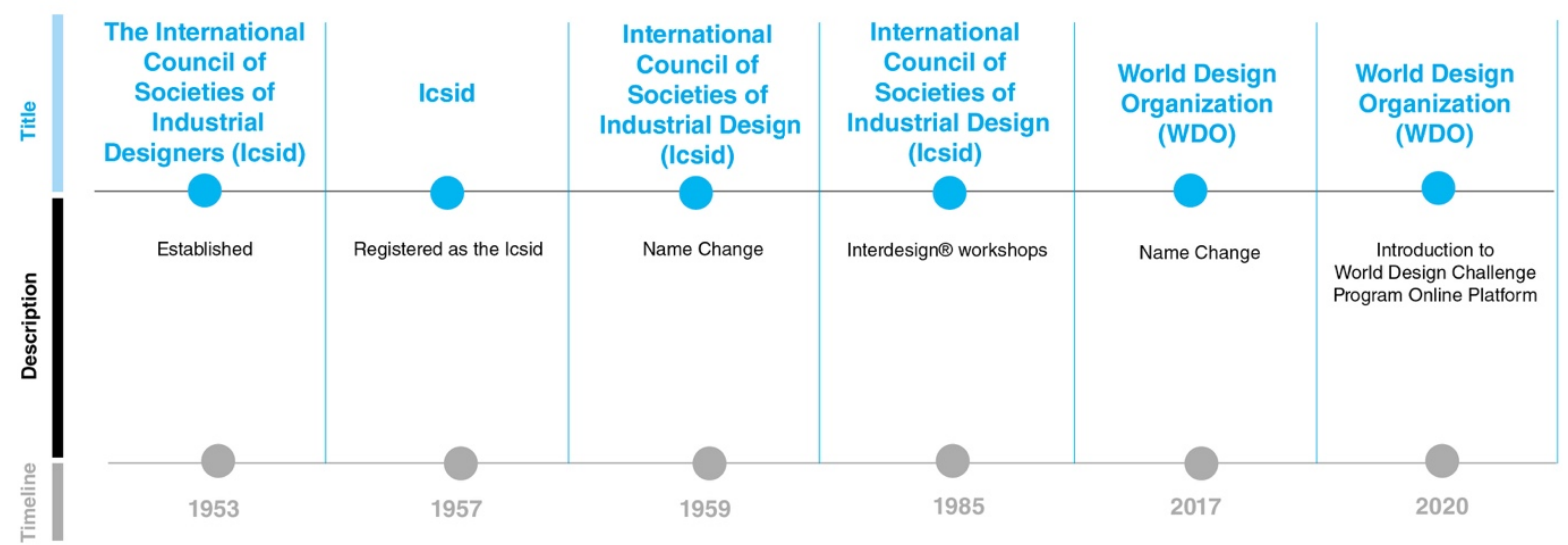

Figure 1. Icsid and WDO Timeline

Icsid initiated a programme called the Interdesign workshop program. The program was prevalent in highlighting the role designers could play in developing design-based solutions to local and global problems. Icsid as an organization held 38 Interdesign workshops in 25 different countries over the span of 35 years. The Interdesign workshops focused on issues such as climate change, urban transportation and traffic, ageing population, green spaces, healthcare access and water management.

Conceptually, the Interdesign workshops aim to take the brainstorming portion within a design process and offer it in a condensed intense two-week time frame. Brainstorming in a condensed timeframe is discussed in Dubberly (2004).

The two-week period included a five-step process as follows:

1. Identify and understand the goals and needs of the business and user

2. Divergent thinking to ideate and generate multiple solutions or visions 
3. Choose the best idea

4. Build a prototype

5. Validate design and determine what and what does not work.

The process is collaborative and intended to be user-centered.

In 2020, due to COVID-19, WDO responded to the imposed restrictions and created a new online remote version of the Interdesign workshops, the World Design Challenge program. The World Design Challenge program brings together international volunteer workgroups that work remotely to address the most urgent pressing global issues. The first World Design Challenge was the COVID-19 Design Challenge, in partnership with IBM Design and Design for America (DFA), which put forward a call that brought over 225 designers from 33 countries to address challenges around the coronavirus pandemic. The COVID-19 World Design Challenge produced various options and valuable products. Some of these options and initiatives included Patient Communication with VitalTalk, FamilyHub and EdDi learning platform.

The COVID-19 World Design Challenge success provided WDO with the opportunity to revaluate how it can contribute towards global issues. Soon after, WDO began offering the international community the ability to partner, allowing them to focus on generating remote creative possibilities.

To date, the WDO has held three different World Design Challenges: The COVID19 Design Challenge, UN Women - Generation Equality Asia Pacific Design Challenge and International Space Station National Laboratories (ISS NL) - Design in Space for Life on Earth Challenge.

The UN Women 'Generation Equality Asia Pacific Design Challenge' had two phases. Phase One brought 112 international participants together virtually to generate a variety of design solutions to help fight Violence Against Women and Girls (VAWG). The objective was to reduce VAWG through targeted behaviour within six challenge statements:

1. Enlisting community leaders and influencers

2. Leveraging media to challenge stereotypes

3. Moving people emotionally and empathically to act

4. Transforming men's sense of entitlement 
5. Changing the mindset that VAWG is normal

6. Influencing parents to raise children to reject harmful gender stereotypes and violence

All participants were divided into the six challenge statement teams. Each of the teams included two facilitators (one with topic expertise and one with design experience), several thought leaders who transitioned between the teams by providing support, resources, and information relevant to the subject and finally the team participants.

The ISS NL 'Design in Space for Life on Earth Challenge' Phase One included 71 space industry leaders, researchers, and designers from 26 countries to address three key challenge statements:

1. How can space-based research address UN Sustainable Design Goals (SDG)?

2. How can we build an orbital university?

3. How can the ISS become a business incubator?

All participants were divided into five teams. There were two UN SDG teams, two orbital university teams and one business team. Each of the teams included one facilitator, two subject matter experts (one with topic expertise and one with design experience), several thought leaders who transitioned between the teams by providing support, resources, and information relevant to the research area and finally the team participants.

The focus of the WDO is to serve as a catalyst for global community in their quest to create a better world through a design tools that generates sustainable design solutions. The WDO continues to be present as a global leader that stands by its values and commitment to the industry of Industrial Design and sustainable initiatives by providing guidance, support and 'design process' enrichment through the new online World Design Challenge program.

\subsection{Purpose of Thesis}

The demand for well-thought-out design solutions for complex problems drives industry, governments, and educational institutions to seek more efficient and effective ways to generate creative out-of-the-box results and outcomes. To meet these demands for unique, positive user-based approaches, WDO has expanded on the traditional method of in-person collaborative 
workspaces for the World Design Challenges and leans on practices that produce robust options to enhance sustainability through the World Design Challenge program. The Interdesign workshops consist of a group of high-level professional industry representatives gathered in a face-to-face setting to generate ideas to address complex global problems. The World Design Challenge program involves professionals and non-professionals gathering in an online environment to generate ideas to address similar issues. The World Design Challenge program puts out a call to the public for participants. WDO screens and assigns applicable participants to a balanced interdisciplinary team. The World Design Challenge program has a higher quantity of participants in comparison to the Interdesign workshops.

This thesis examines three of the World Design Challenges to determine how it can be improved by observing, participating, and extracting experiences from participants. This research provides a synopsis of the researcher's observations while participating in three World Design Challenges. During the observation the researcher examines team dynamics, online obstacles, plus phase content and structure. Through observing three World Design Challenges, the research intends to highlight user experience improvements and point out areas to increase participant retention.

In addition to the observational research, research participants will voice their experience by providing vital insight into their World Design Challenge program experience. The research will provide participants with an opportunity to help shape future iterations of the World Design Challenge program. This thesis will analyze the World Design Challenge program online environment to identify any areas that can be strengthened and provide feedback regarding online collaborative tools.

The primary aim of the thesis is to find answers to the following questions:

1. How can the WDO Program be improved?

2. How can the new online version of WDO's Interdesign workshop be successful online through user experience and participation retention? 


\section{CHAPTER 2: LITERATURE REVIEW}

\subsection{Introduction}

The concept of design thinking and the design thinking process are fundamentally a large field of study. The literature is extensive, but none exactly and historically represents what the WDO World Design Challenge program is presently doing. The literature review takes an Industrial Design milestone approach, which is more closely related to this thesis and the World Design Challenge program.

The intent is to contribute to the existing body of knowledge by analyzing three of WDO's new online World Design Challenge programs through participants' insight to determine how it can be further enhanced and improved. This literature review takes an appropriate approach for this thesis and explores the design thinking process. The timeline begins in 1967 and ends at our present-day 2021 online landscape. These dates and key sources were chosen to highlight significant Industrial Design milestones in design thinking as they relate to the thesis. The milestones in design thinking are fundamentally integrated into WDO World Design Challenge program in some capacity, either within the process, exercises or philosophy. The integration is also dependent on industry, partner, and problem to be solved. The World Design Challenge program does not explicitly use these terms or reference these milestones in the program.

Each of the six-key milestones is assigned a terminology label representing the highlighted body of works. Not all labels are accredited to those sources but rather a category labelling system for the purpose of the literature review.

Many of the six-key sources lines of thought in the timeline are intended for professionals. WDO uses these lines of thought for professionals and anyone who participates in the World Design Challenge program.

\subsection{Lateral Thinking - Design Thinking Process}

In 1967 Edward de Bono introduced a new thought generating technique called lateral thinking (De Bono, 1968, 1970). The lateral thinking concept encourages designers and non-designers to use a step-by-step approach to increase creativity. Lateral thinking is used as a technique to 
deconstruct conventional ways and predetermined patterns of thought to solve problems.

Essentially, the lateral thinking technique is an idea generating tool that helps increase output.

Lateral thinking produces different ways to define a problem, finds new ways to do something effectively and increases confidence in ones thinking (De Bono, n.d.). In addition, Edward de Bono created a widely used method in business called the Six Thinking Hats. Many working environments have benefited from the Six Thinking Hats method (Payette and Barnes, 2017) due to its easy to administer, learn and implement approach. Edward de Bono introduced lateral thinking to professionals so they could thoroughly access the given results. This introduction made creative thinking accessible to all professionals within all industries.

\subsection{Responsible Thinking - Design Thinking Process}

Victor Papanek's Design for the real World: Human Ecology and Social Change became a staple within the design community for understanding the responsibilities of the designer to create products, tools and infrastructures that had a positive impact (Papanek, 1973). As an educator and designer, Victor Papanek's interests were in design and the effects of those designs on people and the environment. Victor Papanek viewed many of the produced products to be ineffective, frivolous, and unsafe (Clarke, 2021). This view led to a movement within the design community to create products and infrastructures that are well thought out and focused on sustainability.

\subsection{Human-Centered Thinking - Design Thinking Process}

In 1978 the Innovation Design Engineering Organization became a pioneer in design thinking. They not only considered sustainability factors but also emphasize aligning products and processes to user needs. IDEO's strategy behind design thinking is to determine what to do and what not to do. Design thinking can help organizations increase products, services and processes to meet the user needs, business goals, achieve global sustainable outcomes and eliminate any elements that should not be part of the process. Design thinking stemmed from the need to problem-solve using a systematic creative approach, generating a non-judgmental space for an abundance of wild ideas through divergent thinking then distilling them through a convergent streamline to produce an out-of-the-box result (Osborn, 2009). The Executive Chair of IDEO, Tim Brown, states (IDEO, n.d.) that "Design thinking is a human-centred approach to innovation that draws from the designer's toolkit to integrate the needs of people, the possibilities of technology, and the requirements for business success." 


\subsection{Social Responsibility - Design Thinking Process}

Socially Responsible Design focuses on the importance of social responsibility when designing products and services for social, environmental, economic, and political issues (Davey, et al, 2005). The paper introduces a new Socially Responsible Model, consisting of eight core features of modern experience that design impacts and maps. They include government, economic policy, fair trade, ecology, social inclusion, health, education and crime. The paper aims to bring awareness to a new design model that enables different design approaches within an overall framework. The paper promotes how design can have an impact on complex issues in the global community. Emphasis is placed on how designers must be aware of how their designs can be misused or abused. Companies also need to examine their roles in society how they impact the user and environment. Overall, there is a growing concern for the well-being of people and the planet.

\subsection{Business Management Thinking - Design Thinking Process}

Roger Martin focused on integrative thinking and design thinking and its relation to the business world. Much of his research work is in strategy, democratic capitalism, integrative thinking, design of business, incentives \& governance, and social innovation (Martin, n.d.). Roger Martin's book The Design of Business promotes moving away from analytical thinking that refines current knowledge and only produces minor improvements (Martin, 2009). Instead, he recommends using design thinking to increase innovation and a competitive business edge. Roger Martin believes that as companies search for significant, game-changing innovation, they turn to the design process to help them achieve those outcomes. Companies are putting in endless efforts and resources into research and development, creative designers, and innovation consultants, only to achieve disappointing results. Roger Martin suggests the integration of integrative thinking and design thinking will help them achieve those innovative results.

\subsection{Virtual Global Thinking - Design Thinking Process}

The WDO's World Design Challenge program utilizes, in some capacity, the many angles of design thinking that have been discussed up to this point. The World Design Challenge program use design thinking in the design process to remove linear analytical approaches that are bogging down the innovation potential. Essentially, for the global community to transcend beyond its present state, we need to produce a customizable strategy to combat our past ways of thinking so 
that it does not dictate our future direction. WDO recognizes the need to offer the design process journey to non-design sectors and industries as a means to identify successful design-driven solutions and as a result, has developed an online model for collaboration. The remote design thinking approach permits a multidisciplinary, international community to come together in a collaborative platform to provide unique solutions to complex problems.

\subsection{Contributions}

This thesis intends to observe participants in the online World Design Challenge program platform to understand better how it can be improved. The research findings will contribute to the Industrial Design community by establishing a better understanding of how complex problems can be addressed by using design thinking in an online landscape. Freire, Del Gaudio and Franzato state the research should include participants and their insights as a user-based approach to incorporate locals from the community of thought to establish a network that will assist in the development (Freire, Del Gaudio, and Franzato, 2018). The World Design Challenge program includes such community members. The new online World Design Challenge program in itself is design thinking producing innovations.

\subsection{Conclusion}

This literature review approach is appropriate for this thesis as it explores the design thinking process through a six-key Industrial Design milestone timeline. Each milestone in the timeline has influenced the World Design Challenge program.

The World Design Challenge program encapsulates all the key milestones in the following ways:

1. The WDO uses a step-by-step approach to generate creative thinking (Edward de Bono)

2. The WDO promotes sustainable option as solutions (Victor Papanek)

3. The WDO aligns their partner's goals with user needs when creating challenge statements (IDEO)

4. The WDO takes on World Design Challenges that address eight the categories in the Social Responsibility Model (Davey, Wootton, Thomas, Cooper, and Press)

5. The WDO brings design thinking to the non-design profession (Roger Martin) 


\section{CHAPTER 3: METHODS}

\subsection{Introduction and Research Overview}

The thesis utilizes three main design research methods as the foundational basis of the study. It involves observation, survey and questionnaire and interview. The combination of methods aims to provide a cohesive and grounded understanding of the thesis structure and the results.

\subsection{Triangulation Approach}

The Triangulation approach applies three different methods to cross-reference results for validations and credibility. Through a mixture of different methods, the weakness of one method may be compensated by the strength of another (Wilson and Sharples, 2015). For this reason, three methods have been studied and integrated as follow:

1. First-hand observation to establish context

2. A survey to determine background and exposure to the topic

3. An interview questionnaire and a transcribed recorded session that provided an interpretation of experience and feedback

\subsection{Delphi Method}

To analyze how the WDO's World Design Challenge program can be improved, it is essential to receive feedback from those who created and participated in the World Design Challenge program. The research includes multiple high-level members from each group. The research also includes an individual from the leadership team as well as participant level so that their personal experiences can be documented. The leadership team consists of high-ranking individuals. This thesis utilized a concept from the Delphi method where a few expert level research participants were used for a small sample group for both the survey, questionnaire and interviews.

The Delphi Method is an effective data tool that utilizes iterations to collect and refine the interpretations of expert experiences by using a variety of question techniques to receive feedback. These question techniques aim to focus on problems, successes, opportunities, and solutions. (Skulmoski et al, 2007). The Delphi Method is used because it elicits information and views from subject matter experts or those who have relevant knowledge on the topic (Robson and McCartan, 2016). 
To provide clarity and answers, the following tasks have been applied:

1. Determine which 'World Design Challenges' would be examined

2. Determine which organizations to include

3. Identify participants by various levels of exposure and participation in each challenge

4. Determine what needs to be discovered by the research

5. Collect feedback based on survey and questionnaire with the participants

6. Document discussions in the interview that are based on the participant questionnaire

7. Summarize findings through the discussions

8. Provide recommendations based on the findings

\subsection{Research Procedure}

The research procedure was established by selecting five WDO representatives, five representatives from the UN Women and three representatives from the International Space Station National Laboratory (ISS NL). The teams were then further divided into levels of participation. The WDO included two leadership and three Secretariat staff. There were two leadership representatives from UN Women, one subject matter expert, one facilitator and one thought leader. The ISS NL also had two leadership members, one subject matter expert and one facilitator (See Figure 2). All thirteen individuals created or participated in a World Design Challenge program. Both the UN Women and ISS NL research participants agreed to take part in the World Design Challenge program and in this thesis research. 


\section{Research Procedure}
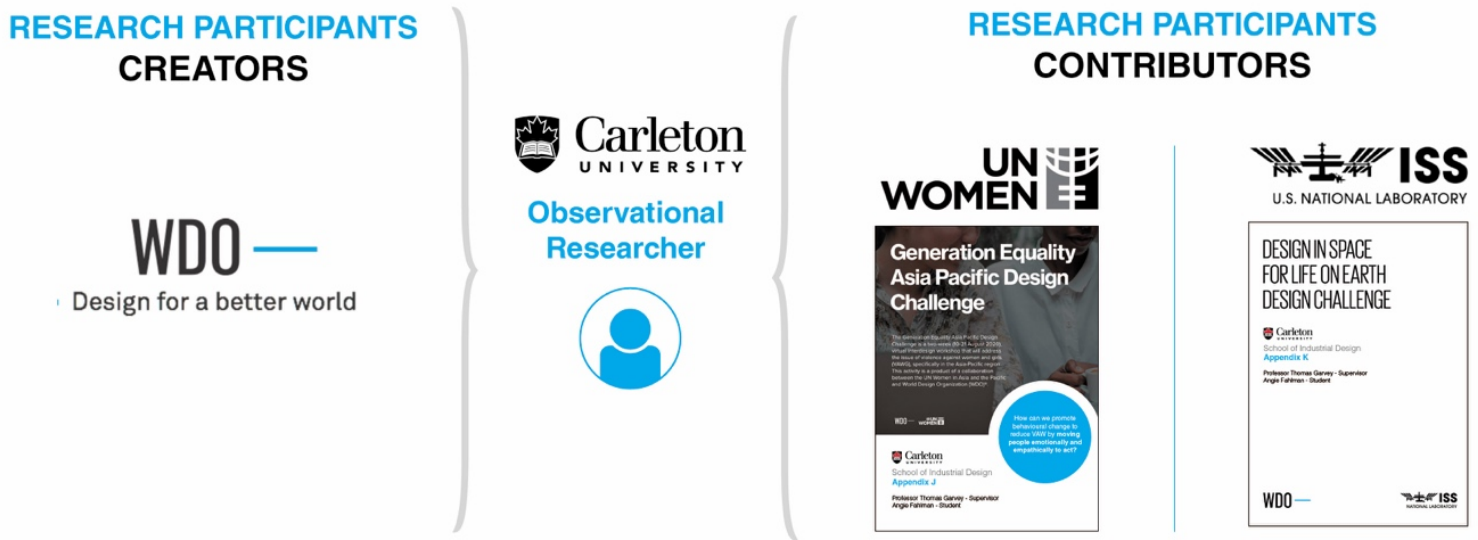

Figure 2. Research Procedure Illustration

The WDO Secretariat initially recruited all individuals by contacting them via email to obtain their permission for the research study. The researcher then contacted the participants to provide them with the research study instructions and the interview package.

The interview package email contained:

- Introduction to the Research

- Interview Agenda and Instructions

- Research Consent Form

- Digital Survey Form

- Digital Interview Questionnaire

- Zoom Interview Video Recorded and Transcribed Session Schedule Booking Link

The research involved three parts (See Figure 3). In the first part, the researcher participated directly in both the UN Women and ISS NL World Design Challenges. The second part included a survey which provided background information to support the third part of the study. The third part included the interview questionnaire. The second and third part of the study were to be completed by the three identified groups (WDO, UN Women and ISS NL). 


\subsection{Part One of Research - Participant Observation}

The initial research included the researcher observing the WDO World Design Challenge program process. A participant observation approach which includes a researcher becoming a member of the observational group, one can hope to obtain knowledge and insight through realworld learning (Robson and McCartan, 2016). The researcher was involved from the onset of Phase One but was not privy to Phase Zero, which involved the process development. The researcher held a facilitator position in the UN Women World Design Challenge and a thought leader position in ISS NL World Design Challenge. Both Phase Ones were two weeks in length while Phase Two for UN Women was five weeks in duration.

\section{Three Part Research Methods}

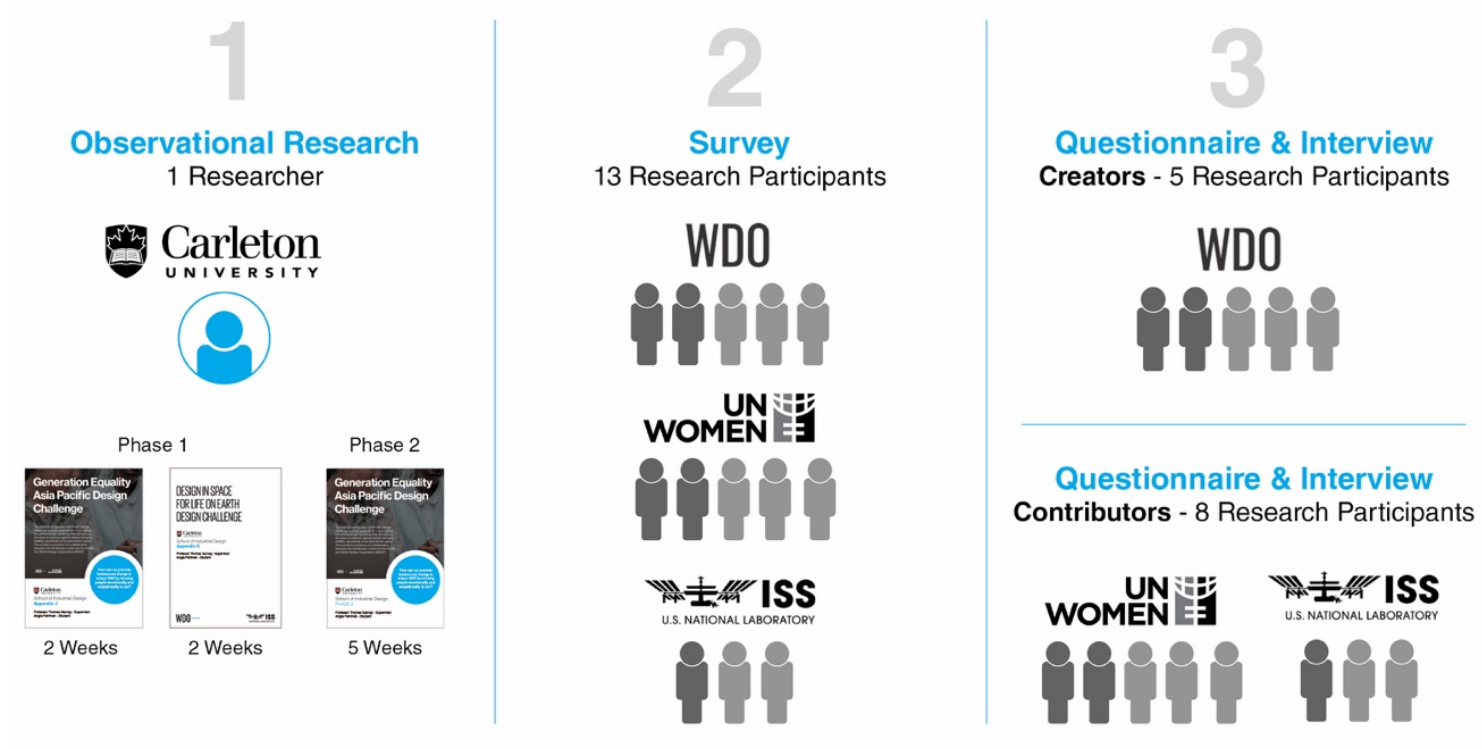

Figure 3. Three Part Research Methods Illustration.

\section{Recruitment Procedures}

WDO and UN Women Asia and the Pacific put out a call for participants to participate in the 'Generation Equality Asia Pacific Design Challenge'. Six teams were created with six different challenge statements. Each of the six teams contained subgroups that included two facilitators (one with topic expertise and one with design experience), several thought leaders transitioned between the teams by providing support, resources, and information relevant to the subject and lastly, the team participants. The researcher participated and observed on Team 3 as a design facilitator. 
WDO and ISS NL Challenge had participants take part in the 'Design in Space for Life on Earth Design Challenge'. Three challenge statements were divided among five teams. Each of the five teams contained subgroups that included one facilitator, two subject matter experts (one with topic expertise and one with design experience), several thought leaders transitioned between the teams by providing support, resources, and information relevant to the subject and the team participants. The researcher participated and observed on SDG Team 1 and 2 as a design subject matter expert.

\section{Observation Procedures}

The observation method included taking meeting notes, plus documenting the team's agenda, completed tasks, homework, struggles and accomplishments. These findings were posted to all team participants using a Slack Channel. All facilitators and subject matter experts held meetings outside the regularly scheduled team meetings. Meetings took place using Zoom. All concerns with the team and the teams progress were recorded using notes and communications correspondences between the facilitator, subject matter experts and in some instances the WDO Secretariat. Once the World Design Challenge program was completed the researcher documented all findings and produced a report documenting the journey. The observational findings are provided in 4.0 and 4.1. The findings are then synthesized into recommendations.

WDO and UN Women Asia and the Pacific put out a call for participants to participate in Phase Two of the 'Generation Equality Asia Pacific Design Challenge. A total of four teams were created with the use of original statements applied in Phase One. However, there was the exclusion of two statement unlike to Phase One. The elimination of statements was a leadership decision, and the research was not privy to the reasoning. Each of the four teams contained subgroups, including leadership team representative, subject matter expert, a facilitator, thought leaders and participants. The teams consisted of some individuals from Phase One but also included new participants. These unique multi-level viewpoints provide a holistic granular synopsis into the inner workings and interpretation of the research question. 


\subsection{Part Two of Research - Survey}

The second part of the research included a survey (See Appendix D) that gathered data and background information on the interviewees. The information was structured to determine the following:

1. Previous exposure to the topic

2. Education level as it pertains to the topic

3. Biases - negative or positive feelings on the subject

4. Level of understanding of the topic

The survey contained nineteen questions of true or false and multiple choice. The survey allowed insight into the interviewee to assess if the individual understood the topic and had a viewpoint that is credible and not based on negative past experiences that might taint findings. This survey does not directly relate to the thesis questions; however, the survey identifies and provides information about the World Design Challenge program users. Knowing the user better through empathy and understanding their strengths and weaknesses concerning the topic, the researcher can reveal how the World Design Challenge program can create a better user experience. The questions were carefully selected and designed to determine the research participants' background, understanding, and exposure to the thesis topic. The questions were designed to expose any bias and experiences concerning the thesis topic.

All research participants were initially approached by the WDO. Those who agreed to be interviewed were sent an invitation email from the researcher. The email outlined the research process, requirements, procedure and contained all the necessary documentation in relation to the research study (consent form, survey, interview questionnaire and a booking Zoom schedule link).

\subsection{Part Three of Research - Questionnaire and Interview}

The third part of the research was a questionnaire that the participants filled out prior to the interview. This approach was developed to allow them to reflect and elaborate on their responses. Each questionnaire contained ten open-ended questions. The WDO research participants received a set that was directed to the creators of the World Design Challenge program while the UN Women and ISS NL research participants received another questionnaire based on their 
experience in the World Design Challenge program. All questions were centered around the design of the WDO's World Design Challenge program process.

All interviewees were then asked the same set of questions in an open discussion forum. The approach was intended to increase the question response level, content as well as eliminate any inconsistencies or misunderstandings.

\subsection{Analysis Procedure}

The data from the surveys were collected, compiled, and analyzed to generate a baseline understanding of all participants. As was recommended by Wilson and Sharples (2015) a set of questions within categories were counted and based on the number of instances that fell into each category, the findings were transformed into statistical analysis. The average response rate established if the group of participants' responses held any validity or provided a general understanding of their knowledge and exposure to the research inquiry. To determine the average response rate for a question, the total number of participants was divided by half; that number became the average indicator. Responses above that number were above average, more than the average, and responses below were below average, less than the average. More than and less than were used to identify the average response. An example is $8 / 13$ responded yes, more than half indicated yes, then the majority responded yes. The responses numerical values are provided, and the interpretive analysis are also given provided in Chapter 4 for each question. The survey questions were given before the interview and were not discussed or verified in the interview; they are independent of the interview questionnaire and interview. The survey responses were considered objectively and not subjectively. A one-filter approach was used. In all cases the numerical values were taken.

The interview questionnaire, transcript and video responses were collected and compiled. All responses were cross-referenced to identify common themes within each question. The collected responses were processed by using the descriptive In Vivo Coding method. The collected data mainly highlighted qualitative responses and required a manual coding method to reveal important information within a three-layer highlighting step. The first layer required a synthesizing of information from the questionnaire that the respondents filled out, the second layer extracted the highlights from the transcript and notes taken during the interview, and the 
final third layer distilled and removed all non-essential or pertinent information. The remaining information included common themes and most vocal points. The In Vivo Coding method often results in common themes and identified patterns (Saldaña, 2009). The In Vivo Coding method was used so that the essential meanings of the information remained and were not removed. The questionnaire and interview responses were equally considered both objectively and subjectively. A two-filter process was used. In most cases, the amount of occurrence dictates the level of importance unless the research participant's comment was of a high level of importance or very detailed, then their response was included in the recommendations. The questionnaire, interview and observation comments were compiled based on the theme category. All responses that had similar connections were compiled into one recommendation. For example, all key responses regarding Phase Zero were collected and combined into one statement for Phase Zero. In addition, the key responses from the questionnaire and interview were converted to suggested recommendations. Example: There was no bridge between phases; it is converted to there needs to be a bridge between phases. Some responses were direct suggestions. 


\section{CHAPTER 4: DATA COLLECTION AND ANALYSIS}

\subsection{Introduction to Participant Observation}

The research included participation observation, where the researcher took part in three WDO 'World Design Challenges'.

The three World Design Challenge programs included:

\section{UN Women Generation Equality Asia Pacific Design Challenge}

Phase One (See Appendix J) and Phase Two.

2. The International Space Station (ISS NL) Design in Space for Life on Earth Design Challenge Phase One (See Appendix K)

Both Phase One World Design Challenges were two weeks in length and Phase Two was five weeks. All World Design Challenge program incorporated global participants.

The teams for each World Design Challenge program were individually structured but comprised of the same roles and responsibilities which included: the leadership team members (WDO and partner organizations), facilitators and subject matter experts, thought leaders and participants. The researcher held the role of design facilitator for the UN Women World Design Challenge program and WDO thought leader for the ISS NL World Design Challenge program.

The different roles allowed the researcher to observe through various perspectives and provided a unique vantage point. Both roles required the researcher to guide participants as well as contribute towards the World Design Challenge program content. The researcher observed the mechanics of interdisciplinary international collaboration, the highs and lows of team dynamics and the inner workings of the WDO World Design Challenge program first-hand. All meetings were documented and Zoom recorded. WDO utilized Slack as the primary means for communications correspondence and Google Drive for all files.

Each World Design Challenge program included a design process structure which is delivered on a digital online whiteboard (See Page 7 of Appendix J and Page 8 of Appendix K). The whiteboard contains staged with exercises/tasks for the participants to navigate through to generate creative thinking and possible solutions. Each section on the whiteboard is delivered 
through a procedure which builds on the previous section, thereby leading the participants through the creative process journey.

Once each World Design Challenge program was complete, the observations and data were collected, including the design process structure, meeting notes and slide decks. The data was reviewed, and a report on finding was created (See Appendix J and K).

\subsection{Introduction to Participant Observation Results}

\section{UN Women Generation Equality Asia Pacific Design Challenge - Phase One (See Appendix J)}

The World Design Challenge program began with stakeholders and partners from the WDO and UN Women (See Figures 1 and 2 of Appendix J), who created six clearly defined challenge statements. The six challenge statements (See Page 2 of Appendix J) set the stage for a cohesive plan of action for the Violence Against Women and Girls (VAWG) initiative. A challenge statement team structure was created so that each of the six teams included two facilitators (a subject matter and a design facilitator). An essential aspect of team dynamics depended on the facilitators knowing their roles. Furthermore, it was crucial for the topic expert facilitator not to derail the creative process but to enhance it by aligning content with objectives. Thought leaders oversaw communications and progress, which provided a sense of reassurance. Ice breaker activities and team member introductions helped the facilitators connect with the participants and learn more about them in this online environment.

A rough timeline and design process structure (See Figure 5 of Appendix $\mathrm{J}$ ) was critical to the participants understanding of expectations. In hindsight, this should be introduced on the first day. On the whiteboard, a timeline diagram was illustrated directly above the existing design process exercises. Its positioning helped promote understanding and provided continuous visual guidance for the agenda.

The participants were guided by listening, nurturing, and inspiring. More importantly, they wanted to feel valued, needed and heard. By paying attention to each participant's strengths, it fostered more significant outcomes. Participants were utilized in a capacity that yields favourable 
results, which increases productivity. These measures were thoroughly exercised throughout the process.

To further assist with the progress, the facilitators should be able to generate excitement and encourage a positive environment by redirecting and defusing any adverse situations. Encouraging participants to see each stage of the process as small milestones that generate significant results helps them feel less overwhelmed. Participants should be enticed to think big and wild and not fear the never done or out-of-the-box thinking.

Finally, generating an environment that allows for creativity to flow freely without being inhibited or weighed down by structures and bottom lines increases creative idea potential. On several occasions, a facilitator may have provided additional work to help initiate the creative process. The additional work consisted of exercises such as brainstorming, empathy and reflection tasks. The researcher called this stage the planting of creative seeds. Planting creative seeds are beneficial in starting the process of deploying ideas. It starts the ball rolling so the participants can build off the initial concept or propel them off in a different direction.

Overall, the Generation Equality Asia Pacific Design Challenge journey created uncertainty in the beginning but also provided learning, collaboration, connecting and excitement. On many levels, it provided an opportunity to evolve, both as individuals and as a group.

\section{The International Space Station National Laboratory (ISS NL) Design in Space for Life on Earth Challenge - Phase One (See Appendix K)}

The ISS NL Design in Space for Life on Earth Challenge report provided an overview of the challenge and the role of the stakeholders. In the report, a timeline and design process structure had been discussed which was initially introduced to increase and track progress but took a different route during this challenge for both groups. The facilitators' and participants' predetermined expectations and knowledge-based insights had been explored to establish why some of the distractions occurred. Finally, fostering creative flow and the minimalist approach of planting seeds for creative inspiration was reviewed.

The World Design Challenge program began with stakeholders and associates from WDO and ISS NL (See Figures 1 and 2 of Appendix K), who streamlined a vast number of directives into 
three challenges statements. The three challenge statements (See page 4) set the dynamics for an exploratory plan in the three areas of interest. Two of the challenge statements had two teams each, equalling five teams in total. There were two teams for the SDG statement, two teams for the university statement and one team for the business incubators.

A challenge statement team structure was created so that each of the three teams included two thought leaders (a subject matter and a design thought leader). Each team had one facilitator and a limited number of participants.

The challenge presented a unique and complicated scenario due to the nature of the topic. Participants needed to be continuously redirected from their self-directed areas of interest. Most participants felt they were trying to generate a research project on ISS NL to solve an SDG. The thought leaders and facilitators tried not to derail the disruptive thinking process by giving examples of possible direction alternatives (planting creative seeds). This approach proved fruitful but also was time-consuming as the participants had to change their lines of thought.

In comparison, Phase One for both 'World Design Challenges' utilized online whiteboards. UN Women used Mural, while ISS NL used Miro. Both products had identical characteristics but Miro outperformed Mural. Miro proved to be less bandwidth draining and had more template features making it more time and productively efficient.

A timeline and design process structure showcased on Miro (See Figures 5 and 7 of Appendix K) for both teams played a vital role in setting expectations. However, even with the structure, some participants became influenced by other team directions and processes which may have affected their concentration area or the end-product. Although both leaders and the facilitators listened, nurtured, and inspired the participants, only a few remained to the end of the World Design Challenge program to answer the call to produce a finished product. At the end of the World Design Challenge program, both teams were excited and eager to make a product that could provide a possible solution that may benefit the planet and ISS NLs longevity. The teams felt proud of the products they produced, and most are excited for Phase Two.

Finally, ISS NL Design in Space for Life on Earth Challenge allowed teams to come together and produce a process and plan that can be broken apart or used as a whole to potentially solve an 
SDG goal. The well-structured challenge platform allowed teams to solve the design goal and be part of the solution.

\section{Analysis: 3. UN Women Generation Equality Asia Pacific Design Challenge - Phase Two}

Phase Two of the Generation Equality Asia Pacific Design Challenge provided additional insight into the World Design Challenge program. The success of Phase One left many participants excited to begin Phase Two. The lapse in time between the phases did cause the participants to question if Phase Two would take place. Pre-scheduling the phases would alleviate, prepare, and incite excitement in the teams as they were eager to continue the journey to generate change. It should be noted that there were team participant changes from Phase One to Phase Two. Three-four members from Phase One contributed to Phase Two for Team 3. Team 3 was comprised of four main participants.

Another point to note is Phase Two increased the time duration of the challenge time from two to five weeks. The change did cause team members to adjust their schedules to fit the new timeline. However, this was not an error from the leadership team as they answered the demand for a longer challenge time frame. The adjustment did have an unforeseen adverse effect as it caused exhaustion among members and drained their schedules. The five-week time commitment might be too much to expect from volunteers due to family and work obligations. It was observed that not only the length of the phase, but a combination of the length and the level of deliverables also led to such outcomes.

The vital issue of deliverables and scope of work became an obstacle for most teams. Many teams had problems navigating from Phase One to Phase Two as they felt that there needed to be a bridge between the two phases. It is suggested that Phase Two should be a concept reflection and refinement stage to ensure all aspects of the concept or product have been thoroughly thought out and meet the required user and business goals. Additionally, might be beneficial to maintain the two-week duration but divide the deliverables into more micro manageable pieces. This approach will also allow for reflection between phases, provide clarity and promote confidence for the next phase.

In addition to bridging between the phases, Phase Two manifested a shift in role distribution. The design facilitator took on a more prominent role as subject matter experts were only 
integrated when topic content was needed. During Phase One, both roles' participation was more equally allocated. This shift of roles between phases should be examined as the facilitator may require more time or have an increased perception of expectations on their schedule. However, if Phase Two becomes the reflection and refinement stage, then this situation may not occur. It also became apparent that skilled facilitation is a sought-after commodity. The facilitator has a direct correlation to the team's success if the teams are well-balanced and committed. Without a well-balanced committed team, the facilitator will struggle against the odds of generating successful outcomes.

Overall, Phase Two provided a unique lens into the importance of the preparation and development of WDO's World Design Challenge program. WDO should be commended as it sets the groundwork for perpetuating situations where it can perfect the development of the creative process phases.

\subsection{Introduction to Survey}

The survey was part of the research package which was emailed to all three groups. The WDO, UN Women and ISS NL research participants all received the same survey. The research participants were asked to complete the survey before the Zoom interview and return it along with the consent form. The purpose of the survey was to provide a baseline understanding of the participants design process exposure, their education in relation to the topic and any underlining bias they may have that might impede their answers. The survey does not directly relate to the thesis questions; however, it identifies and provides information about the World Design Challenge program users. It is used to obtain information about the user, their strengths and weakness in relation to the topic, which intern will reveal how the World Design Challenge program can create a better user experience for this user group.

Once the survey data was collected, it was organized based on each of the three organizations; then, it was reviewed and analyzed as one data set. The data provided insight into the participants knowledge and background on the subject matter. The information obtained through the survey conveyed a baseline to help determine the interviewees expertise on the topic.

Figure 4 survey questions design were based on yes or no responses and multiple choice. The full survey table showcases all the responses per group (See Appendix G). 


\section{Survey Question - 13 Research Participant Responses}

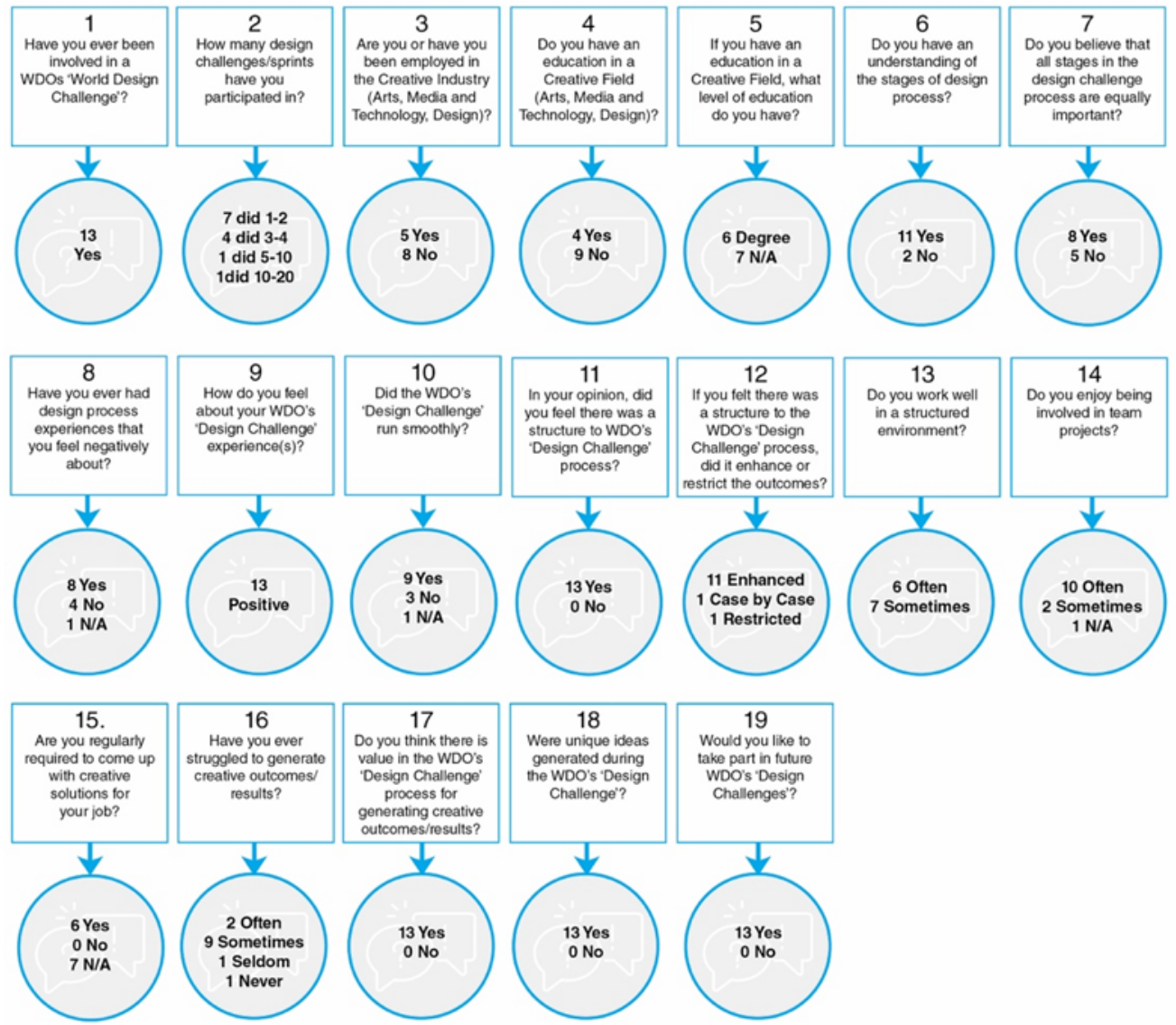

Figure 4. Survey Question Responses

\subsection{Survey Analysis}

Analysis presented based on each survey question.

\section{Have you ever been involved in a WDO's 'World Design Challenge'?}

\begin{tabular}{|c|l|c|c|c|c|c|c|c|c|c|c|c|c|c|c|}
\hline \multirow{2}{*}{ Survey Question } & \multicolumn{9}{|c|}{ Participant (A - WDO, B - UN Women, C - ISS NL) } & \multicolumn{3}{c|}{$\begin{array}{c}\text { Response } \\
\text { Results }\end{array}$} \\
\cline { 2 - 14 } & A1 & A2 & A3 & A4 & A5 & B6 & B7 & B8 & B9 & B10 & C11 & C12 & C13 & \\
\hline 1 & $\begin{array}{l}\text { Have you ever been involved in a } \\
\text { WDO's 'World Design Challenge'? }\end{array}$ & Y & Y & Y & Y & Y & Y & Y & Y & Y & Y & Y & Y & Y & $\begin{array}{l}13 / 13 \\
\text { Responded Yes }\end{array}$ \\
\hline
\end{tabular}

Results: All three groups and thirteen research participants responded yes to having been involved in some capacity with a WDO 'World Design Challenge'.

Analysis: Based on the results all thirteen research participants have had first-hand knowledge of a World Design Challenge and could provide feedback on their experience. 


\section{How many design challenges/sprints have you participated in?}

\begin{tabular}{|c|c|c|c|c|c|c|c|c|c|c|c|c|c|c|c|}
\hline \multirow{2}{*}{\multicolumn{2}{|c|}{ Survey Question }} & \multicolumn{13}{|c|}{ Participant (A - WDO, B - UN Women, C - ISS NL) } & \multirow{2}{*}{$\begin{array}{l}\text { Response } \\
\text { Results }\end{array}$} \\
\hline & & A1 & A2 & A3 & A4 & A5 & B6 & B7 & B8 & B9 & B10 & C11 & C12 & C13 & \\
\hline 2 & $\begin{array}{l}\text { How many design challenges/sprints } \\
\text { have you participated in? }\end{array}$ & $3-4$ & $3-4$ & $3-4$ & 3-4 & $3-4$ & $1-2$ & $1-2$ & $1-2$ & $1-2$ & $1-2$ & $1-2$ & $1-2$ & $\begin{array}{l}10- \\
20\end{array}$ & $\begin{array}{l}1-2=7,3-4=4 \\
5-10=1,10-20 \\
=1\end{array}$ \\
\hline
\end{tabular}

Results: Five out of five WDO research participants have participated in three to four design challenges/sprints. Each UN Women research participant has only participated in one to two design challenges/sprints, and ISS NL had two research participants state they have participated in one to two challenges/sprints, and one person has participated in ten to twenty challenges/sprints.

Analysis: Based on these results most research participants have had minimal exposure to design challenges and sprints outside of the WDO's 'World Design Challenge' program, which makes them not able to compare their experience to another challenge outside the program. This would not make them subject matter expert on the topic.

3. Are you or have you been employed in the Creative Industry (Arts, Media and Technology, Design)?

\begin{tabular}{|c|c|c|c|c|c|c|c|c|c|c|c|c|c|c|c|}
\hline \multirow{2}{*}{\multicolumn{2}{|c|}{ Survey Question }} & \multicolumn{13}{|c|}{ Participant (A - WDO, B - UN Women, C - ISS NL) } & \multirow{2}{*}{$\begin{array}{c}\text { Response } \\
\text { Results }\end{array}$} \\
\hline & & A1 & A2 & A3 & A4 & A5 & B6 & B7 & B8 & B9 & B10 & C11 & $\mathrm{C12}$ & C13 & \\
\hline 3 & $\begin{array}{l}\text { Are you or have you been employed } \\
\text { in the Creative Industry (Arts, Media } \\
\text { and Technology, Design)? }\end{array}$ & $\mathrm{Y}$ & $\mathrm{N}$ & $\mathrm{N}$ & $\mathrm{Y}$ & $\mathrm{Y}$ & $\mathrm{N}$ & $\mathrm{N}$ & $\mathrm{N}$ & $\mathrm{N}$ & $\mathrm{N}$ & Y & $\mathrm{N}$ & $Y$ & $\begin{array}{l}\text { Yes }=5 \\
\text { No }=8\end{array}$ \\
\hline
\end{tabular}

Results: Three out of five WDO research participants have been employed in the Creative Industry. None of the UN Women research participants have been employed in the Creative Industry, which leaves two out of three of the ISS NL research participants who have been employed in the Creative Industry field.

Analysis: These results indicated that less than half of the research participants have a complete understanding of the creative process within the Creative Industry. Their lack of exposure to the subject matter establishes that the World Design Challenge program is well designed as they were able to understand and perform in the design challenge. 
4. Do you have an education in a Creative Field (Arts, Media and Technology, Design)?

\begin{tabular}{|c|c|c|c|c|c|c|c|c|c|c|c|c|c|c|c|}
\hline \multirow{2}{*}{\multicolumn{2}{|c|}{ Survey Question }} & \multicolumn{13}{|c|}{ Participant (A - WDO, B - UN Women, C - ISS NL) } & \multirow{2}{*}{$\begin{array}{c}\text { Response } \\
\text { Results }\end{array}$} \\
\hline & & A1 & A2 & A3 & A4 & A5 & B6 & B7 & B8 & B9 & B10 & C11 & C12 & C13 & \\
\hline 4 & $\begin{array}{l}\text { Do you have an education in a } \\
\text { Creative Field (Arts, Media and } \\
\text { Technology, Design)? }\end{array}$ & $\mathrm{Y}$ & $\mathrm{Y}$ & Y & $\mathrm{N}$ & $\mathrm{Y}$ & $\mathrm{N}$ & $\mathrm{N}$ & $\mathrm{N}$ & $\mathrm{N}$ & $\mathrm{N}$ & $Y$ & $\mathrm{~N}$ & Y & $\begin{array}{l}\text { Yes }=4 \\
\text { No }=9\end{array}$ \\
\hline
\end{tabular}

Results: The responses show that two WDO research participants have an education in the Creative Field. None of the UN Women are educated in Creative Industry, and two out of three ISS NL research participants have an education in this area.

Analysis: The results show that very few have had a formal education in the Creative Field. These results indicate that the participant's feedback will not be founded on formal training.

5. If you have an education in a Creative Field, what level of education do you have?

\begin{tabular}{|l|l|c|c|c|c|c|c|c|c|c|c|c|c|c|c|}
\hline \multirow{2}{*}{ Survey Question } & \multicolumn{6}{|c|}{ Participant (A - WDO, B - UN Women, C - ISS NL) } & \multicolumn{2}{c|}{$\begin{array}{c}\text { Response } \\
\text { Results }\end{array}$} \\
\cline { 2 - 15 } & A1 & A2 & A3 & A4 & A5 & B6 & B7 & B8 & B9 & B10 & C11 & C12 & C13 & \\
\hline 5 & $\begin{array}{l}\text { If you have an education in a Creative } \\
\text { Field, what level of education do you } \\
\text { have? }\end{array}$ & D & D & D & - & D & - & - & - & - & - & D & - & D & $\begin{array}{l}\text { Degree }=6 \\
\text { N/A }=7\end{array}$ \\
\hline
\end{tabular}

Results: The research shows that WDO has three research participants who hold a Degree in the Creative field and earned a Ph.D. All UN Women research participants have non-creative educations, and one ISS NL research participant holds a Degree, and one holds a Graduate Degree. The research shows that those who have a creative education hold post-secondary degrees or higher.

Analysis: The results indicate that half feel they have an education, but these numbers contradict question four. Only four stated that they have an education in the creative field, but six of the research participants state their level of education in question five. These numbers and the contradiction could mean that two misunderstood the line of questioning. 
6. Do you have an understanding of the stages of the design process?

\begin{tabular}{|c|c|c|c|c|c|c|c|c|c|c|c|c|c|c|c|}
\hline \multirow{2}{*}{\multicolumn{2}{|c|}{ Survey Question }} & \multicolumn{13}{|c|}{ Participant (A - WDO, B - UN Women, C - ISS NL) } & \multirow{2}{*}{$\begin{array}{l}\text { Response } \\
\text { Results }\end{array}$} \\
\hline & & A1 & A2 & A3 & A4 & A5 & B6 & B7 & B8 & B9 & B10 & C11 & C12 & C13 & \\
\hline 6 & $\begin{array}{l}\text { Do you have an understanding of the } \\
\text { stages of design process? }\end{array}$ & $\mathrm{Y}$ & Y & $\mathrm{Y}$ & $\mathrm{Y}$ & $\mathrm{Y}$ & $\mathrm{N}$ & Y & $\mathrm{Y}$ & $\mathrm{Y}$ & Y & Y & $\mathrm{N}$ & Y & $\begin{array}{l}\text { Yes }=11 \\
\mathrm{No}=2\end{array}$ \\
\hline
\end{tabular}

Results: Data shows that all the WDO research participants state they understand the design process stages. Four out of five UN Women understand the stages, and two out of three ISS NL believe they understand the stages. The results indicate that most think they understand design process stages.

Analysis: The results indicate that most think they understand design process stages. The results show that most participants feel they know the stages now that they have participated in a World Design Challenge program.

\section{Do you believe that all stages in the design challenge process are equally important?}

\begin{tabular}{|c|c|c|c|c|c|c|c|c|c|c|c|c|c|c|c|}
\hline \multirow{2}{*}{\multicolumn{2}{|c|}{ Survey Question }} & \multicolumn{13}{|c|}{ Participant (A - WDO, B - UN Women, C - ISS NL) } & \multirow{2}{*}{$\begin{array}{c}\text { Response } \\
\text { Results }\end{array}$} \\
\hline & & A1 & A2 & A3 & A4 & A5 & B6 & B7 & B8 & B9 & B10 & C11 & C12 & C13 & \\
\hline 7 & $\begin{array}{l}\text { Do you believe that all stages in the } \\
\text { design challenge process are equally } \\
\text { important? }\end{array}$ & $\mathrm{N}$ & $\mathrm{N}$ & $\mathrm{Y}$ & $\mathrm{N}$ & $\mathrm{Y}$ & $\mathrm{Y}$ & $\mathrm{Y}$ & $\mathrm{Y}$ & $\mathrm{Y}$ & Y & $\mathrm{N}$ & $\mathrm{N}$ & Y & $\begin{array}{l}Y e s=8 \\
\text { No }=5\end{array}$ \\
\hline
\end{tabular}

Results: Three out of five WDO research participants believe that all the World Design Challenge program stages are not equally important. All the UN Women believe the stages are equally important, and only one out of two of the ISS NL believes that the stages are important equally. More than half of the research participants think that the stages are equal in the design process.

Analysis: The results show that the research participants do not value one stage of the design challenge over another. These results could mean they did not feel one stage had more value or they enjoyed one stage more. 
8. Have you ever had design process experiences that you feel negatively about?

\begin{tabular}{|c|c|c|c|c|c|c|c|c|c|c|c|c|c|c|c|}
\hline \multirow{2}{*}{\multicolumn{2}{|c|}{ Survey Question }} & \multicolumn{13}{|c|}{ Participant (A - WDO, B - UN Women, C - ISS NL) } & \multirow{2}{*}{$\begin{array}{c}\text { Response } \\
\text { Results }\end{array}$} \\
\hline & & A1 & A2 & A3 & A4 & A5 & B6 & B7 & B8 & B9 & B10 & C11 & C12 & C13 & \\
\hline 8 & $\begin{array}{l}\text { Have you ever had design process } \\
\text { experiences that you feel negatively } \\
\text { about? }\end{array}$ & - & $\mathrm{N}$ & $\mathrm{N}$ & $\mathrm{Y}$ & $\mathrm{Y}$ & $\mathrm{N}$ & $\mathrm{N}$ & $\mathrm{N}$ & $\mathrm{N}$ & $\mathrm{N}$ & Y & $\mathrm{N}$ & $Y$ & $\begin{array}{l}\text { Yes }=4 \\
N o=8 \\
N / A=1\end{array}$ \\
\hline
\end{tabular}

Results: Two WDO research participants stated no, and two stated yes, while one did not respond. None of the UN Women have had a negative design process experience, while two out of three of the ISS NL have had a negative experience.

Analysis: The results show that the majority have not had a negative design process experience, which means they are less likely to have a pre-embedded negative bias. This fact is beneficial for the World Design Challenge program.

9. How do you feel about your WDO's 'World Design Challenge' experience(s)?

\begin{tabular}{|c|l|c|c|c|c|c|c|c|c|c|c|c|c|c|c|}
\hline \multirow{2}{*}{ Survey Question } & \multicolumn{8}{|c|}{ Participant (A - WDO, B - UN Women, C - ISS NL) } & \multicolumn{2}{c|}{$\begin{array}{c}\text { Response } \\
\text { Results }\end{array}$} \\
\cline { 2 - 14 } & A1 & A2 & A3 & A4 & A5 & B6 & B7 & B8 & B9 & B10 & C11 & C12 & C13 & \\
\hline 9 & $\begin{array}{l}\text { How do you feel about your WDO's } \\
\text { 'Design Challenge' experience(s)? }\end{array}$ & P & P & P & P & P & P & P & P & P & P & P & P & P & Positive = 13 \\
\hline
\end{tabular}

Results: All thirteen research participants feel positive about their WDO's World Design Challenge program experience.

Analysis: The results show that all thirteen research participants feel positive about their experience, thereby reflecting positively on the World Design Challenge program.

10. Did the WDO's 'World Design Challenge' run smoothly?

\begin{tabular}{|l|l|c|c|c|c|c|c|c|c|c|c|c|c|c|c|}
\hline \multirow{2}{*}{ Survey Question } & \multicolumn{9}{|c|}{ Participant (A - WDO, B - UN Women, C - ISS NL) } & \multicolumn{2}{c|}{$\begin{array}{c}\text { Response } \\
\text { Results }\end{array}$} \\
\cline { 2 - 14 } & A1 & A2 & A3 & A4 & A5 & B6 & B7 & B8 & B9 & B10 & C11 & C12 & C13 & \\
\hline 10 & $\begin{array}{l}\text { Did the WDO's 'Design Challenge' } \\
\text { run smoothly? }\end{array}$ & Y & Y & Y & Y & Y & N & N & - & Y & Y & Y & N & Y & $\begin{array}{l}\text { Yes }=9 \\
\text { No }=3 \\
\text { N/A }=1\end{array}$ \\
\hline
\end{tabular}

Results: All WDO research participants believe the World Design Challenge program ran smoothly. Two UN Women research participants answered yes, and two answered no, while one 
did not respond. Two ISS NL participants answered yes, and one answered no. The majority felt the World Design Challenge program went smoothly. The three no responses were not within the WDO.

Analysis: The results indicate that the majority felt the World Design Challenge program ran smoothly, stating that the program is well-thought-out.

11. In your opinion, did you feel there was a structure to WDO's 'World Design Challenge' process?

\begin{tabular}{|c|c|c|c|c|c|c|c|c|c|c|c|c|c|c|c|}
\hline \multirow{2}{*}{\multicolumn{2}{|c|}{ Survey Question }} & \multicolumn{13}{|c|}{ Participant (A - WDO, B - UN Women, C - ISS NL) } & \multirow{2}{*}{$\begin{array}{c}\text { Response } \\
\text { Results }\end{array}$} \\
\hline & & A1 & A2 & A3 & A4 & A5 & B6 & B7 & B8 & B9 & B10 & C11 & C12 & C13 & \\
\hline 11 & $\begin{array}{l}\text { In your opinion, did you feel there } \\
\text { was a structure to WDO's 'Design } \\
\text { Challenge' process? }\end{array}$ & $\mathrm{Y}$ & $\mathrm{Y}$ & Y & Y & $\mathrm{Y}$ & Y & $\mathrm{Y}$ & $\mathrm{Y}$ & Y & Y & Y & Y & Y & $\begin{array}{l}\text { Yes }=13 \\
\text { No }=0\end{array}$ \\
\hline
\end{tabular}

Results: All thirteen respondents believed there was structure to WDO World Design Challenge program.

Analysis: The results show that all research participants perceived that there was structure to the format. The high number of responses show that the research participants felt the program was not loosely developed.

\section{If you felt there was a structure to the WDO's 'World Design Challenge' process, did it} enhance or restrict the outcomes/results?

\begin{tabular}{|l|l|c|c|c|c|c|c|c|c|c|c|c|c|c|c|}
\hline \multicolumn{2}{|c|}{ Survey Question } & \multicolumn{9}{|c|}{ Participant (A - WDO, B - UN Women, C - ISS NL) } & \multicolumn{2}{c|}{$\begin{array}{c}\text { Response } \\
\text { Results }\end{array}$} \\
\cline { 2 - 11 } & A1 & A2 & A3 & A4 & A5 & B6 & B7 & B8 & B9 & B10 & C11 & C12 & C13 & \\
\hline 12 & $\begin{array}{l}\text { If you felt there was a structure to the } \\
\text { WDO's 'Design Challenge' process, } \\
\text { did it enhance or restrict the } \\
\text { outcomes/results? }\end{array}$ & E & E & E & E & E & R & E & E & E & E & E & C & E & $\begin{array}{l}\text { Enhanced }=11 \\
\text { Case by } \\
\text { Case =1 } \\
\text { Restricted }=1\end{array}$ \\
\hline
\end{tabular}

Results: All five of the WDO research participants felt that WDO World Design Challenge program enhanced the outcomes/results, where only four out of five of the UN Women indicated that the structure enhanced the outcomes/results. One of the UN Women participants felt the process was restricted. Two ISS NL believed the process improved outcomes, and one responded that it was a case by case. It should be noted that "Case by Case" was not an option but written in by hand. 
Analysis: These results align with questions eleven. It proves that the structure enhanced comes. The high response rate indicates there that the structure design was effective.

\section{Do you work well in a structured environment?}

\begin{tabular}{|l|l|c|c|c|c|c|c|c|c|c|c|c|c|c|c|}
\hline \multicolumn{2}{|c|}{ Survey Question } & \multicolumn{9}{|c|}{ Participant (A - WDO, B - UN Women, C - ISS NL) } & \multicolumn{2}{c|}{$\begin{array}{c}\text { Response } \\
\text { Results }\end{array}$} \\
\cline { 2 - 12 } & A1 & A2 & A3 & A4 & A5 & B6 & B7 & B8 & B9 & B10 & C11 & C12 & C13 & \\
\hline 13 & $\begin{array}{l}\text { Do you work well in a structured } \\
\text { environment? }\end{array}$ & O & O & S & O & S & O & S & O & O & S & S & S & S & $\begin{array}{l}\text { Often }=6 \\
\text { Sometimes }=7\end{array}$ \\
\hline
\end{tabular}

Results: Three WDO research participants felt they work well in a structured environment, while two thought they only worked well sometimes in that working situation. Three out of five UN Women work well in a structured environment, and the other two only sometimes. All three ISS NL stated that they sometimes work well in a structured environment.

Analysis: The results may show that half of the participants are highly productive in a structured situation and may enjoy the more rigid predefined structure, while the other half are not. That means only half will flourish in these conditions.

\section{Do you enjoy being involved in team projects?}

\begin{tabular}{|l|l|c|c|c|c|c|c|c|c|c|c|c|c|c|c|}
\hline \multicolumn{2}{|c|}{ Survey Question } & \multicolumn{8}{|c|}{ Participant (A - WDO, B - UN Women, C - ISS NL) } & \multicolumn{2}{c|}{$\begin{array}{c}\text { Response } \\
\text { Results }\end{array}$} \\
\cline { 2 - 12 } & A1 & A2 & A3 & A4 & A5 & B6 & B7 & B8 & B9 & B10 & C11 & C12 & C13 & \\
\hline 14 & $\begin{array}{l}\text { Do you enjoy being involved in team } \\
\text { projects? }\end{array}$ & - & S & S & O & O & O & O & O & O & O & O & O & O & $\begin{array}{l}\text { Often }=10 \\
\text { Sometimes }=2 \\
\text { N/A }=1\end{array}$ \\
\hline
\end{tabular}

Results: Two WDO research participants enjoy team projects, and two do not. One did not respond. All the UN Women and ISS NL research participants enjoy working on team projects. Analysis: The results show that those who often enjoy team projects might thrive better in World Design Challenge program due to the team dynamics. 
15. Are you regularly required to come up with creative solutions for your job?

\begin{tabular}{|c|c|c|c|c|c|c|c|c|c|c|c|c|c|c|c|}
\hline \multirow{2}{*}{\multicolumn{2}{|c|}{ Survey Question }} & \multicolumn{13}{|c|}{ Participant (A - WDO, B - UN Women, C - ISS NL) } & \multirow{2}{*}{$\begin{array}{c}\text { Response } \\
\text { Results }\end{array}$} \\
\hline & & A1 & A2 & A3 & A4 & A5 & B6 & B7 & B8 & B9 & B10 & C11 & C12 & C13 & \\
\hline 15 & $\begin{array}{l}\text { Are you regularly required to come up } \\
\text { with creative solutions for your job? }\end{array}$ & - & - & $\mathrm{N}$ & $\mathrm{Y}$ & Y & Y & - & - & - & Y & - & Y & - & $\begin{array}{l}\text { Yes }=6 \\
\text { No }=0 \\
N / A=7\end{array}$ \\
\hline
\end{tabular}

Results: Two out of five WDO research participants come up with creative solutions for their job. Only one UN Women and ISS NL responded yes. Half of the participants regularly exercise creative thinking in their regular work lives.

Analysis: The results indicate that half of the research participants who regularly exercise their creative thinking may find the World Design Challenge program less mentally straining.

\section{Have you ever struggled to generate creative outcomes/results?}

\begin{tabular}{|l|l|c|c|c|c|c|c|c|c|c|c|c|c|c|c|}
\hline \multicolumn{2}{|c|}{ Survey Question } & \multicolumn{9}{|c|}{ Participant (A - WDO, B - UN Women, C - ISS NL) } & \multicolumn{2}{c|}{$\begin{array}{c}\text { Response } \\
\text { Results }\end{array}$} \\
\cline { 2 - 11 } & A1 & A2 & A3 & A4 & A5 & B6 & B7 & B8 & B9 & B10 & C11 & C12 & C13 & \\
\hline 16 & $\begin{array}{l}\text { Have you ever struggled to generate } \\
\text { creative outcomes/results? }\end{array}$ & O & S & S & S & N & N & O & S & S & S & S & SE & S & $\begin{array}{l}\text { Often }=2 \\
\text { Sometimes }=9 \\
\text { Seldom }=1 \\
\text { Never }=1\end{array}$ \\
\hline
\end{tabular}

Analysis: Three of the WDO and UN Women research participants sometimes struggle to generate creative results, while one responded as they often struggle and another never struggles.

Two of the ISS NL research participants sometimes struggle, while one seldom does struggle. More than half have encountered struggles when trying to generate creative outcomes, and therefore they would benefit from a design process exposure.

Analysis: The results indicate that half the research participants may have experienced discomfort when participating in the World Design Challenge program. However, it does not indicate which of the ones that struggled were the same participants from question fifteen who regularly must come up with creative solutions in their jobs. 
17. Do you think there is value in the WDO's 'World Design Challenge' process for generating creative outcomes/results?

\begin{tabular}{|c|c|c|c|c|c|c|c|c|c|c|c|c|c|c|c|}
\hline \multirow{2}{*}{\multicolumn{2}{|c|}{ Survey Question }} & \multicolumn{13}{|c|}{ Participant (A - WDO, B - UN Women, C - ISS NL) } & \multirow{2}{*}{$\begin{array}{c}\text { Response } \\
\text { Results }\end{array}$} \\
\hline & & A1 & A2 & A3 & A4 & A5 & B6 & B7 & B8 & B9 & B10 & C11 & C12 & C13 & \\
\hline 17 & $\begin{array}{l}\text { Do you think there is value in the } \\
\text { WDO's 'Design Challenge' process for } \\
\text { generating creative outcomes/results? }\end{array}$ & $\mathrm{Y}$ & $\mathrm{Y}$ & Y & $\mathrm{Y}$ & $\mathrm{Y}$ & Y & Y & $\mathrm{Y}$ & $\mathrm{Y}$ & Y & Y & Y & Y & $\begin{array}{l}\text { Yes }=13 \\
\text { No }=0\end{array}$ \\
\hline
\end{tabular}

Results: All thirteen research participants responded yes to seeing value in the WDO's World Design Challenge program process for generating creative outcomes.

Analysis: The results show that everyone felt that the program had great value and therefore perceived the program to be a contributor to the design community.

18. Were unique ideas generated during the WDO's 'World Design Challenge'?

\begin{tabular}{|l|l|c|c|c|c|c|c|c|c|c|c|c|c|c|c|}
\hline \multicolumn{2}{|c|}{ Survey Question } & \multicolumn{8}{|c|}{ Participant (A - WDO, B - UN Women, C - ISS NL) } & \multicolumn{2}{c|}{$\begin{array}{c}\text { Response } \\
\text { Results }\end{array}$} \\
\cline { 2 - 13 } & A1 & A2 & A3 & A4 & A5 & B6 & B7 & B8 & B9 & B10 & C11 & C12 & C13 & \\
\hline 18 & $\begin{array}{l}\text { Were unique ideas generated during } \\
\text { the WDO's 'Design Challenge'? }\end{array}$ & $Y$ & $Y$ & $Y$ & $Y$ & $Y$ & $Y$ & $Y$ & $Y$ & $Y$ & $Y$ & $Y$ & $Y$ & $Y$ & $\begin{array}{l}\text { Yes }=13 \\
\text { No }=0\end{array}$ \\
\hline
\end{tabular}

Results: All thirteen research participants responded yes to WDO's World Design Challenge program's ability to generate unique ideas.

Analysis: The results indicate that everyone felt that the WDO's World Design Challenge program resulted in unique ideas based on their experience. The high level of yes responses would suggest that the program is successful at generating out-of-the-box outcomes.

19. Would you like to take part in future WDO's 'World Design Challenge?

\begin{tabular}{|l|l|c|c|c|c|c|c|c|c|c|c|c|c|c|c|}
\hline \multicolumn{2}{|c|}{ Survey Question } & \multicolumn{8}{|c|}{ Participant (A - WDO, B - UN Women, C - ISS NL) } & \multicolumn{2}{c|}{$\begin{array}{c}\text { Response } \\
\text { Results }\end{array}$} \\
\cline { 2 - 12 } & A1 & A2 & A3 & A4 & A5 & B6 & B7 & B8 & B9 & B10 & C11 & C12 & C13 & Res \\
\hline 19 & $\begin{array}{l}\text { Would you like to take part in future } \\
\text { WDO's 'Design Challenges'? }\end{array}$ & Y & Y & Y & Y & Y & Y & Y & Y & Y & Y & Y & Y & Y & $\begin{array}{l}\text { Yes }=13 \\
\text { No }=0\end{array}$ \\
\hline
\end{tabular}


Results: All thirteen research participants responded that they wanted to take part in future WDO's World Design Challenge program.

Analysis: The results show that the research participants would participate in further phases and possible other World Design Challenges. The high number of yes responses bodes well for the World Design Challenge program.

\subsection{Introduction to Questionnaire and Interview}

The Questionnaire and Interview portion of the research was divided into two groups. Group one consisted of the WDO and the creators while group two consisted of UN Women and ISS NL contributors. Both groups were asked to fill out the questionnaire prior to the interview. Each questionnaire version contained questions that pertain directly towards the particular group. The purpose of the questionnaire being sent before the interview was to allow the participants to think through their answers and be prepared for and reflect on the line of questioning. The questionnaire was designed to learn about the participant's World Design Challenge program experience.

Once the questionnaire data was collected, it was organized based on two versions. This was based on the questionnaire form and the interview Zoom transcript along with researcher's notes from the Zoom interview session. Each layer of information was bolded and highlighted per question, then vital common themes and meanings were extracted and finally combined. Once that was completed, the data was reviewed and analyzed to create one summary set of feedback per question. The data provided insight into the participants' personal experience of the WDO's World Design Challenge program. The information received through the questionnaire and interview provided a clear picture of their experience through their lens.

The purpose of the study, interview questions, consent form and information regarding the recorded interview was disclosed to the interviewees in the invitation email prior to the interview. The interviewees provided confirmation and acknowledged they understood they were being recorded and that Zoom transcribe was activated. The interviewees answered all ten questions and provided additional insight. The interviews were pre-scheduled for 60 mins per session. Most sessions took the entire sixty mins. One individual was unable to schedule a session and opted to provide all answers in the digital interactive form. 
The questionnaire and interview question designs were based on open-ended questions (See

Figure 5). The complete questionnaire and interview table showcases all the summaries per group (See Appendix I). 


\section{Questionnaire \& Interview - WDO 5 Research Participant Responses}

\begin{tabular}{|c|}
\hline $\begin{array}{l}1 \\
\text { Do you believe there could be a fixed set of design } \\
\text { process stages? Why? }\end{array}$ \\
\hline $\begin{array}{l}\text { Based on your experience, what are the main factors } \\
\text { of the process that contribute to a WDO's 'Design } \\
\text { Challenges' success? List them in order of importance. }\end{array}$ \\
\hline $\begin{array}{l}\text { Who are the key actors (Actor examples, but not limited to } \\
\text { Topic experts, thought leaders, facilitators) in the WDO's } \\
\text { 'Design Challenges' process that enhance better creative } \\
\text { outcomes? List them in order of ranking. One is the } \\
\text { largest enhancer. }\end{array}$ \\
\hline
\end{tabular}

\section{4}

What are the biggest obstacles in the WDO's 'Design Challenges' process and structure?

\section{5}

What are the most useful tools in generating creative thinking?

\section{6}

Do you think the same tasks/exercises should be used in the WDO's 'Design Challenges' process for creating success outcomes/ results? Why?

\section{7}

What part of the WDO's 'Design Challenges' process is the most vital?

\section{8}

As creators who guide users, what are your biggest positive or negative challenges?

\section{9}

What were the critical building blocks in creating the WDO's 'Design Challenges'?

\section{0}

Do you have recommendations that would improve the WDO's 'World Design Challenge' process and increase successful outcomes/results?

\section{Answer Summary}

A structured process is necessary for guidance, but it should be flexible.

\section{Answer Summary}

Structure in Phase Zero, guidelines and well thought out system setup is vital.

\section{Answer Summary}

In order of ranking - Leadership team, WDO

Secretariat, subject matter experts, thought

leaders, participants, facilitators

\section{Answer Summary}

There is a lack of trust in the design process. Time zones and lack of time. Breath of participants and

facilitators skill sets. Structure of Phase Zero with clear objectives. Flexibility-process adjustments

\section{Answer Summary}

Whiteboard for collaboration, generative thinking such as brainstorming and mind mapping were identified. Reflection was also indicated.

\section{Answer Summary}

The use of the same tasks were encouraged as long as they are flexible based on challenge.

\section{Answer Summary}

Clear set of objectives and challenge statements. Providing background and support to teams.

\section{Answer Summary}

Negative part is lack of resources, trust, training, time zones, design experts, and feeling heard.

\section{Answer Summary}

In sync trusting partnership with mutual open dialogue. Knowing the why with clear objectives and challenge statements - Phase Zero.

\section{Answer Summary}

Well throughout challenge structure through phases and process.

Figure 5. Questionnaire and Results Diagram 


\subsection{WDO Questionnaire and Interview Results and Analysis}

1. Do you believe there could be a fixed set of design process stages? Why?

Extracted Results, Themes and Summary of Responses:

- A fixed process provides a framework that provides guidance

- There is a basic structure of the design process that does not need to be applied in a sequential order (empathize, define, ideate, prototype, test)

- The stages do not need to be linear in one direction but provides a feedback loop

- Good flexibility is required for the design process stages

Quote: "Yes, I believe there are defined process stages, but I do not see their sequence as fixed, as design is so iterative. Yes, but not fixed but flexible."

Analysis: A structured process is necessary for guidance, but it should be flexible. Most believe that there is a basic structure, but not all the exercise needs to be applied in order. The WDO research participants felt very strongly about having a basic structure but wanted flexibly. The WDO felt there was structure and flexibility within their World Design Challenge program for all stages and exercises.

2. Based on your experience, what are the main factors of the process that contribute to a WDO's World Design Challenge program success? List them in order of importance. Challenges' success?

Extracted Results, Themes Summary of Responses:

- A collective agreement and strong collaborative working relationship is a major success factor

- There needs to be an interesting subject matter with clear objectives to create success

- The criteria for selection of participants is important so there are committed teams

- Teams that are balanced with the same trained level of facilitators

- Structured phases that contain whiteboards with guides, templates with examples, orientation sessions, pre-scheduled weekly meetings, and instruction on content

Quote: "1. Clear objectives of the challenge, 2. Arriving at the criteria for selection of participants, 3. Selecting a balanced team of participants including leaders/facilitators, 4 . Providing the guidelines to the facilitators, 5. Periodic monitoring/Coaching when needed No clear objectives." 
Analysis: The results indicate that a Phase Zero is critical to success. The structure, guidelines and well thought out system setup is vital. There appeared to be a consensus that the World Design Challenge program setup was the prelude to successful outcomes. This would mean that WDO recognizes that they are instrumental in the design process and structure.

3. Who are the key actors (Actor examples, but not limited to topic experts, thought leaders, facilitators) in the WDO's World Design Challenge program process that enhance better creative outcomes? List them in order of ranking. One is the largest enhancer.

Extracted Results, Themes and Summary of Responses:

- WDO, leadership teams, WDO Secretariat were identified as the key actors

- Subject matter experts and thought leaders are in demand

- Participants with different skill are an asset

- Facilitators were not highest on the list

Quote: "There are several layers. 1) Partnership alignment to benefit, 2) Secretariat - shaping the process, program managers, abstract information and organize it. 3) Volunteers - different backgrounds, skill sets and disciplines."

Analysis: Ranking has been established in following order: Leadership team, WDO Secretariat, subject matter experts, thought leaders, participants, facilitators. It appears that WDO and the partners have slightly different views on who the key actors are in the World Design Challenge program.

4. What are the biggest obstacles in the WDO's World Design Challenge program process and structure?

Extracted Results, Themes and Summary of Responses:

- The most significant obstacles are the time zone differences, which affected the timing of meetings

- Having multiple World Design Challenge programs within a given span

- The structure of the design of the phases were highlighted as area to be improved

- Having access to the tools, resources, and technologies was an identified obstacle

- Having a contractual Phase Zero and determining clear objectives

- A lack of trust in the process that can lead to not relinquishing control in non-design stakeholders was highlighted 
- An evolving process that is no perfect.

- Creating different projects that require adjustments to make the most sense was indicated

- Accessing a variety of participants and skill set of facilitators were noted

Quote: "Phase Zero - trust is a big obstacle - trust in the process!"

Analysis: WDO believes that there is a lack of trust in the design process. Time zones and the lack of time were reoccurring comments. The variety of participants and facilitators skill sets were established as significant obstacles. The structure of Phase Zero, along with clear objectives posed to be areas that needed further refinement. Finally, flexibility in the process and the ability to adjust were highlighted.

\section{What are the most useful tools in generating creative thinking?}

Extracted Results, Themes and Summary of Responses:

- Virtual whiteboard platforms such as Miro and Mural were identified as the most useful tools

- Generative thinking, brainstorming, mind mapping and reflection were highlighted as important tools

- Zoom recordings, note taking and workshops were highlighted as key tools

Quote: "Certainly in the context of the WDO Design Challenges the virtual whiteboards (Mural and Miro) have been game changers - far better even than actual whiteboards it just really pushes teams to be more 'creative'."

Analysis: Whiteboards for collaboration and generative thinking such as brainstorming and mind mapping were identified. The platforms provide vital tools in the virtual environment. Both products had learning curve issues noted. WDO felt that participants who had not used the tools before the Virtual whiteboard platforms would benefit from a training session. Workshops for guidance were recommended to learn how to function in some of the whiteboard exercises. It was interesting to note that some WDO research participants identified brainstorming, mind mapping and reflection exercise as tools.

6. Do you think the same tasks/exercises should be used in the WDO's World Design Challenge program process for creating success outcomes/ results? Why?

Extracted Results, Themes and Summary of Responses: 
- Using the same tasks such as: empathy, define, ideation, prototyping and validate where indicated as tools and exercises because they have proven to be successful

- Some felt that tools, exercises, and templates may vary, as they can be expanded on or shortened depending on the type of 'World Design Challenge'

- Based on the situation, modifications can be done, or new tasks introduced

- Many believed there should the same tasks but only if they are flexible

Quote: "Ultimately, the design thinking process should/could remain the same (empathy, define, ideation, prototype, validate, etc.) regardless of the challenge. However, the tools, exercises and templates may vary, be expanded on or shortened depending on the type of challenge, its objectives, the level of skill of the participants, the amount of time available for the challenge, etc."

Analysis: Some WDO research participants believed that the use of the same tasks and templates is encouraged if they are flexible. It was suggested that flexibility should be based on the 'World Design Challenge'.

7. What part of the WDO's World Design Challenge program process is the most vital for successful outcomes/results? Why?

Extracted Results, Themes and Summary of Responses:

- Clear objectives and goal setting is vital for success

- Clear objectives and goals set the foundation as they produce easily understood defined challenge statements

- Increase background information on participants

- Prioritization exercise to help identity what ideas are the best

- Proven success templates with prioritization exercise to help identity what ideas are the best

- Orientation for facilitators and subject matter expertise, weekly check-ins while monitoring progress

Quote: "Without clear objectives and easily digested challenge statements teams can be off to a rocky start."

Analysis: A set of clearly understood objectives with well-defined challenge statements were stated as being vital to successful outcomes. Orientating the facilitators, topic experts and participants while monitoring and supporting them throughout the challenge is believed to 
increase success. Making templates accessible with exercise criteria that is explained in greater detail could help eliminate confusion. The WDO research participants recognize that the WDO's contributions are vital to ensuring that these points are addressed.

8. As creators who guide users, what are your biggest positive or negative challenges?

Extracted Results, Themes and Summary of Responses:

- Increasing trust and providing more training to all will positively impact of the World Design Challenge

- It is important to feel valued and heard for all team members

- Time zones were identified as a negative aspect of the program, as it is difficult to manage and schedule meetings that suit all schedules

- There is a lack of designers and experts in design thinking that are readily available to partake in the World Design Challenge program

Quote: "Negative challenge is managing the work over time zones and accommodating the timing to as many participants as possible."

Analysis: The WDO research participants identified time zone scheduling as an issue. This issue is hard to resolve when including international participants. By creating a database of names of design experts, their abilities and those who are educated in facilitating will increase create a better participant experience and therefore build trust in the process.

9. What were the critical building blocks in creating the WDO's World Design Challenge program?

Extracted Results, Themes and Summary of Responses:

- It is important to align with the right partner who embraces the design mission and open dialogue

- Using international calls and Zoom capabilities are key building blocks

- It is vital to set expectations with clear objectives and challenge statements in Phase Zero of the World Design Challenge program

- The 'why' of the challenge needs to be worked out with the partner at the beginning, before Phase One

Quote: "1. Getting to the "why" of the challenge first." 
Analysis: The WDO identified partner relations and their trust as crucial building blocks. This factor is vital moving forward. They acknowledge that the 'why' of the challenge, along with clear objectives and challenge statements, are essential in Phase Zero.

10. Do you have recommendations to improve the WDO's World Design Challenge program process and increase successful outcomes/results?

Extracted Results, Themes and Summary of Responses:

- The use of different approaches by facilitators caused bottlenecks in the workflow and increased confusion across the teams, so it is recommended to minimize the approaches

- It is beneficial to commit more time to challenges but limited the amount of design challenges per quota

- Increase facilitation orientation and training

- Align more thought leaders with relevant background

- Increase playback sessions and dialogue with tangible feedback

- It would be beneficial if the World Design Challenges were self-sustaining economically

- Having a bridge at the end of each phase with a defined timeline for the next phase that includes clear communicated expectations

- Phase One and all phases determined before the initial kick-off

- A selected few wanted a celebratory event at the end of each phase and an information session for future direction and phases

- It was suggested that by managing expectations trust in the process will be built

Quote: "One of the key areas that I would like to see us develop further is to provide more 'training' on our process to the design facilitators."

Analysis: The findings identified several critical points directly related to building the World Design Challenge program. Research participants expressed the need to have a well throughout challenge structure through each phase and within the process.

\subsection{UN Women and ISS NL Questionnaire and Interview Results and Analysis}

Figure 6 highlights questionnaire and interview question design were based on open-ended questions. The complete questionnaire and interview table showcases all the summary responses (See Appendix I). 


\section{Questionnaire \& Interview - UN Women \& ISS NL 8 Research Participant Responses}

\begin{tabular}{l}
\hline \\
Do you believe there could be a fixed set of design \\
process stages? Why? \\
\hline $\begin{array}{l}\text { Based on your experience, what are the main factors } \\
\text { of the process that contribute to a WDO's 'Design } \\
\text { Challenges' success? List them in order of importance. }\end{array}$
\end{tabular}

\section{3}

Who are the key actors (Actor examples, but not limited to Topic experts, thought leaders, facilitators) in the WDO's 'Design Challenges' process that enhance better creative outcomes? List them in order of ranking. One is the largest enhancer.

\section{4}

What are the biggest obstacles in the WDO's 'Design Challenges' process and structure?

\section{5}

What are the most useful tools in generating creative thinking?

\section{6}

Do you think the same tasks/exercises should be used in the WDO's 'Design Challenges' process for creating success outcomes/ results? Why?

\section{7}

What part of the WDO's 'Design Challenges' process is the most vital for successful outcomes/results? Why?

\section{8}

Do you believe the WDO's 'World Design Challenge' process should be applied as a problem-solving technique for most industries?

\section{9}

Describe your WDO's 'World Design Challenge' experience(s)?

\section{Answer Summary \\ A structured process is necessary for guidance, but it should be flexible.}

\section{Answer Summary}

Facilitator who are educated, trained and given guidance have been identified.

Answer Summary
1) Design Facilitators/Coaches Designers who
are good facilitators, 2) WDO - template builders/
"directionalists" WDO provides framework for
the facilitators to follow.3) Leadership team
(stakeholders) - objective setters. Client objective set-
ters.4) Subject matter experts Provide context,
5) Diverse participants

Answer Summary

Facilitators who are skilled, challenge adaptability and flexibility, more WDO involvement as their involvement is pinnacle.

\section{Answer Summary}

Collaborative and guidance tools were identified such as whiteboard, WDO engagement, empathy mapping, personas, analysis, mind mapping.

\section{Answer Summary}

There is confidence in many of the exercises, but the order and duration could be customized as long as there are clear instructions for each and how they tie together.

\section{Answer Summary}

WDO involvement and direction are important including the build of the challenge, research and exercises were highlighted and facilitation and topic experts are required.

\section{Answer Summary}

There is confidence that the process can be effective for most industries as long as it continues to evolve, but some question its ability to be adapted to the non-tangible.

\section{Answer Summary}

Overall everyone enjoy the experience and felt they were transformed creatively.

\section{Answer Summary}

Most feedback was directed at the structure and building of the challenge from phase to phase and its flexibility.

Do you have recommendations that would improve the WDO's 'World Design Challenge' process and increase successful outcomes/results?

Figure 6. Questionnaire and Results Diagram 
1. Do you believe there could be a fixed set of design process stages? Why?

Extracted Results, Themes and Summary of Responses:

- Steps that WDO undertakes in the design challenges is a logical process; not sure if the same approach should be undertaken for all World Design Challenge programs

- Not sure if the template is a clear fit for social justice issues or any industry, depends on what you are trying to answer

- Other tracks and steps may be needed before going directly into Phase Two

- Should be a set, but not sure about a standard set

- No, a fixed set, as the facilitator should decide as they are moving on through the process

- After Phase One, there should be a deeper phase to refine the product

- Good to be structured, but facilitators should have their reflection about the process to determine what more is needed to be achieved

- Empathy, personas, mapping is good but should not limit us.

- Do believe that a template with some tasks would be helpful.

- Timeline should be scripted

- Structure helps everyone understand the lay of the land

- Yes, structure that builds in divergent and convergent stages is important.

- Set of task exercises, flexibility because not every framework requires the same task

Quote: "Biggest wondering, is whether such a design format process structure, the way that it's elaborated here and now in this design challenge is actually whether that's a clear fit for social justice issues that are really based on the invisibility of attitudes beliefs and this design challenge."

Analysis: The research participants believe there should be structure as it is necessary for guidance, but it should be flexible, so facilitators have freedom to adjust according to the challenge. Many of the research participants think there should be a reflective and refinement stage before proceeding to the next phase. It appears they want direction but with the freedom to explore, reflect and refine.

2. Based on your experience, what are the main factors of the process that contribute to a WDO's 'World Design Challenge' success? List them in order of importance. 
Extracted Results, Themes and Summary of Responses:

- Diversity of participants representing different knowledge and skillsets are the main factors

- A practice of respectful listening, where dialogue invites differences, and where facilitators skilfully guide discussions to decision making

- Facilitation among leaders is sorely needed to navigate the landscape

- Container for the process has been useful in managing the creative process

- A workshop is required for understanding what that process is and what to expect

- Facilitators who are not just well-grounded in the experience, but also the facilitation

- Supporting facilitators will increase success factors

- Main factors 1) Planning tools, 2) Agenda, 3) Teamwork collaboration

- Outline and guidelines that do not limit participants

- Basic orientation and goals

- Approach and the result might not fit the needs

- Willingness to be open to exercise changes

- Structure needs to state what you are creating and its intent, but not too structured

- Trust is important and a clear objective using the right tools

- Important tools are Miro, Zoom, Slack, Mural, brainstorming

Quote: "A diversity of participants is present and engaged, representing different knowledge and skills sets, from different backgrounds of human experience."

Analysis: The main factors contributing to a successful World Design Challenge program are educated and trained facilitators. Offering more support and guidance for facilitators will increase success. Many feel an education session would be beneficial. Most research participant put value in a clear objective and using the right tools. The communication and collaborative tools that have been identified as main factors. These insights are achievable and attainable.

3. Who are the key actors (Actor examples, but not limited to topic experts, thought leaders, facilitators) in the WDO's 'World Design Challenge' process that enhance better creative outcomes? List them in order of ranking. One is the largest enhancer.

Extracted Results, Themes and Summary of Responses:

- The WDO leadership team, WDO Secretariat, UN Woman and ISS NL leadership team are key actors

- Key actors are design professionals, design facilitation, plus design students 
- Design facilitators and designers who are good facilitators

- WDO is the template builders and the "directionalists", as WDO provides the framework for the facilitators to follow

- Leadership teams are the objective setters

- Subject matter experts provide context and key to understanding direction

- Diverse participants help enhance the creative outcomes

Quote: "WDO board members and staff design professionals, design faculty and design students Those who are not designers, who bring in other perspectives on the human experience."

Analysis: The research participants have identified the WDO and leadership teams as the primary actors. Secondary actors are the facilitators and subject matter experts. Finally, the participants are last. The ranking differs from the WDO, as they put participants above facilitators.

4. What are the biggest obstacles in the WDO's 'World Design Challenge' process and structure?

Extracted Results, Themes and Summary of Responses:

- Some facilitators might be experts in their fields but that does not make them skilled in or good at facilitation

- An even allocation of good facilitators make for an uneven process between teams

- The setup should include facilitators and subject matter experts, so they hit the ground running

- Provide a pre-schedule meetings in a master calendar

- Template that is adaptable and demonstrates, flexibility and adaptability

- The WDO should not trust the process without their presence and therefore they should be more involved.

- Stakeholders need to be understanding of each other

- The biggest obstacles are the virtual world and the present limitations, scheduling in different time zones, timing, and team building

- Limited financial resources

- Provide creative workshop and set the expectation

- WDO has too many challenges at the same time, so they are stretch thin-conflicting priorities

- Feasibility not always considered 
- There is great creativity but sometimes without a basis in reality

- Provide a lecture or guide on the process

- More testing and refinement is needed before moving to next phase

Quote: "Facilitators are experts in their respective fields, but they are not necessarily skilled or good facilitators."

Analysis: Not having skilled facilitators is an obstacle as they guide the process and teams. Subject matter experts and facilitators who are educated in facilitation appear to be a recurring theme. Ensuring that the program is adaptable and flexible is highlighted often and should be a consideration when design the World Design Challenges. Everyone wants more WDO involvement as their involvement is pinnacle for successful outcomes. Their involvement might be decreased if good facilitation increased.

\section{What are the most useful tools in generating creative thinking?}

Extracted Results, Themes and Summary of Responses:

- Whiteboard, Google and Slack, empathy mapping, personas, analysis, mind mapping

- An increased level of engagement by WDO board members

- Interactions with board members spur creativity

- Collaborating is considered a useful tool

- Facilitators involved in the creation and development of the whiteboard

- Understanding logic behind the flow

Quote: "Slack. Mural - interactions with board members was spot on for me in terms of spurring creativity."

Analysis: Including collaborative, communication and guidance tools were identified. The whiteboard helped frame all the exercises mentioned. There is a repeated call for WDO to be engaged more as their advice is essential for facilitators and teams.

6. Do you think the same tasks/exercises should be used in the WDO's 'World Design Challenge' process for creating success outcomes/ results? Why?

Extracted Results, Themes and Summary of Responses:

- The same exercises and tasks can be used across different projects

- The exercises are consistent and proven to work well in similar settings 
- The orientation that prepares people with basic design knowledge for tasks is essential

- A customize framework for each 'World Design Challenge' program

- Examine why there the suggested frame works are used

Quote: 'It is also important to explain WHY these are the suggested frameworks. I am not sure this was clear enough in the challenge I participated in. Why an empathy map? Why a storyboard?'

Analysis: There is confidence in many exercises, but the order and duration could be customized if there are clear instructions for each and how they tie together.

7. What part of the WDO's 'World Design Challenge' process is the most vital for successful outcomes/results? Why?

Extracted Results, Themes and Summary of Responses:

- The WDO Board members and staff are an essential part and there more involvement is required

- The session with Surya was vital as he explain the 'how'

- Phase Zero should include all the right people for building a strong foundation

- Facilitators and subject matter experts are crucial

- There needs to be a common understanding among facilitators

- The ethnographic research, brainstorming and analysis, plus empathy mapping are important

- Solutions that are grounded in reality are vital

Quote: "Phase zero, putting it those right people in place. Lot of time in building the Foundation." Analysis: The involvement and direction from WDO are essential to successful outcomes. The building of the World Design Challenge, including the research and exercises, are required for great results. Good facilitation and topic experts are a requirement. There appears to be a need for guidance from WDO and good facilitators as they are associated with successful outcomes.

8. Do you believe the WDO's 'World Design Challenge' process should be applied as a problemsolving technique for most industries? 
Extracted Results, Themes and Summary of Responses:

- The WDO World Design Challenge is extremely useful in combating problems that are hard to tackle

- I am not convinced that the design process can address invisible problems like the attitudes and beliefs

- The process can be applied if the subject matter experts are involved

- The process can be applied to any industry

- The process can be applied to concrete deliverables that are material products

- Design process is not an exact match for all.

- The process is useful

- There is an assumption is that framework or common language is established

- The process is great for the development sector

- The human-centred design should be used in planning and implementing development work

Quote: "The WDO process is clearly successful when there is a concrete deliverable that is a material product."

Analysis: There is a confidence that the process can be effective for most industries as long as it continues to evolve but some question its ability to be adapted to the non-tangible.

\section{Describe your WDO's 'World Design Challenge' experience(s)?}

Extracted Results, Themes and Summary of Responses:

- It was a positive experience

- It was an incredible journey of learning

- The World Design Challenge shifted my thinking

- In the beginning there was anxiousness, but it became more clear

- Could not fully trust the tools

- The experience was eye-opening and it was lots of fun

- It was fun, engaging, stretching, inspiring, educational, evolving, mind-opening

- Great teams, excellent facilitators, outstanding content and storytelling of the teams.

- Outstanding and provided great results

- The proposed solutions were quite large and not feasible

- There needs to be some imposed guidelines to keep things grounded 
- Good experience and learned a lot

- It created an interest in the design process

- Whirlwind and it was very intense

- It set expectations

- There was good support from the WDO Secretariat - very impressive

Quote: "Absolutely eye opening. Preparation was amazing (Andrea is amazing), Positive experience, widely share and explore this process."

Analysis: Overall, everyone enjoyed the experience and felt they were transformed creatively. The experience left many wanting to explore the concept of design process further. No one appeared to have a negative experience.

10. Do you have recommendations that would improve the WDO's 'World Design Challenge' process and increase successful outcomes/results?

Extracted Results, Themes and Summary of Responses:

- The facilitators need an orientation session before meeting with participants for team building

- There needs to be clarity about the proposal, the content and the structure of the proposal

- There needs to be more conversations with the leadership team and the facilitators

- Providing examples would be beneficial

- Providing basic information about design, subject content, group participation and instructions on how to use of the tools

- Identifying sponsor for funding that could have also help shape the idea

- The efforts were excellent and required no change

- Great teams selected, great facilitators, beautiful presentations

- There needs to be a understanding of the phases and how they align

- Expectations need to be set for all volunteers unaffiliated with either WDO or the partner

- Smoother transition from Phase One as there was no mention of Phase Two

Quote: "Facilitator's session before meeting with participants. Team building. Topic and knowledge exchange."

Analysis: Most feedback was directed at the structure and building of the challenge from phase to phase and its flexibility. An equally important factor was the facilitation component. Facilitators are deemed essential to the outcome and results that are generated by the team. 


\subsection{Key Findings and Summary}

Part One - Observational Approach:

UN Women Generation Equality Asia Pacific Design Challenge - Phase One

UN Women Phase One was WDO second World Design Challenge program at that time. Considering this fact, the World Design Challenge program had a very well-thought-out design process structure in place. The World Design Challenge program was highly successful, and most teams were ignited with ambitions to generate social change.

Over the two weeks of the World Design Challenge program, several recurring themes emerged which included as follow:

1. A visual timeline guide on the whiteboard is required to help team members conduct better time management.

2. Facilitators are required to evaluate the skillsets of the team members so that they are utilized in a capacity that yields favourable results to increases productivity.

3. Facilitators need to generate excitement and encourage a positive environment by redirecting and defusing non-productive situations.

4. Facilitators need to know how to effectively facilitate to help team members to think outside-of-the-box.

One thing that should be factored in is the observational researcher was exposed to a productive, well-functioning and highly efficient team.

The International Space Station's (ISS NL) Design in Space for Life on Earth Challenge Phase One

ISS NL Phase One was the third World Design Challenge. The researcher participated as a design thought leader for two teams working on the same challenge statement. This vantage point provided insight into different team dynamics and facilitation styles.

Additionally, this World Design Challenge provided a unique opportunity to examine topicrelated issues. For starters, the high-profile call attracted many individuals who had invested in personal interests. Many team members were confused and tried to generate a research project on ISS to solve an SDG. The confusion proved to be costly from a time and productivity standpoint. Both teams were influenced and distracted by other teams' direction and progress. 
A notable observed issue is many team members did not attend or participate due to various reasons despite the positive reinforcement by the facilitator and thought leader. The participants who remained were highly productive and efficient.

Both teams felt proud of the products they produced and excited for Phase Two. However, there was a void and confusion at the end of Phase One because teams were not given a date and direction for the next phase.

\section{UN Women Generation Equality Asia Pacific Design Challenge - Phase Two}

United Nations Women Challenge Phase Two was the first WDO Phase Two World Design Challenge programand as such should be viewed slightly different due to the following reasons:

1. The duration of Phase Two changed from two weeks to five weeks.

2. The objectives were framed differently than Phase One.

3. Facilitation roles changed based on the requirements of Phase Two.

WDO decided to answer participants' requests to increase the World Design Challenge programtime did have the anticipated desired effect. Instead, it only became draining on the volunteer's schedules and their capacity to participate.

Phase Two's objective substantially changed the way teams functioned. Many groups were confused as they did not feel the products from Phase One were in their finished form. Phase Two's objectives were to take the product and identify potential stakeholders and funding partners, spec the development, and bid it out. The lack of product refinement became an obstacle for Phase Two's scope of work and deliverables.

Another key finding was the roles within facilitation altered as the topic experts were not as needed as in Phase One and therefore created a shift in workload and responsibilities for the design facilitators.

In the end, Phase Two proved to be ambitious and may have been too much for most teams to complete all objectives. The success of Phase Two is that all teams managed to refine their products, so they were better thought out for the partner and the users.

Overall, the two-week World Design Challenge programhad a well-structured platform that allowed teams to solve the design goal and be part of the solution. 


\section{Part Two - Survey:}

All research participants have first-hand exposure and knowledge of WDO World Design Challenge programand can provide insight into the design process. The following findings regarding the research participants were uncovered in the survey:

- Less than half have been employed in the Creative Industries.

- Less than half have an education in the creative field.

- Five out of Six who do have an education in the creative field have a degree.

- Almost all believe they understand the stages in the design process.

- More than half believe that all the stages in the design process are equally important.

- Only four out of thirteen have had a negative creative experience.

- All participants had a positive WDO 'World Design Challenge' experience.

- Nine out of thirteen felt the 'World Design Challenge' ran smoothly.

\section{Part Three (WDO - Creators) - Questionnaire and Interview:}

The questionnaire and interview for the creators of the WDO's World Design Challenge program provided the following key findings:

- Most believed that there should be structure in the design process because participants need guidance, but it should be flexible.

- The creators felt that Phase Zero was a key factor for a successful World Design Challenge.

- The main actors that contribute to the success of the World Design Challenge are, in order, as follows: Leadership team, WDO Secretariat, subject matter experts, thought leaders, participants and facilitators.

- The biggest obstacles are trust, managing time zones, building Phase Zero, determining agreed-upon clear objectives, a breath of participants and facilitators with skillsets.

- The most valuable tools are virtual whiteboarding platforms, brainstorming, mind mapping and reflection.

- WDO identified that the same set of tasks are beneficial as long as they permit flexibility.

- The most important part is setting up a clear set of objectives and challenge statement.

- The biggest obstacles are the lack of resources and time. Plus, partners need to believe and trust in the process. There is also not enough training for facilitators, and finally, time zones are challenging. 
- WDO suggests that they need to work through the structure of the phases for the process.

\section{Part Three (UN Women \& ISS NL - Contributors) - Questionnaire and Interview:}

The questionnaire and interview for the Contributors of the WDO World Design Challenge program provided the following key findings:

- A structured process is necessary for guidance, but it should be flexible and adaptable.

- The key actor for success was identified as trained and education facilitator.

- Collaborative and guidance tools were identified, such as whiteboard, WDO engagement, empathy mapping, personas, analysis, mind mapping.

- WDO involvement and direction are important including the build of the challenge.

- There is confidence in many exercises, but the order and duration could be customized if there are clear instructions on how they tie together.

- There is a confidence that the process can be effective for most industries if it continues to evolve but some question its ability to be adapted to the non-tangible.

- Overall, everyone enjoys the experience and felt they were transformed creatively.

- Most feedback was directed at the structure and building of the challenge from phase to phase and its flexibility. 


\section{CHAPTER 5: CONCLUSION}

\subsection{Summary of Results and Recommendations}

The aim of this thesis was to analyze the World Design Organization's (WDO) World Design Challenge program to determine how it can be further improved. The World Design Challenge programis presently the new online version of the Interdesign workshop and is quickly gaining global demand. As interest is increasing for the new online online version it is important to identify areas for improvement to ensure World Design Challenge program is successful remotely.

This thesis provided an opportunity to observe and receive feedback for two World Design Challenges. One World Design Challenge contained two phases which provided three observational instances. All three observation instances offered extensive insight into the inner workings of the online World Design Challenge program. The survey solidified the research participants' background knowledge on the World Design Challenge program and design process. The research questionnaire and interview provided exclusive feedback regarding the World Design Challenge program through participant insight. Overall, participants were positively transformed by their World Design Challenge programexperience. Many expressed they had a newfound understanding and curiosity for using design to solve problems. They were eager to provide feedback as they felt they had an invested interest in improving the World Design Challenge program.

The research revealed a variety of notable items. Both Phase One World Design Challenges offered an online design process framework on virtual whiteboards. Each Phase One World Design Challenge used different online whiteboard platforms. UN Women Generation Equality Asia Pacific Design Challenge used a whiteboard by Mural. The International Space Station National Laboratories (ISS NL) - Design in Space for Life on Earth Challenge utilized a whiteboard by Miro. The design process framework on the whiteboards for both World Design Challenge programs contained divided stages that incorporated exercises. The intent of the stages and exercises were to guide the teams along with the design process journey. WDO adjusted the framework from the initial UN Women World Design Challenge program to ISS NL World Design Challenge program. A timeline was added to the whiteboard which permitted teams to gauge and track their progress according to due dates. The flexibility with offering a World 
Design Challenge program online provided rapid responses in accordance to the required changes. This flexibility allows WDO to respond quickly to adjust and refine the World Design Challenge program, thereby increasing user experience. Another item to note is that the actors' roles were modified between both World Design Challenge programs.

The UN Women World Design Challenge incorporated subject matter experts in design and topic content to facilitate each team. The World Design Challenge for the ISS NL included subject matter experts in design and topic content as thought leaders for two teams. Each of those teams had one facilitator who had a background in design. The change provided the researcher with the opportunity to observe how the change in roles effected team dynamics and outcomes.

Phase One's success brought the introduction to Phase Two. For Phase Two, WDO increased UN Women World Design Challenge from two weeks to five weeks. The increase is intended to allow participants to complete Phase Two's objectives. These objectives included stakeholder exploration for funding partners, product specification for price quotes, a proposal document and finally, a polished presentation. The increase in duration and multiple deliverables posed to be too much on the teams and their schedules. In addition, Phase Two did not permit an opportunity to reflect on what was done and refine the product from Phase One. The teams felt the need to perfect the product before working on the specifications. The lack of product reflection and refinement caused disruption and confusion among the participants and teams.

Based on the researcher's observations and the participants' feedback, a list of recommendations was created which aimed to outline improvements towards the World Design Challenge program. The recommendations intend to increase team dynamics, address online and remote obstacles, enhance program structure, increase user experience, maintain participant retention, and promote membership value.

The recommendations are as follows:

1. Phase Zero - It is recommended to spend additional time building a well-thought-out structure in Phase Zero. The recommendation is to make each World Design Challenge a custom build to address the partner's problem and achieve their goal. This approach would help partners trust in the design process and increase membership value. 
2. Phases - It is suggested that all phases be predetermined and mapped out. There should be a provision of timeline for all phases, duration between phases and each phase's objective before the start of Phase One. This approach will allow the associated partners to see the entire journey. It is also suggested that the phases be structured in micro-pieces so that each phase and its objectives are achievable. Each phase should be two weeks in duration but with more defined micro-goals. There should be a reflection and product refinement stage after each phase. It is recommended that Phase Two be the product refinement stage where convergent thinking is building on the feasibility.

3. Participants - Each World Design Challenge should have an in-depth understanding and background on participants who answer the World Design Challenge program call. A questionnaire and validation process to verify participant claims are suggested.

4. Facilitation - It is recommended to include an orientation session to educate facilitators on good facilitation technics and methods. A series of online videos or workshops that facilitators must complete before the World Design Challenge. Once the program is complete, the facilitator will receive a certification credential. The courses can also be offered outside of WDO's World Design Challenge program at a cost for those who want to be educated on design process facilitation.

5. Topic and Challenge Statements - To increase the level of participant comprehension it is recommend that WDO offer an orientation session to educate all teams on the topic and the challenge statements. This approach would decrease confusion and help teams understand the relationship between the subject matter and the problem that the statement is trying to solve.

6. Icebreaker - WDO would potentially see an increase in team relations if time was allotted to acquaint team members. A pre-kick-off virtual gathering with breakout rooms for the teams and facilitators to learn more about each other. There should be activities and games to help participants to become familiar with each other. This would compensate for the lack of the traditional dinners that are held during Interdesign workshops.

7. Online Technology - It is also advised to provide all participants with tutorial links prior to the World Design Challenge so participants are familiar with the online tools. 
As for communication and file sharing options a list of recommendations is provided:

a) Slack - Perfect for team and facilitation communications. It is recommended to make an additional channel for each team that includes the facilitators, subject matter experts and thought leaders so they can organize and tackle issues outside the team channel.

b) Google Doc, slides and Sheets are some mediums considered perfect for sharing files and working collaboratively and simultaneously.

c) Zoom - Zoom is a great online visual meeting space. It is recommended that WDO offer all facilitators, subject matter experts and thought leaders Zoom accounts that allow for transcribe for accessibility and saving zoom meetings to cloud.

d) Miro - Miro proved to be a better online whiteboard option. The new desktop app decrease lag-time. It is recommended to allow other teams view other teams' boards. Template options are easy to use for non-technical participants.

e) Mural - Mural is not as efficient as Miro. There are limited template options for participants. The bandwidth issue with Mural, which effect productivity.

f) Scheduling - It is advised to make a meeting schedule application that adjusts to time zones available to teams. Calendly is an example of such software.

8. Commitment - It is suggested that WDO offer participants with a full schedule timetable, which is available on the whiteboards and in the introductory presentation. The timetable would outline the core schedule, prescheduled meetings, playback, and check-in sessions. This approach would establish a clear understanding of scheduling and time requirements and, therefore, the full extent of their commitment.

9. Timing - It is recommended that WDO only schedule a limited amount of World Design Challenges in a particular timeframe, so there is no overlap. 
10. WDO Leadership - It is suggested that WDO leadership increase their participation. Although, if teams and facilitators were better educated and familiar with the process, they would feel more comfortable on the journey and require less guidance.

11. Examples - It is advised to provide examples of completed exercises to help the teams understand what they are trying to achieve. The examples are visual aids for comprehension.

12. Design Process - It is recommended that the World Design Challenge program should have a base core structure which can be customization, flexible and adaptable. Exercises in each phase are based on the objectives and challenge statements. The online World Design Challenge program allows for customization.

13. Development - It is recommended that WDO integrate an academic program and course developer to foster and increase content comprehension for participants and teams. The integration will take upfront time but decrease confusion and increase confidence.

14. Moving forward, it is recommended that WDO communicate to all future partners that the World Design Challenge program will be perpetually evolving. It is not perfect nor in a finished packaged form. As such, World Design Challenge program will exist in a continuous state of refinement. This level of transparency will set the stage for expectations and prepare partners for a journey based on pushing barriers, focusing on user experiences and sustainable creative outcomes.

The research provided participants with an opportunity to help shape future iterations of the World Design Challenge program. This thesis analyzed the World Design Challenge program online environment to identify areas that can be improved and provided feedback regarding the program and online collaborative tools. 


\subsection{The Adjusted World Design Challenge Program Structure}

The new structure would increase the time it takes to build Phase Zero. Phase Zero would include the partner in the development. The partner would be informed of the customized approach. A program and course developer would assist both groups in the development of the World Design Challenge. All phases for the entire problem-solving journey would be mapped out in this period. Between each phase, WDO would allow for an opportunity for participants to reflect on the journey, product and refine. This would be labelled at the reflection stage. The labelling for the reflection's stages would need to be examined. For example, is the reflection phase Phase Two, or is it Phase One Refection Phase. Each phase would only be for a two-week period. However, the reflection stages only need to be three to five days. When developing the phases, the objectives for each phase would be thought out and stated. The expectation for the objectives should be reasonably designed to be achievable within two weeks. A timetable of the entire journey would be provided. The timetable would include all meetings outside of the team meetings, which would also be included in the whiteboard.

The Miro whiteboard structure would be designed, so each stage is well thought out according to the problem to be solved. A timeline with the journey is mapped out on the whiteboard. Within each stage on the whiteboard, there is a detailed explanation of the stages and exercises that include completed examples. A separate Slack challenge would be created outside the team channel to increase communications between the facilitators, thought leaders, and subject matter experts. To increase the use of collaborative materials, Google Docs would include all required templates for the World Design Challenge. The Google Drive would include folders for meeting notes and team videos. Zoom accounts with transcribing and cloud saving would be created for all facilitators, subject matter experts and thought leaders.

In Phase Zero, the WDO would validate all the participants backgrounds. A facilitator orientation session would educate and instruct the facilitators on the challenge statements and World Design Challenge process. The selected facilitators would be required to take a certification course. In addition to supporting the facilitators, participants would be invited to an orientation session to educate teams on the topic and the challenge statements. The participants would be sent an email with links to technology tutorials and a link to Calendly for slotting in their availability for meetings. Finally, WDO would offer a pre-kick-off virtual gathering for participants to become familiar with each other. 


\subsection{Limitations of Thesis}

This thesis journey presented and uncovered several limitations. Initially, the researcher and the thesis supervisor identified seventeen research participants to be included in the case study. However, scheduling issues and time zone differences decreased the number of research participants to thirteen. Due to these same factors, one participant only provided written feedback by filling out the survey, consent, and questionnaire form.

Another issue arose within the stage of research participants' involvement in the UN Women Generation Equality Asia Pacific Design Challenge - Phase Two. These research participants were already taxed with meetings and obligations, so scheduling the interviews was difficult.

One notable limitation was the naming protocol for the World Design Challenge program. The WDO has yet to establish the program's naming since the World Design Challenge program began as the Interdesign workshop was temporarily inactive due to COVID-19. The naming protocol caused confusion.

\subsection{Contributions}

The research results contributed to the limited existing knowledge of the WDO World Design Challenge program. As the World Design Challenge program is a new online option, there is little to no knowledge of the remote program. This thesis contributes to WDO and the design communities' understanding of remote design process delivery for global initiatives. This research provided feedback on several virtual collaborative tools in hopes of increasing efficiency. The online World Design Challenge program was explored to expand on the present design process knowledge for a remote landscape.

To date, there are no established programs that offer the same design solutions as the World Design Challenge program. This new online experience will continue to expand to meet the demand for online collaborative workspaces to address design solutions. 


\subsection{Further Research}

Based on the research findings and the participants positive experience with the WDO World Design Challenge program, it is recommended that the WDO continue to obtain feedback so they can evolve to meet the vigorous demands to produce unique design solutions remotely. Due to the World Design Challenge program being an online platform, it has the potential to progress further as new technological advancements become available.

It is proposed that an Interdesign workshop 2.0 toolkit be developed to help increase collaborative thinking and from the Interdesign workshop to the online virtual platform. The toolkit would better outline the future path of both programs and how they could work in unison but independent of each other. The toolkit could better address issues of bridging the rich experience of the physical face-to-face experience of the Interdesign workshops to the non-physical online virtual experience.

It is suggested that the WDO consider running both the Interdesign workshop and World Design Challenge program as both have unique attributes. The Interdesign workshop provides an inperson collaborative experience that fosters face-to-face human connections between like-minded individuals who wish to physically gather to create constructive change. While the World Design Challenge program still offers a collaborative experience, it also allows the participant to contribute remotely. The efficiency and availability aspects of this program permit participants to contribute regardless of physical and financial limitations.

The research uncovered many positive aspects of the WDO World Design Challenge program and provided helpful insight into improving its present structure. Upon completing the research, all findings will be made available to the World Design Organization and the research participants. 


\section{REFERENCES}

Clarke, A. (2021). Victor Papanek: Designer for the Real World. Boston: MIT Press.

Brown, T. (n.d.). Design Thinking Defined. https://designthinking.ideo.com/\#about-this-site.

De Bono, E. (1968). New Think: The Use of Lateral Thinking in the Generation of New Ideas. New York: Basic Books.

De Bono, E. (1970). Lateral Thinking: A Textbook of Creativity. London: Penguin Books.

De Bono, E. (n.d.). What is Lateral Thinking. https://www.edwddebono.com/lateral-thinking.

Davey, C. et al. (2005). Design for the Surreal World? A New Model of Socially Responsible Design. In Proceedings of the 6th International Conference of the European Academy of Design, EAD06, 29-31 March. Bremen: University of the Arts Bremen.

Dubberly, H. (2004). [Beta Unpublished] How Do You Design? A Compendium of Methods. San Francisco: Dubberly Design Office.

Freire, K., Del Gaudio, C., and Franzato, C. (2018). Design-Driven Strategies for Creative Social Innovation Ecosystems. International Journal of Knowledge Engineering and Management. Volume 6. Number 16. 46-49.

Martin, R. (2009). The Design of Business: Why Design Thinking Is the Next Competitive Advantage. Boston: Harvard Business Review Press.

Martin, R. (n.d.). Meet Roger. https://rogerlmartin.com/meet-roger.

Osborn, A. (2009). Unlocking Your Creative Power: How to Use Your Imagination to Brighten Life, to Get Ahead. Amherst, Massachusetts: Hamilton Books.

Papanek, V. (1973). Design for the Real World: Human Ecology and Social Change. New York: Pantheon Books.

Payette, P., and Barnes, B. (2017). Teaching for Critical Thinking: Edward de Bono's Six Thinking Hats. The National Teaching \& Learning Forum. Volume 26, Issue 3. 8-10.

Robson, C., and McCartan, K. (2016). Real World Research - Fourth Edition. New Jersey: John Wiley \& Sons.

Saldana, J. (2009). The Coding Manual for Qualitative Researchers. London: Sage Publications Ltd.

Skulmoski, G., Hartman, F., and Krahn, J. (2007). The Delphi Method for Graduate Research. Journal of Information Technology Education. Volume 6. 001-021.

Wilson, J., and Sharples, S. (2015). Evaluation of Human Work. Boca Raton: CRC Press. 


\title{
APPENDICES
}

\section{Appendix A}

\section{Email to World Design Organization and Participants}

\section{Email to World Design Organization}

\author{
This introduction email provides communication content and structure.
}

\section{World Design Organization}

\author{
Email Address
}

Hello Name:

Please allow me to introduce myself; my name is Angie Fahlman; I am a student at Carleton University in the School of Industrial Design, under Professor Thomas Garvey's supervision. Presently, I am working on a thesis that is focused on design process. The research study aims to analyze the WDO's 'World Design Challenge' process and outcomes to understand better how the design process can be improved. The research hopes to identify strengths and weaknesses, and possible gaps. In summary, the primary aim will seek to find answers to the following questions:

1. How can the WDOs 'World Design Challenge' process be improved?

2. How can the WDO's 'World Design Challenge' produce more successful outcomes?

Several WHO staff (see list at the end of this email) who created the UN Women 'The Generation Equality Asia Pacific Design Challenge' and the ISS NL 'Design in Space for Life on Earth Challenge' have been identified as candidates that could provide vast insight into the WDO's 'Design Challenge' process. It would be greatly appreciated if the WDO would invite the identified staff members to participate in the study. The staff would be under no pressure to participate and would only agree of their own free to complete a survey and take part in a brief interview. WDO will not be privy to the data but will be provided with the findings.

If they wish to participate, only 1 hour of their time is required. All information gathered is private and confidential, and they can opt-out at any time before the interview. Withdraw deadline is one week after scheduled interview. This research has been cleared by Carleton University Research Ethics Board-B (CUREB-B Clearance \# 115348).

\section{The research includes:}

1) Survey - One digital PDF survey will be emailed to them and should take approximately 20 minutes to complete. The survey is to establish their design process background and exposure.

2) Interview - A pre-scheduled date and time Zoom recorded interview will take approximately 40 minutes to complete. The interview will contain relevant questions about the WDO's 'Design Challenge' process.

To reduce the correspondences' level and save the employee valuable time, if they agree, they will be sent an additional email that will contain a consent form along with a digital PDF survey and interview questionnaire. The consent form will need to be printed, signed and returned via email. They fill out the survey and interview questions and also return them along with the consent form. The consent form and survey need to be returned prior to the scheduled interview time. The purpose of sending the interview questionnaire prior to the interview is to allow the employee the opportunity to consider all questions thoroughly. Zoom recordings and transcriptions are mandatory. It should also be noted there will be no compensation for their participation outside of knowledge enrichment in the area of design process. 
Any data information obtained will be stored on a password-encrypted HD in a locked, secure location. Once findings are extracted, all data information will be destroyed. Only the results with a summary of de-identified data in the report will be made available to the World Design Organization and the public.

For further information, please contact me at the information indicated below. Thank you in advance for considering sending out the email invites to all of the identified staff and contributing to my education and my quest for understanding the creative design process. I look forward to your response and participation.

Sincerely,

Angie Fahlman

angiefahlmna@cmail.carleton.ca 


\section{Email to Individuals from the WDO and who participated in WDO's 'Design Challenges' \\ This introduction email provides communication content and structure.}

Name

Email Address

Hello Name:

Please allow me to introduce myself; my name is Angie Fahlman; I am a student at Carleton University in the School of Industrial Design, under Professor Thomas Garvey's supervision. Presently, I am working on a thesis that is focused on design process. Based on your involvement and participation with the World Design Organization's (WDO) Challenges, you were identified as a candidate that could provide vast insight into the WDO's 'Design Challenge' process. It would be greatly appreciated if you would be willing to complete a survey and take part in a brief interview.

If you wish to participate, only 1 hour of your time is required. All information gathered is private and confidential, and you can opt-out at anytime before the interview. Withdraw deadline is one week after scheduled interview. This research has been cleared by Carleton University Research Ethics Board-B (CUREB-B Clearance \# 115348).

\section{The research includes:}

1) Survey - One digital PDF survey will be emailed to you and should take approximately

20 minutes to complete. The survey is to establish your design process background and exposure.

2) Interview - A pre-scheduled date and time Zoom recorded interview will take approximately 40 minutes to complete. The interview will contain relevant questions about the WDO's 'Design Challenge' process.

To reduce the correspondences' level and save your valuable time, if you agree, I will be sending you an additional email that will contain a consent form along with a digital PDF survey and interview questionnaire. The consent form will need to be printed, signed and returned via email. Please fill out the survey interview questions and also return them along with the consent form. The consent form, survey and interview questions need to be returned prior to the scheduled interview time. The purpose of sending you the interview questionnaire prior to the interview is to allow you the opportunity to consider all questions thoroughly. Zoom recordings and transcriptions are mandatory. It should also be noted there will be no compensation for your participation outside of knowledge enrichment in the area of design process.

Any data information obtained will be stored on a password-encrypted HD in a locked, secure location. Once findings are extracted, all data information will be destroyed. Only the results with a summary of de-identified data in the report will be made available to the World Design Organization and the public.

For further information, please contact me at the information indicated below. Thank you in advance for contributing to my education and my quest for understanding the creative design process. I look forward to your response and participation.

Sincerely, Angie Fahlman angiefahlmna@cmail.carleton.ca 


\section{Appendix B}

\section{CONSENT FORM}

\section{Consent Form}

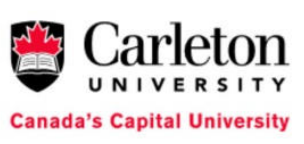

\section{Informed Consent Form}

Name and Contact Information of Researchers:

Angela Fahlman

Carleton University, School of Industrial Design, Master of Design (MDes)

Tel.:

Email: angiefahlman@cmail.carleton.ca

Supervisor and Contact Information: Ph. D. Thomas Garvey, thomasgarvey@cunet.carleton.ca

\section{Project Title}

Design research for WDO's 'Design Challenge'

Project Sponsor and Funder (if any)

N/A

Carleton University Project Clearance

Clearance \#:115348 Date of Clearance

Invitation

You are invited to participate in a research project because you have either created or participated in World Design Challenge 'Design Challenge'. The information in this form is intended to help you understand what we are asking of you so that you can decide whether you agree to participate in this study. Your participation in this study is voluntary. A decision not to participate will not be used against you in any way, nor affect your status with the World Design Organization. As you read this form and decide whether to participate, please ask all the questions you might have, take whatever time you need, and consult with others as you wish.

\section{What is the purpose of the study?}

This thesis research study aims to analyze the World Design Organization's 'Design Challenge' process to understand better how the process can be improved through a more strategized and fluid approach. The research hopes to identify strengths and weaknesses, and possible gaps. As a result, the primary aim will also seek to find answers to the following questions:

1. How can the World Design Organization's 'Design Challenge' process be improved?

2. How can the WDO's 'Design Challenge' produce more successful outcomes?

\section{What will I be asked to do?}

Complete a digital PDF survey that will be provided by email.

Print, sign and send back required forms.

Complete a Zoom recorded interview. 


\section{Consent Form}

Version 2019-03-28

Risks and Inconveniences

We do not anticipate any risks to participating in this study.

\section{Possible Benefits}

You may not receive any direct benefit from your participation in this study. However, your participation may allow researchers to understand better the WDO's 'Design Challenge' process and design process.

Compensation/Incentives

N/A

\section{No waiver of your rights}

By signing this form, you are not waiving any rights or releasing the researchers from any liability.

\section{Withdrawing from the study}

If you withdraw your consent during the study, all information collected from you before your withdrawal will be destroyed will still be used unless you request that it be removed from the study data.

After the study, you may request that your data be removed from the study and deleted by notice given to the Principal Investigator (named above) one week after the scheduled interview.

\section{Confidentiality}

We will treat your personal information as confidential, although absolute privacy cannot be guaranteed. No information that discloses your identity will be released or published without your specific consent

Research records may be accessed by the Carleton University Research Ethics Board in order to ensure continuing ethics compliance.

The results of this study may be published or presented at an academic conference or meeting, but the data will be presented so that it will not be possible to identify any participants unless you give your express consent.

Data will be collected by email, Zoom video recordings and interview transcripts. All data will be kept in a file on a password-protected secure external $\mathrm{HD}$, which will be stored in a location in Ottawa, Ontario, Canada, in a locked cabinet. Zoom video recordings will also be stored locally on the external HD in addition to the "In-session" data.

"In-session" data, such as the audio, video and chat transcript from the interview, will be stored locally on the researcher's computer. Operation data, such as meeting and performance data, will be stored and protected by Zoom on servers located in [the geographic location relevant to you as identified by Zoom], but may be disclosed via a court order or data breach. (Note: The researcher may need to contact the company to learn the server location) 


\section{Data Retention}

Your identified data will be destroyed after findings have been recorded. Any de-identified data will be available in a summary form in a report.

New information during the study

In the event that any changes could affect your decision to continue participating in this study, you will be promptly informed.

\section{Ethics review}

This project was reviewed and cleared by the Carleton University Research Ethics Board [B]. If you have any ethical concerns with the study, please contact Carleton University Research Ethics Board by email at ethics@carleton.ca).

\section{Statement of consent - print and sign name}

I voluntarily agree to participate in this study.

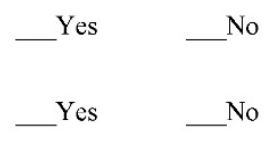

I agree to be video-recorded through ZOOM and allow

the researcher to transcribe the recordings.

(Zoom recorded interviews are a requirement and not optional)

Signature of participant

Date

Research team member who interacted with the participant

I have explained the study to the participant and answered any and all of their questions. The participant appeared to understand and agree. I provided a copy of the consent form to the participant for their reference.

Signature of researcher

Date 


\title{
Appendix C
}

\section{RESEARCH PACKAGE}

\section{RESEARCH PACKAGE}

\author{
MDes Research Topic
}

How can the World Design Organization improve its

'Design Challenge' process and identify its

present strengths and weaknesses?

\section{To Research Study 16 Participants \\ 'Design Challenge' Creators \\ World Design Organization (WDO) - 5 Participants}

'Design Challenge' Contributors

United Nations Women (UN Women) - 5 Participants International Space Station (ISS NL) - 6 Participants 


\title{
GLOSSARY OF TERMS
}

\author{
WDO's 'Design Challenge' \\ 'World Design Challenge' is a proprietary \\ programme by the World Design Organization, \\ which is a virtual workshop experience where \\ groups of voluntary participants are guided through \\ facilitated sessions to address issues through the \\ lens of design in order to propose relevant and \\ impactful solutions.
}

\section{Design Process}

The series of actions and constructs a designer uses to generate creative solutions.

\section{Design Sprints}

The series of actions and constructs a designer uses to generate creative solutions within a short interval of time.

\section{Design Creators}

Employees at the World Design Organization (WDO) who created the 'World Design Challenge' Process.

\section{Design Contributors}

Individuals who contributed and participated at various level in any of the World Design Organization 'World Design Challenges'. 


\section{RESEARCH AGENDA}

This research package contains the following materials:

\section{Creators and Contributors}

Part One of the Research Session

Participants will be provided with the interview package which includes:

1. Introduction Email to Participants

2. Research Consent Form (to be signed by the Participants)

3. Digital PDF Survey Form

4. Interview Questions (Digital PDF Form)

(for Participant to familiarize themselves with the questions and prepare for the interview)

5. Participant and Researcher agree on interview session time

\section{Part Two of the Research Session}

Zoom recorded interview with transcribe - Session with the Participant

1. Interview Discussion Session: 60 minutes 


\section{INTRODUCTION}

\section{Research Topic Introduction}

The demand for well-thought-out design solutions for complex problems drives industry, governments and educational institutions to seek more efficient and effective ways to generate creative out-of-the-box results and outcomes. To meet the request for unique, positive user-based approaches, designers need to abandon some traditional methods and lean on practices that produce more robust options to enhance sustainability.

Before introducing the 'World Design Challenge' initiative,' which the World Design Organization (WDO) developed, we must discuss the term design process. For this research, we will define the term design process as a series of actions and constructs a designer uses to generate creative solutions. The design process usually dictates that a set of structures with various tasks will produce the building blocks for a finished product or prototype. The 'Design Challenge' uses this line of thought with the addition of a condensed timeframe. The 'Design Challenge' also has a refined technique whereby the WDO develops an entire system that helps their client and the 'Design Challenge' participants along a creative journey.

\section{Research Topic Aim}

The World Design Organization's primary focus is to serve as a catalyst for others in their quest to create a better world through a design tool that generates sustainable design solutions.

This thesis research study aims to analyze the WDO's 'World Design Challenge' process and outcomes to understand better how the process can be improved through a more strategized and fluid approach. The research hopes to identify strengths and weaknesses, and possible gaps. In summary, the primary aim will seek to find answers to the following questions:

1. How can the WDOs 'World Design Challenge' process be improved?

2. How can the WDO's 'World Design Challenge' produce more successful outcomes? 


\section{Appendix D}

\section{RESEARCH PACKAGE - SURVEY}

\section{Survey for 'Design Challenge' Creators and Contributors \\ Research Topic: How can the WDO's 'World Design Challenge' improve its \\ design process structure and identify its present strengths and weaknesses.}

\section{Questions}

Name:

Dear Participants, Please read the instruction carefully. This survey should take approximately 20 minutes to complete.

\section{INSTRUCTIONS}

- This is a digital PDF form. Please save this form to your desktop to retain answers in the form.

- Answer ALL questions to the best of your ability.

\section{Rounding scale}

Round to the closest numerical point or most applicable answer.

\section{Return survey}

Please return the survey via email to one of the following email address links. angiefahlman@cmail.carleton.ca or / and thomasgarvey@cunet.carleton.ca

TERMINOLOGY

WDO's 'Design Challenge' is a proprietary programme by the World Design Organization, which is a virtual workshop experience where groups of voluntary participants are guided through facilitated sessions to address issues through the lens of design in order to propose relevant and impactful solutions. Creative process refers to a series of actions to generate a creative outcome. The actions/activities can be taken in a team environment or individually.

\section{Design Sprints}

The series of actions and constructs a designer uses to generate creative solutions within a short interval of time.

\section{Survey Questions}

START HERE - YOU GOT THIS!

1. Have you ever been involved in a WDO's 'World Design Challenge'?

Yes No

2. How many design challenges/sprints have you participated in?
0
$1-2$
3-4
$5-10$
$10-20$

3. Are you or have you been employed in the Creative Industry (Arts, Media and Technology, Design)?

Yes

No See clarification for definition of Creative Industry https://www. davidparrish.com/creative-industries-definitions/

4. Do you have an education in a Creative Field (Arts, Media and Technology, Design)?
Yes
No

5. If you have an education in a Creative Field, what level of education do you have?
High School
Diploma
Degree
Graduate
Doctorate
Not Applicable

6. Do you have an understanding of the stages of design process?

Yes

No 
7. Do you believe that all stages in the design challenge process are equally important?

Yes No

8. Have you ever had design process experiences that you feel negatively about?

Yes No

9. How do you feel about your WDO's 'Design Challenge' experience(s)?

Negative Uncertain Positive Not Applicable

YOU ARE HALF

WAY THERE!

10. Did the WDO's 'Design Challenge' run smoothly?

Yes No

11. In your opinion, did you feel there was a structure to WDO's 'Design Challenge' process?

Yes No

12. If you felt there was a structure to the WDO's 'Design Challenge' process, did it enhance or restrict the outcomes/results?

Enhanced Restricted

13. Do you work well in a structured environment?

Often Sometimes Seldom Never

14. Do you enjoy being involved in team projects?

Often Sometimes Seldom Never

15. Are you regularly required to come up with creative solutions for your job?

Yes No

16. Have you ever struggled to generate creative outcomes/results?

Often Sometimes Seldom Never

17. Do you think there is value in the WDO's 'Design Challenge' process for generating creative outcomes/results?

Yes No

18. Were unique ideas generated during the WDO's 'Design Challenge'?

Yes No

19. Would you like to take part in future WDO's 'Design Challenges'?

Yes

No

YOU DID IT - THANK YOU! 


\title{
Appendix E
}

\section{RESEARCH PACKAGE - INTERVIEW QUESTIONS}

\author{
Interview Questions for 'Design Challenge' Creators \\ Research Topic: How can the WDO's 'World Design Challenge' improve its \\ design process structure and identify its present strengths and weaknesses.
}

\section{Questions}

Name:

Dear WDO's ‘Design Challenge' Creators,

This interview should take approximately $\mathbf{4 0}$ minutes to complete.

Instructions

- The Zoom interview will be video recorded with transcriptions for research purposes. You will receive a PDF digital copy of the interview questions before the interview to fill out and become familiar with the questions. Please fill out your response and return this form via email (angiefahlman@ cmail.carleton.ca) before the pre-scheduled interview time.

- Answer ALL questions to the best of your ability.

- You are free to stop the interview at any point.

Interview Questions

1. Do you believe there could be a fixed set of design process stages? Why?

2. Based on your experience, what are the main factors of the process that contribute to a WDO's 'Design Challenges' success? List them in order of importance.

3. Who are the key actors (Actor examples, but not limited to Topic experts, thought leaders, facilitators) in the WDO's 'Design Challenges' process that enhance better creative outcomes? List them in order of ranking. One is the largest enhancer. 
4. What are the biggest obstacles in the WDO's 'Design Challenges' process and structure?

5. What are the most useful tools in generating creative thinking?

6. Do you think the same tasks/exercises should be used in the WDO's 'Design Challenges' process for creating success outcomes/ results? Why?

7. What part of the WDO's 'Design Challenges' process is the most vital for successful outcomes/results? Why?

8. As creators who guide users, what are your biggest positive or negative challenges?

9. What were the critical building blocks in creating the WDO's 'Design Challenges'?

10. Do you have recommendations that would improve the WDO's 'World Design Challenge' process and increase successful outcomes/results? 


\section{Interview Questions for 'Design Challenge' Contributors}

Research Topic: How can the WDO's 'World Design Challenge' improve its

design process structure and identify its present strengths and weaknesses.

\section{Questions}

Name:

Dear WDO ‘Design Challenge’ Contributors,

This interview should take approximately $\mathbf{4 0}$ minutes to complete.

Instructions

- The Zoom interview will be video recorded with transcriptions for research purposes.

You will receive a PDF digital copy of the interview questions before the interview to fill out and become familiar with the questions. Please fill out your response and return this form via email (angiefahlman@ cmail.carleton.ca) before the pre-scheduled interview time.

- Answer ALL questions to the best of your ability.

- You are free to stop the interview at any point.

Interview Questions

1. Do you believe there could set of tasks/exercises in the design process? Why?

2. Based on your experience, what are the main factors that contribute to a successful creative process? List them in order of importance.

3. Who are the key actors in the 'Design Challenge' process that enhance better creative outcomes? List them in order of ranking. One is the largest enhancer. (Actor examples, but not limited to Topic experts, thought leaders, facilitators) 
4. What are the biggest obstacles in the WDO's 'World Design Challenge' process? Both in structure and process.

5. What are the most useful tools in generating creative thinking?

6. Do you think the same tasks/exercises should be used in the WDO's 'Design Challenges' process for creating success outcomes/ results? Why?

7. What part of the WDO's 'Design Challenges' process is the most vital for successful outcomes/results? Why?

8. Do you believe the WDO's 'World Design Challenge' process should be applied as a problem-solving technique for most industries?

9. Describe your WDO's 'World Design Challenge' experience(s)?

10. Do you have recommendations that would improve the WDO's 'World Design Challenge' process and increase successful outcomes/results? 


\section{Appendix F}

\section{SUPERVISOR SIGNATURE FORM}

\section{Supervisor Signature Form}

\section{Carleton \\ U N I VER I T Y \\ Canada's Capital University}

\section{SUPERVISOR/SPONSOR SignATURE Form}

For consideration of submitted ethics protocols, the Carleton University Research Ethics Boards require evidence that all student protocol documents (i.e., undergraduate, graduate and post-doctoral fellows) have been reviewed and approved by a faculty supervisor or sponsor.

Instructions:

After filling out the details in the text below, faculty sponsor/supervisors should either

1) Print and scan this document, or

2) Email the text of the document (below; with signature optional) to the lead researcher

The form or email can then be uploaded (in PDF format) with the protocol, to the CUResearch.

As the faculty supervisor or sponsor, I confirm that I have reviewed and that I approve for submission for ethics review, the protocol entitled CUREB-B (Research Involving Very Low Risk) from Angie Fahlman on February 22, 2021.

Signature of Faculty

Supervisor/Sponsor:

Thomas
Garvey

Name of Faculty Supervisor/Sponsor:

Thomas Garvey

Date:

February 22, 2021 


\section{Appendix G}

\section{SURVEY DOCUMENTATION}

\begin{tabular}{|c|c|c|c|c|c|c|c|c|c|c|c|c|c|c|c|}
\hline \multirow{2}{*}{\multicolumn{2}{|c|}{ Survey Question }} & \multicolumn{13}{|c|}{ Participant (A - WDO, B - UN Women, C - ISS NL) } & \multirow{3}{*}{\begin{tabular}{|l}
\multicolumn{1}{|c}{$\begin{array}{c}\text { Response } \\
\text { Results }\end{array}$} \\
$\begin{array}{l}13 / 13 \\
\text { Responded Yes }\end{array}$
\end{tabular}} \\
\hline & & A1 & A2 & A3 & A4 & A5 & $\mathrm{B} 6$ & B7 & B8 & B9 & B10 & C11 & & & \\
\hline 1 & $\begin{array}{l}\text { Have you ever been involved in a } \\
\text { WDO's 'World Design Challenge'? }\end{array}$ & $\mathrm{Y}$ & Y & $\mathrm{Y}$ & Y & Y & Y & $\mathrm{Y}$ & $\mathrm{Y}$ & $\mathrm{Y}$ & Y & $\mathrm{Y}$ & $\mathrm{Y}$ & Y & \\
\hline 2 & $\begin{array}{l}\text { How many design challenges/ } \\
\text { sprints have you participated in? }\end{array}$ & $3-4$ & 3-4 & 3-4 & $3-4$ & $3-4$ & $1-2$ & $1-2$ & $1-2$ & $1-2$ & $1-2$ & $1-2$ & $1-2$ & $\begin{array}{l}10- \\
20\end{array}$ & $\begin{array}{l}1-2=7,3-4=4 \\
5-10=1,10-20 \\
=1\end{array}$ \\
\hline 3 & $\begin{array}{l}\text { Are you or have you been } \\
\text { employed in the Creative } \\
\text { Industry (Arts, Media and } \\
\text { Technology, Design)? }\end{array}$ & $\mathrm{Y}$ & $\mathrm{N}$ & $\mathrm{N}$ & Y & Y & $\mathrm{N}$ & $\mathrm{N}$ & $\mathrm{N}$ & $\mathrm{N}$ & $\mathrm{N}$ & $Y$ & $\mathrm{~N}$ & $Y$ & $\begin{array}{l}\text { Yes }=5 \\
\text { No }=\mathbf{8}\end{array}$ \\
\hline 4 & $\begin{array}{l}\text { Do you have an education in a } \\
\text { Creative Field (Arts, Media and } \\
\text { Technology, Design)? }\end{array}$ & $Y$ & $\mathrm{~N}$ & $\mathrm{~N}$ & $N$ & $Y$ & $\mathrm{~N}$ & $\mathrm{~N}$ & $\mathrm{~N}$ & $\mathrm{~N}$ & $\mathrm{~N}$ & $Y$ & $\mathrm{~N}$ & $Y$ & $\begin{array}{l}\text { Yes }=\mathbf{4} \\
\text { No }=\mathbf{9}\end{array}$ \\
\hline 5 & $\begin{array}{l}\text { If you have an education in a } \\
\text { Creative Field, what level of } \\
\text { education do you have? }\end{array}$ & $D$ & $\mathrm{D}$ & - & $D$ & $\mathrm{D}$ & - & - & - & - & - & D & - & $D$ & $\begin{array}{l}\text { Degree }=6 \\
N / A=7\end{array}$ \\
\hline 6 & $\begin{array}{l}\text { Do you have an understanding of } \\
\text { the stages of design process? }\end{array}$ & $Y$ & $Y$ & $Y$ & $Y$ & $Y$ & $\mathrm{~N}$ & $Y$ & $Y$ & $Y$ & $Y$ & $Y$ & $\mathrm{~N}$ & $Y$ & $\begin{array}{l}\text { Yes }=11 \\
\text { No }=\mathbf{2}\end{array}$ \\
\hline 7 & $\begin{array}{l}\text { Do you believe that all stages in } \\
\text { the design challenge process are } \\
\text { equally important? }\end{array}$ & $\mathrm{N}$ & $\mathrm{N}$ & $\mathrm{Y}$ & $N$ & $Y$ & $Y$ & $Y$ & $Y$ & $\mathrm{Y}$ & $Y$ & $\mathrm{~N}$ & $\mathrm{~N}$ & $Y$ & $\begin{array}{l}Y e s=\mathbf{8} \\
\text { No }=\mathbf{5}\end{array}$ \\
\hline 8 & $\begin{array}{l}\text { Have you ever had design } \\
\text { process experiences that you feel } \\
\text { negatively about? }\end{array}$ & - & $\mathrm{N}$ & $\mathrm{N}$ & $Y$ & $Y$ & $\mathrm{~N}$ & $\mathrm{~N}$ & $\mathrm{~N}$ & $\mathrm{~N}$ & $\mathrm{~N}$ & $Y$ & $\mathrm{~N}$ & $Y$ & $\begin{array}{l}\text { Yes }=8 \\
\text { No }=4 \\
\text { N/A }=1\end{array}$ \\
\hline 9 & $\begin{array}{l}\text { How do you feel about your } \\
\text { WDO's 'Design Challenge' } \\
\text { experience(s)? }\end{array}$ & $\mathrm{P}$ & $P$ & $\mathrm{P}$ & $\mathrm{P}$ & $P$ & $\mathrm{P}$ & $\mathrm{P}$ & $\mathrm{P}$ & $\mathrm{P}$ & $P$ & $\mathrm{P}$ & $\mathrm{P}$ & $\mathrm{P}$ & Positive $=13$ \\
\hline 10 & $\begin{array}{l}\text { Did the WDO's 'Design Challenge' } \\
\text { run smoothly? }\end{array}$ & $Y$ & $Y$ & $Y$ & $Y$ & $Y$ & $\mathrm{~N}$ & $N$ & - & $Y$ & $Y$ & $Y$ & $\mathrm{~N}$ & $Y$ & $\begin{array}{l}\text { Yes }=9 \\
\text { No }=3 \\
\text { N/A }=1\end{array}$ \\
\hline 11 & $\begin{array}{l}\text { In your opinion, did you feel there } \\
\text { was a structure to WDO's 'Design } \\
\text { Challenge' process? }\end{array}$ & $Y$ & $Y$ & $Y$ & $Y$ & $Y$ & $Y$ & $Y$ & $Y$ & $Y$ & $Y$ & $Y$ & $Y$ & $Y$ & $\begin{array}{l}\text { Yes }=13 \\
\text { No }=\mathbf{0}\end{array}$ \\
\hline 12 & $\begin{array}{l}\text { If you felt there was a structure } \\
\text { to the WDO's 'Design Challenge' } \\
\text { process, did it enhance or restrict } \\
\text { the outcomes/results? }\end{array}$ & $\mathrm{E}$ & $\mathrm{E}$ & $E$ & $E$ & $E$ & $\mathrm{R}$ & $E$ & $E$ & $\mathrm{E}$ & $E$ & $E$ & C & $E$ & $\begin{array}{l}\text { Enhanced }=11 \\
\text { Case by Case } \\
=1 \\
\text { Restricted }=1\end{array}$ \\
\hline 13 & $\begin{array}{l}\text { Do you work well in a structured } \\
\text { environment? }\end{array}$ & 0 & O & $S$ & 0 & $S$ & 0 & $S$ & 0 & 0 & $S$ & $S$ & $S$ & $S$ & $\begin{array}{l}\text { Often }=6 \\
\text { Sometimes }=7\end{array}$ \\
\hline 14 & $\begin{array}{l}\text { Do you enjoy being involved in } \\
\text { team projects? }\end{array}$ & - & $S$ & S & $\mathrm{O}$ & 0 & 0 & 0 & 0 & $\mathrm{O}$ & 0 & 0 & 0 & 0 & $\begin{array}{l}\text { Often }=10 \\
\text { Sometimes }=\mathbf{2} \\
\mathrm{N} / \mathrm{A}=\mathbf{1}\end{array}$ \\
\hline 15 & $\begin{array}{l}\text { Are you regularly required to } \\
\text { come up with creative solutions } \\
\text { for your job? }\end{array}$ & - & - & $\mathrm{N}$ & $Y$ & $Y$ & $Y$ & - & - & - & $Y$ & - & $Y$ & - & $\begin{array}{l}\text { Yes }=6 \\
\text { No }=0 \\
\text { N/A }=7\end{array}$ \\
\hline 16 & $\begin{array}{l}\text { Have you ever struggled to } \\
\text { generate creative outcomes/ } \\
\text { results? }\end{array}$ & 0 & $S$ & $S$ & $S$ & $\mathrm{~N}$ & $\mathrm{~N}$ & 0 & $S$ & $S$ & $S$ & $S$ & SE & $S$ & $\begin{array}{l}\text { Often }=\mathbf{2} \\
\text { Sometimes = } 9 \\
\text { Seldom }=1 \\
\text { Never }=1\end{array}$ \\
\hline 17 & $\begin{array}{l}\text { Do you think there is value in } \\
\text { the WDO's 'Design Challenge' } \\
\text { process for generating creative } \\
\text { outcomes/results? }\end{array}$ & $Y$ & $Y$ & $Y$ & $Y$ & $Y$ & $Y$ & $Y$ & $Y$ & $Y$ & $Y$ & $Y$ & $Y$ & $Y$ & $\begin{array}{l}\text { Yes }=13 \\
\text { No }=\mathbf{0}\end{array}$ \\
\hline 18 & $\begin{array}{l}\text { Were unique ideas generated } \\
\text { during the WDO's 'Design } \\
\text { Challenge'? }\end{array}$ & $Y$ & $Y$ & $Y$ & $Y$ & $Y$ & $Y$ & $Y$ & $Y$ & $\mathrm{Y}$ & $Y$ & $Y$ & $Y$ & $Y$ & $\begin{array}{l}Y e s=13 \\
\text { No }=\mathbf{0}\end{array}$ \\
\hline 19 & $\begin{array}{l}\text { Would you like to take part in } \\
\text { future WDO's 'Design } \\
\text { Challenges'? }\end{array}$ & $Y$ & $Y$ & $Y$ & $Y$ & $Y$ & $Y$ & $Y$ & $Y$ & $Y$ & $Y$ & $Y$ & $Y$ & $Y$ & $\begin{array}{l}\text { Yes }=13 \\
\text { No }=0\end{array}$ \\
\hline
\end{tabular}




\section{Appendix H}

\section{WDO QUESTIONNAIRE and INTERVIEW DOCUMENTATION}

\begin{tabular}{|c|c|c|}
\hline \multicolumn{2}{|r|}{ Questionnaire and Interview } & $\begin{array}{c}\text { WDO } \\
\text { Combined Results - Extracted Themes and Summary of Responses }\end{array}$ \\
\hline 1 & $\begin{array}{l}\text { Do you believe there could be a fixed } \\
\text { set of design process stages? Why? }\end{array}$ & $\begin{array}{l}\text { - Fixed process provides a framework that provides guidance. } \\
\text { - There is a basic structure of the design process that does not need to be applied in a } \\
\text { sequence (empathize, define, ideate, prototype, test). } \\
\text { - Not linear in one direction but provides a feedback loop. } \\
\text { - Good Flexibility } \\
\text { Summary: A structured process is necessary for guidance, but it should be } \\
\text { flexible. }\end{array}$ \\
\hline 2 & $\begin{array}{l}\text { Based on your experience, what are } \\
\text { the main factors of the process that } \\
\text { contribute to a WDO's 'Design } \\
\text { Challenges' success? List them in } \\
\text { order of importance. Challenges' } \\
\text { success? List them in order of } \\
\text { importance. }\end{array}$ & $\begin{array}{l}\text { - Collective agreement and strong collaborative working relationship } \\
\text { - Interesting subject matter with clear objectives } \\
\text { - Criteria for selection of participants committed teams that are balanced and guidelines } \\
\text { for facilitators with coaching } \\
\text { - Structured phases and whiteboards with guides, templates with examples, orientation } \\
\text { sessions, pre-scheduled weekly meetings, evaluations on facts } \\
\text { Summary: Structure in Phase Zero, guidelines and well thought out system setup } \\
\text { is vital. }\end{array}$ \\
\hline 3 & $\begin{array}{l}\text { Who are the key actors (Actor } \\
\text { examples, but not limited to topic } \\
\text { experts, thought leaders, facilitators) } \\
\text { in the WDO's 'Design Challenges' } \\
\text { process that enhance better creative } \\
\text { outcomes? List them in order of } \\
\text { ranking. One is the largest enhancer. }\end{array}$ & $\begin{array}{l}\text { - WDO, Leadership Team, Secretariat, Partnership alignment } \\
\text { - Subject Matter Experts/Thought Leaders } \\
\text { - Participants with different skill sets } \\
\text { - Facilitators } \\
\text { Summary: In order of ranking - Leadership team, wDO Secretariat, subject matter } \\
\text { experts, thought leaders, participants, facilitators }\end{array}$ \\
\hline 4 & $\begin{array}{l}\text { What are the biggest obstacles in the } \\
\text { WDO's 'Design Challenges' process } \\
\text { and structure? }\end{array}$ & $\begin{array}{l}\text { - Time zones, Timing with multiple challenges } \\
\text { - Structure of design, tools, resources and technologies plus contractual Phase Zero, } \\
\text { clear objectives } \\
\text { - Lack of trust in the process that can lead to not relinquishing control in non-design } \\
\text { stakeholders } \\
\text { - Process is evolving, not perfect. Different projects require adjustments that make the } \\
\text { most sense to circumstance - flexible } \\
\text { - Breath of participants, the skill set of facilitators } \\
\text { Summary: There is a lack of trust in the design process. Time zones and lack of } \\
\text { time. Breath of participants and facilitators skill sets. Structure of Phase Zero with } \\
\text { clear objectives. Finally, flexibility-process adjustments. }\end{array}$ \\
\hline 5 & $\begin{array}{l}\text { What are the most useful tools in } \\
\text { generating creative thinking? }\end{array}$ & $\begin{array}{l}\text { - Miro/Mural - Whiteboard } \\
\text { - Generative thinking, brainstorming, mind mapping and reflection } \\
\text { - Recordings, note-taking and workshops } \\
\text { Summary: Whiteboard for collaboration, generative thinking such as } \\
\text { brainstorming and mind mapping were identified. Reflection was also indicated } \\
\text { as an essential tool. }\end{array}$ \\
\hline 6 & $\begin{array}{l}\text { Do you think the same tasks/exercises } \\
\text { should be used in the WDO's 'Design } \\
\text { Challenges' process for creating } \\
\text { success outcomes/ results? Why? }\end{array}$ & $\begin{array}{l}\text { - Yes, the same tasks - empathy, define, ideation, prototyping and validate as they have } \\
\text { proven to be successful } \\
\text { - Tools, exercise and templates may vary, expanded on shortened depending on the } \\
\text { type of challenge } \\
\text { - Based on the situation, modifications can be done, or new tasks introduced. } \\
\text { - Yes, as long as it is flexible } \\
\text { Summary: The use of the same tasks was encouraged as long as they are flexible } \\
\text { based on the 'World Design Challenge. }\end{array}$ \\
\hline 7 & $\begin{array}{l}\text { What part of the WDO's 'Design } \\
\text { Challenges' process is the most vital } \\
\text { for successful outcomes/results? } \\
\text { Why? }\end{array}$ & $\begin{array}{l}\text { - Clear objective/goal setting, so based on a solid foundation with easily understood } \\
\text { defined challenge statements } \\
\text { - Providing the participants with enough background information } \\
\text { - Prioritization exercise to help identity what ideas are the best } \\
\text { - Proven success templates, with prioritization exercise to help identify what ideas are } \\
\text { the best } \\
\text { - Orientation for facilitators and subject matter expertise, weekly check-ins while } \\
\text { monitoring progress } \\
\text { Summary: Clear objectives, educate and provide monitored support, plus } \\
\text { templates. }\end{array}$ \\
\hline 8 & $\begin{array}{l}\text { As creators who guide users, what are } \\
\text { your biggest positive or negative } \\
\text { challenges? }\end{array}$ & $\begin{array}{l}\text { - Trust and providing more training } \\
\text { - Everyone feels valued and heard } \\
\text { - Time zone } \\
\text { - Lack of a designer/expert in design thinking } \\
\text { - Lack of resources } \\
\text { Summary: A negative aspect is lack of resources, trust, training, time zones, } \\
\text { design experts, and feeling heard. }\end{array}$ \\
\hline 9 & $\begin{array}{l}\text { What were the critical building blocks } \\
\text { in creating the WDO's 'Design } \\
\text { Challenges'? }\end{array}$ & $\begin{array}{l}\text { - Right partner who embrace design mission, Phase Zero } \\
\text { - Collaboration agreement, dialogue with the client and introducing the design } \\
\text { experience } \\
\text { to the client } \\
\text { - International calls, Zoom capabilities } \\
\text { - Setting expectations, a clear set of objectives and challenge statements } \\
\text { - Getting to the why of the challenge } \\
\text { Summary: In sync trusting partnership with open mutual dialogue. It is knowing } \\
\text { the why with clear objectives and challenge statements - Phase Zero. }\end{array}$ \\
\hline 10 & $\begin{array}{l}\text { Do you have recommendations that } \\
\text { would improve the WDO's 'World } \\
\text { Design Challenge' process and } \\
\text { increase successful outcomes/ } \\
\text { results? }\end{array}$ & $\begin{array}{l}\text { - These differences in approaches caused bottlenecks and confusion across the teams } \\
\text { - Greater commitment of time to challenges with limited design challenges per quota } \\
\text { - Pre challenge facilitator orientation with training and thought leaders with relevant } \\
\text { background } \\
\text { - Playbacks more as a dialogue with tangible feedback } \\
\text { - More can be provided in week before launch } \\
\text { - Challenges are self-sustaining economically } \\
\text { - Bridge the end of each phase and defined timing of the next phase with clear } \\
\text { communicated expectations } \\
\text { - Phase } 1-3 \text { stages determined before the initial kick-off with all gaps figured out } \\
\text { articulated to everyone } \\
\text { - Event ends quite abruptly, left unanswered and unsatisfied with the results. } \\
\text { - Build trust by managing expectations } \\
\text { Summary: Key findings identified well throughout challenge structure through } \\
\text { phases and process. }\end{array}$ \\
\hline
\end{tabular}




\section{Appendix I}

\section{UN WOMEN and ISS NL QUESTIONNAIRE and INTERVIEW DOCUMENTATION}

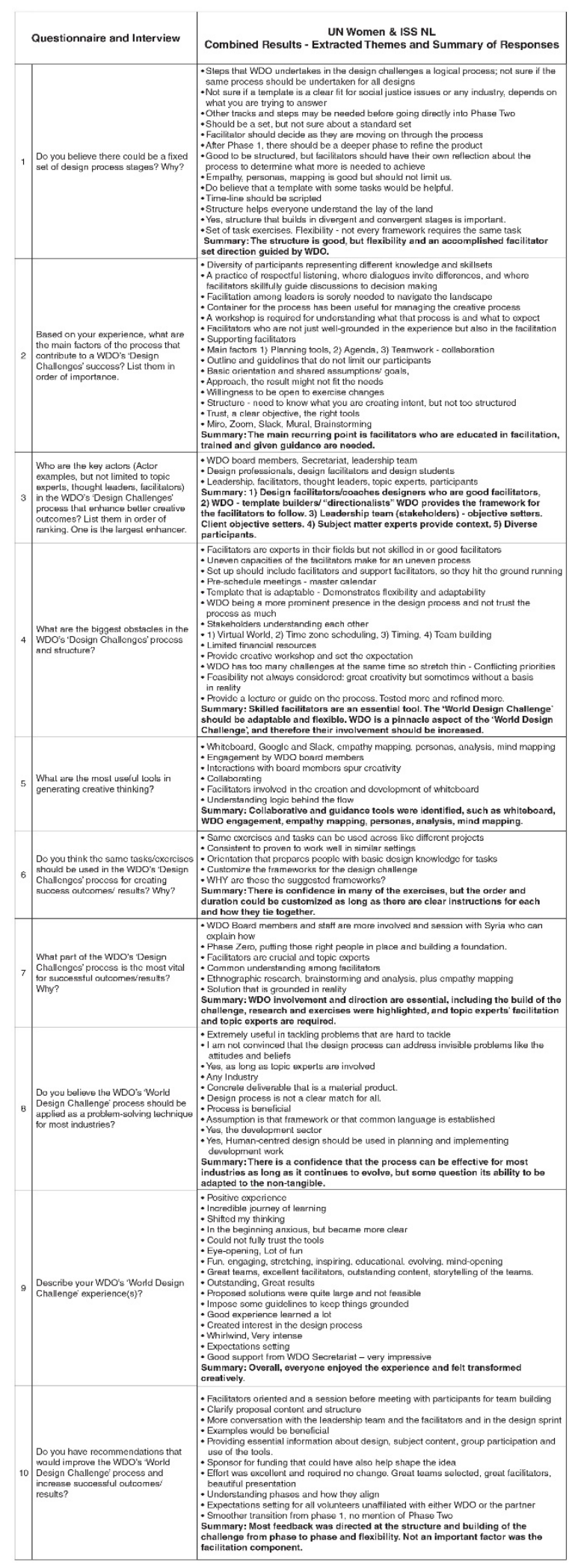




\section{Generation Equality Asia Paciffic Design Challenge}

The Generation Equality Asia Pacific Design Challenge is a two-week (10-21 August 2020), virtual Interdesign workshop that will address the issue of violence against women and girls (VAWG), specifically in the Asia-Pacific region. This activity is a product of a collaboration between the UN Women in Asia and the Pacific and World Design Organization (WDO) ${ }^{\circledR}$.

\section{WDO- woMnN䊎}

\section{Carleton \\ universitr}

School of Industrial Design Appendix J

Professor Thomas Garvey - Supervisor Angie Fahlman - Student
How can we promote behavioural change to reduce VAW by moving people emotionally and empathically to act? 


\section{Tables of Contents}

Preface and Summary of experience 1-2

Change generators 3

Objective and six challenge statements 4

Roles and responsibilites 5

Team 3 names and titles 6

Timeline, creative process and progress diagram $\quad 7$

Apendix I - Playback 1 presentation 8-9

Apendix II - Playback 2 presentation 10-12

Apendix III - Daily activities

(agenda, homework and meeting notes) 
The Generation Equality Asia Pacific Design Challenge was a unique opportunity to obtain exposure to the social design process. Till this point, I did not fully understand the importance and relevance of social design. Due to the multi-complex nature of social design, an interdisciplinary approach was necessary to produce a successful product. For that reason, a diverse set for leaders, facilitators and participants were gathered into teams. The design sprints provided an optimal situation to observe how the interdisciplinary teams, defined problems, manifested persona scenarios, explored ideas, and produced prototypes.

The challenge provided me with an intense level of design growth, which can be taken into different industries and various social systems. I fully appreciated the opportunity to grow as a Carleton Unversity student and member of the creative community.

\section{Exerience Summary}

This summary statement will provide insight into the Generation Equality Asia Pacific Design Challenge journey. The summary will begin by providing a brief overview of the challenge, stakeholders and their roles. The creative process will be outlined, which sets expectations. A timeline deployment will be introduced to increase and track progress. Also, navigating participant's strengths will be explored to help create team structure. Finally, fostering creative flow and planting seeds for creative inspiration is discussed.

The challenge began with stakeholders and associates from the World Design Organization and United Nations Women (see figures 1 and 2) who streamlined multiple directives into six clearly defined challenges. The six challenge statements (See page 2) set the stage for a cohesive plan of action for the VAW initiative. A challenge statement team structure was created so that each of the six teams included two facilitators (a topic and a design facilitator). Participants were then divided among the teams. An essential aspect of this team dynamic depended on the facilitators knowing their roles. To avoid confrontation, the design facilitator must reframe from instilling their opinion in areas where there is a more knowledgeable topic expert at hand. It is also equally crucial for the topic expert facilitator not to derail the creative process but to enhance it by aligning content with objectives. Thought leaders oversaw communications and progress, which calmed team settings and provided a sense of reassurance. Ice breaker activities and team member introductions helped the facilitators understand the participants and their life exposures.

A rough timeline and design process structure (See figure 5) is critical to the participants understanding of expectations. In hindsight, this should be introduced on the first day. The timeline and design process diagram was illustrated directly above the existing design process journey examples. Its positioning helped promote process understanding and provided continuous visual guidance for the agenda. 
Navigating participants is no easy task. It requires listening, nurturing and inspiring. More importantly, they must feel valued, needed and heard. By paying attention to each participant's strength, you can better utilize their gifts to foster more significant outcomes. Participants should be utilized in a capacity that yields favourable results, which increases productivity.

To further assist with the progress, the facilitators must generate excitement and encourage a positive environment by redirecting and defusing any negative or toxic situations. Encouraging participates to see each stage of the process as small milestones that generate a significant result helps them feel less overwhelmed. Participants should be enticed to think big and wild and not fear the never done or out-of-the-box thinking.

Finally, generating an environment that allows for creativity to flow freely without being inhibited or weighed down by structures and bottom lines increase creative idea potential. On several occasions, a facilitator may have to do some work to help initiate the creative process. I call this stage the planting of creative seeds. Planting creative seeds are beneficial in starting the process of deploying ideas. It starts the ball rolling so the participants can build off the initial concept or propel them off in a different direction.

Overall, the Generation Equality Asia Pacific Design Challenge journey ignited fear, learning, collaboration, connecting, and excitement. On many levels, it provided an opportunity to evolve. Both as individuals and as a group whose mission was to help create social change. I feel privileged to have been a small part of the challenge. 


\section{Change Generators \\ WDO AND UN WOMEN}

Leadership Teams

Thought Leaders

Facilitators - Topic Facilitators, Design Facilitators

Participants

Together for the common goal to ingnite change.

How can we promote behavioural change to reduce VAW by moving people emotionally and empathically to act? 


\section{Six Challenge Statements}

\section{Objective}

To create gender equity by working towards solutions that will end violence against women.

\section{Six Challenge Statements}

How can we promote behavioural change to reduce VAW by:

1) Enlisting community leaders and influencers

2) Leverage media to challenge steriotypes

3) Move people emotionally and empathetically to act to prevent VAW

4) Tranforming men's sense of entitlement and ability over women and resources

5) Changing the mindset that VAW is normal / acceptable

6) Influencing parents to raise children to reject harmful gender steriotypes and violence.

Figure 1. (Mural by WDO)

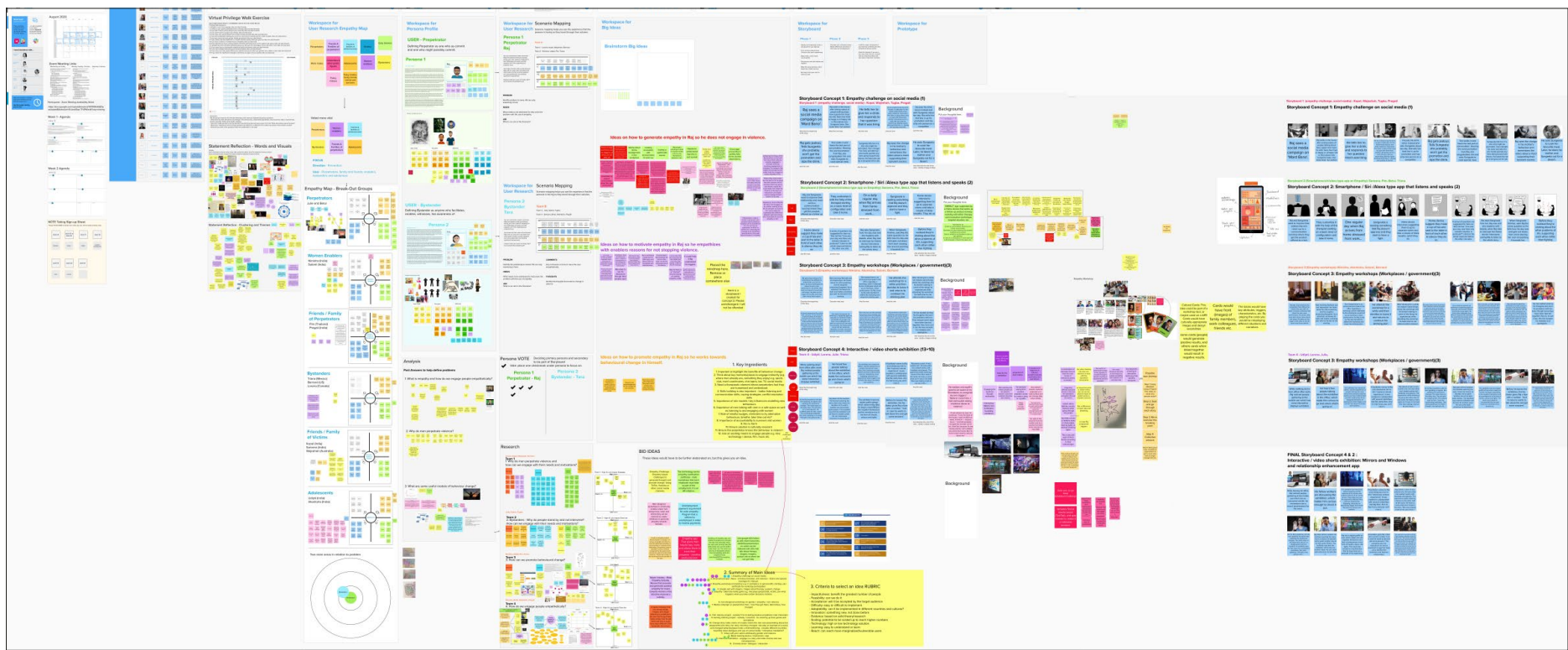

Figure 2. (Spread Sheet Supplied by WDO)

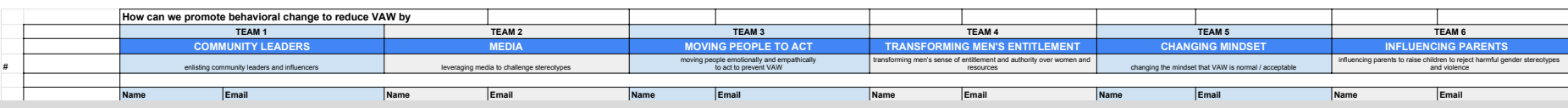




\section{Roles and Responsibilites}

WDO

\section{Remote collaboration}

Leadership Team

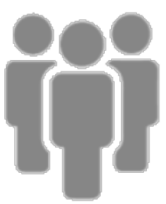

\section{(6) UN \\ WOMEN E WDO -

\section{Facilitators}
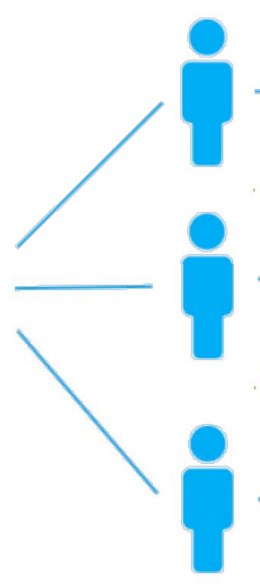

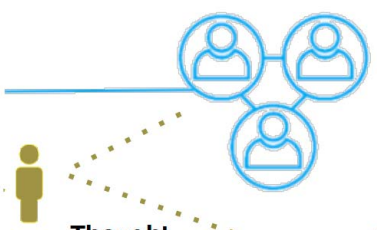

Thought" $\cdots$

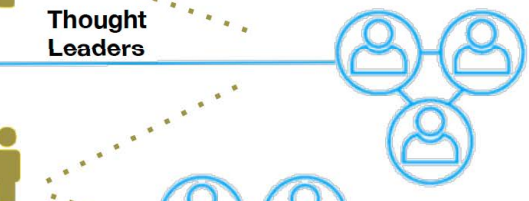

Communications Tools

A number of software will be at the disposal of all stakeholders including: Mural, Slack, Zoom, GoogleDrive and Basecamp.

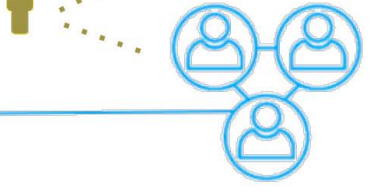

M

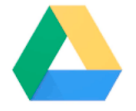

\%lack

Google Drive

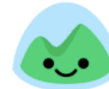

Basecamp

\section{Leadership Team}

- Provides overall direction to the project development and management

- Identified facilitators and oversaw participant selection process

- Convene Zoom check-in meetings with team facilitators (Wednesdays)

- Oversee Mural boards

- Serve as a point of contact to facilitators and thought leaders on Slack

- Attend playbacks (Fridays)

- Drafts and circulates all material related to project

\section{Facilitators}

- Leaders will be assigned to team and given the email addresses of team members

- Convene Zoom meetings (daily or other as determined by team)

- Oversee the team Mural board, online workshopping and collaboration

- Serve as a point of contact for team members on Slack channels

- Work assignments between calls

- Relay progress reports to leadership team (Wednesdays)

- Slack Channel for Facilitators

- Attend playbacks (Fridays)

- Ensure a positive and respectful team environment
Participants

- Contribute to the team's development of a design solution

- Contribute to team presentations

- Attend team meetings throughout design challenge

- Participate in playback sessions

- Participate in completion of templates for playback sessions

- Attend playback sessions

- Treat information disclosed with sensitivity, abiding by all ethical research considerations

- Respect the sensitive nature of the design challenge 


\begin{tabular}{|c|c|}
\hline \multirow{3}{*}{ ean 3} & TEAM 3 \\
\hline & MOVING PEOPLE TO ACT \\
\hline & $\begin{array}{l}\text { moving people emotionally and empathically } \\
\text { to act to prevent VAW }\end{array}$ \\
\hline & Name \\
\hline
\end{tabular}

Faciltator - UN Women

Faciltator - Design

Thought Leader

Thought Leader

Thought Leader

Participant

Participant

Participant

Participant

Participant

Participant

Participant

Participant

Participant

Participant

Participant

Participant

Participant

Student Participant

Student Participant

Student Participant

Student Participant

Student Participant 


\section{Appendix I \\ PLAYBACK 1 \\ Presentation}




\section{Appendix I}

\section{PLAYBACK 1}

Presentation

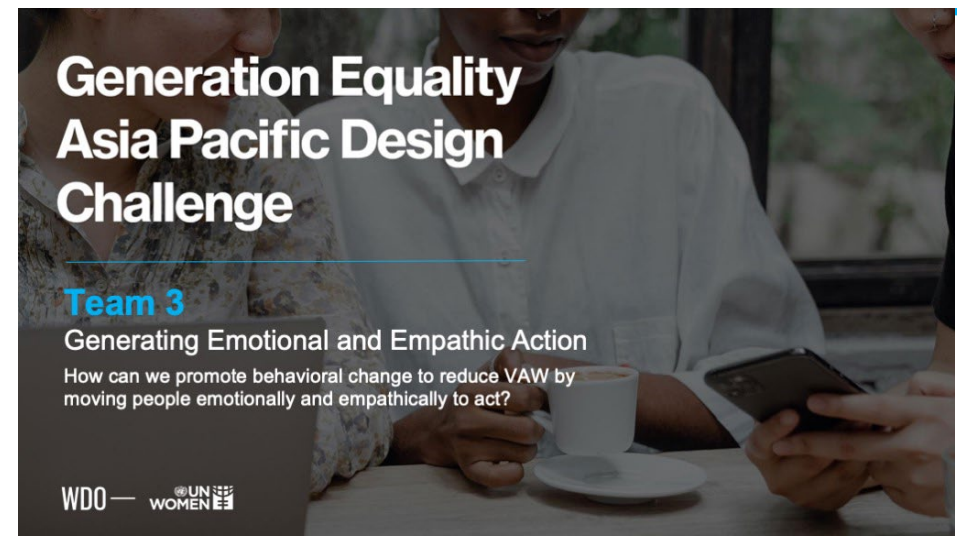

Design Process Journey
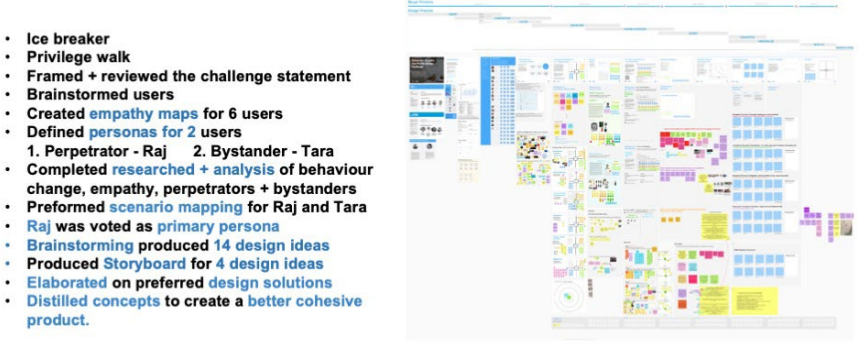

WDO - womeñie

Main Persona and Scenario
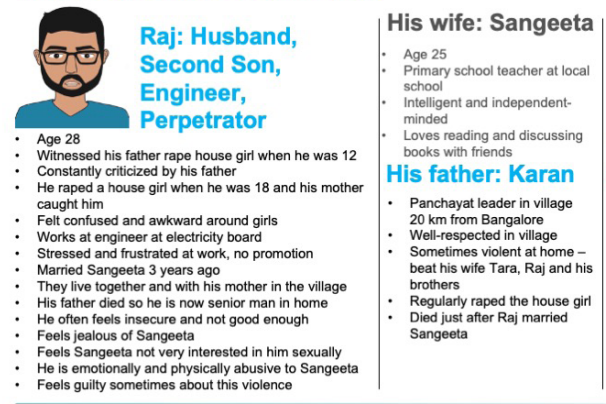

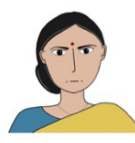

His mother: Tara Age 47
High caste family, but poor as Da High caste family, but poor as Dad
alcoholic
Married well due to beauty, but at age 15 Married well due to beauty, but at age 15
Five children including Raj Paid off the house girl that Raj raped Feels Raj could do better in his life Harsh and critical towards Sangeeta but

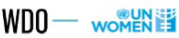

Key Ingredients

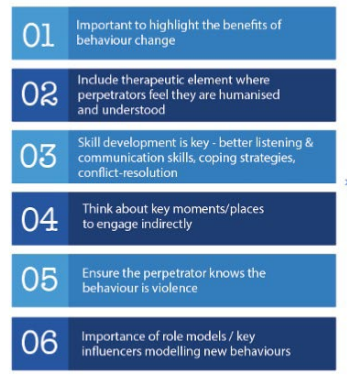

\begin{tabular}{|c|c|}
\hline Ory & 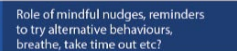 \\
\hline 08 & $\begin{array}{l}\text { Importance of men connecting with other } \\
\text { menin assitespace }\end{array}$ \\
\hline 09 & $\begin{array}{l}\text { Importance of accountability to } \\
\text { surviviors and women }\end{array}$ \\
\hline 10 & $\begin{array}{l}\text { Do no ham -do not put women at } \\
\text { gleater risk }\end{array}$ \\
\hline 11 & $\begin{array}{l}\text { Ensure solution is culturally } \\
\text { resosant }\end{array}$ \\
\hline 12 & 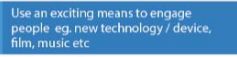 \\
\hline
\end{tabular}

WDO - wOMEN

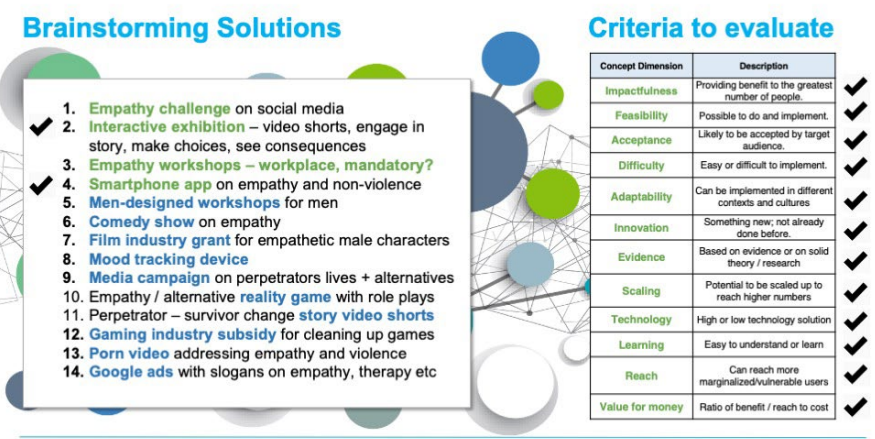

WDO- wOMENi觜
(1)
Our main design solution

A travelling interactive multimedia video exhibition which includes a supportive smartphone app integration that promotes behavioural change and healthy, non-violent relationships. The interactive video exhibition is a mobile vehicle that travels to different urban and rural locations with high rates of violence against women - as a
standalone exhibitition or at a concert or sporting event Promoted via tradtion and social media.

The exhibition showcases short videos from 5 different cultural backgroun violence with testimony from him and the survivor and their story of change. content can evolve by integrating new stories

Visitors then participate in art and gaming activities that engage them emotionally, prompt reffection and allow them to test behaviours. The activities. It does not come in the form of a lecture but rather as an immersive
and

A behavioural change relationship enhancement app and other The axtrons reach all users regardless of finances and access to

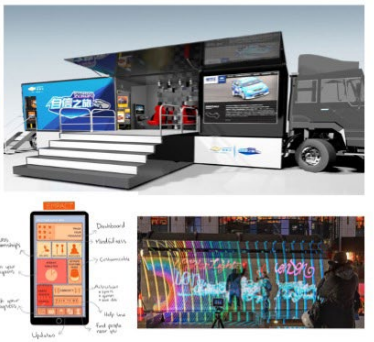
WDO - wOMENi:
Storyboard for main solution

Can be deployed to rural and urban locations.

Vehicle customized for location dynamics/restrictions. Great for sporting and community events.

Shows change has benefits, is possible and how to do it

Ignites thought and reflection

FINAL Storyboard Concept 4 \& 2 :

Interactive / video shorts exhibition: Mirrors and Windows and relationship enhancement app

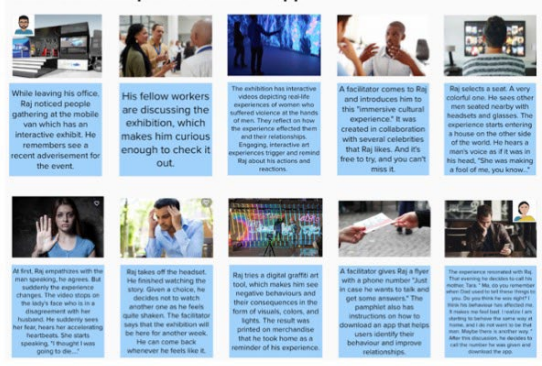

WDO- WOMEN
Other design ideas: Smartphone / home device app

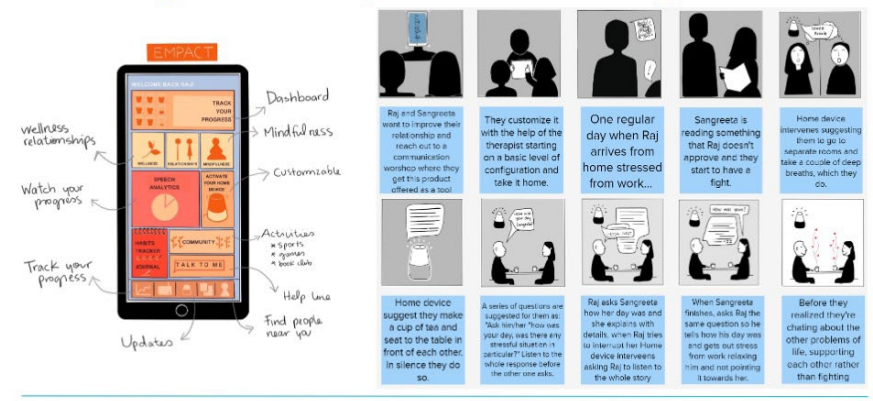

WDO - wOMEN 


\section{Appendix II \\ PLAYBACK 2 \\ Presentation}




\section{Appendix II}

\section{PLAYBACK 2}

Presentation

\section{Generation Equality Asia Pacific Design Challenge}

Team 3

Generating Emotional and Empathic Action How can we promote behavioral change to reduce VAW by moving people emotionally and empathically to act?

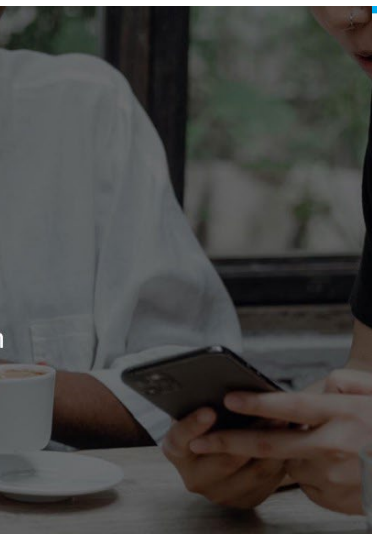

Design Process Journey
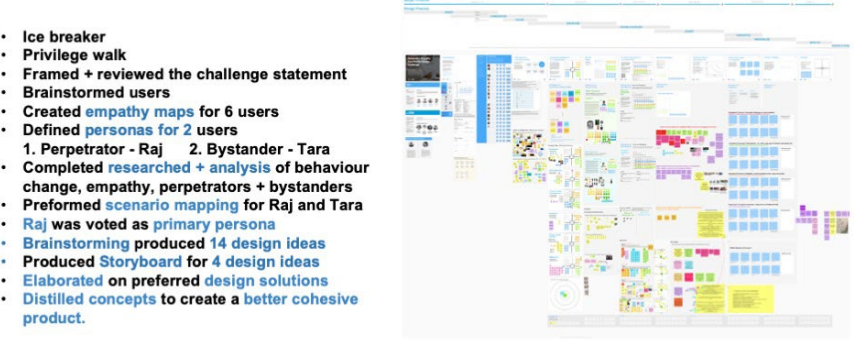

WDO - woMEN

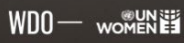

Main Persona and Scenario
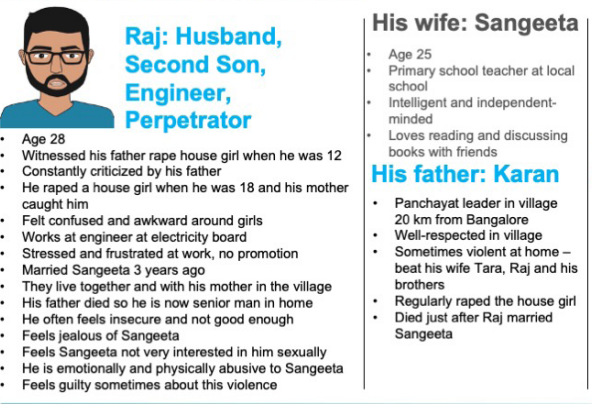

WDO - woMNN

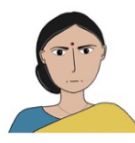

His mother: Tara

Age 47
High caste family, but poor as $\mathrm{Dad}$ Malcholic
alchilly, but poor as Dad
Maried well due to beauty, but at age 15 Five children including Rai : Marriage Feels Raj could do beterer in nis lifie Harsh and cotricical towards Sangeeta but
Key Ingredients

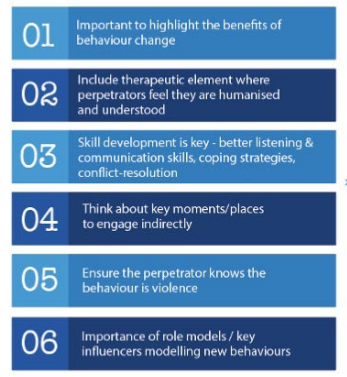

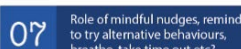

08 Importance of menconnecting witi other
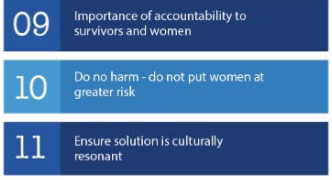

$12 \begin{aligned} & \text { Use an excting means to engage } \\ & \text { people eq anew elechnology / device, } \\ & \text { film,musicetc }\end{aligned}$

WDO - wOMENA

Our main design solution

A travelling interactive multimedia video exhibition which includes a supportive smartphone app integration that promotes behavioural change and healthy, non-violent relationships. The interactive video exhibition is a mobile vehicle that travels to different urban and rural locations with high rates of violence against women - as a
standalone exhibition or at a concert or sporting event Promoted via tradtion and social media.

The exhibition showcases short videos from 5 different cultural backgro violence with testimony from him and the survivor and their story of change. content can evolve by integrating new stories

Visitors then participate in art and gaming activities that engage them emotionally, prompt reflection and allow them to test behaviours. The
exhibition draws the attention of the user through compelling visuals an activities. It does not come in the form of a lecture but rather as an immersite A behavioural change relationship enhancement app and other resources are promoted through demonstrations and provided to attendees. The exhibition can reach all users regardless of finances and access to

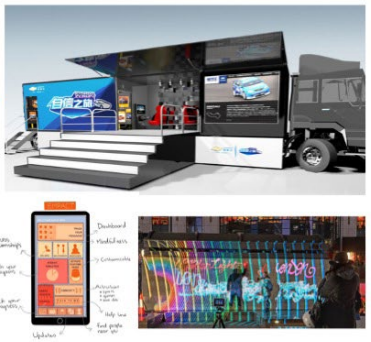
WDO - womeniti

WDO - womeñ

\section{$\left(\frac{1}{3}\right.$}

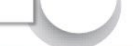

Storyboard for main solution

Can be deployed to rural and urban locations.

Vehicle customized for location dynamics/restrictions.

Great for sporting and community events.

Shows change has benefits, is possible and how to do it

Ignites thought and reflection

FINAL Storyboard Concept 4 \& 2 :

Interactive / video shorts exhibition: Mirrors and Windows

and relationship enhancement app

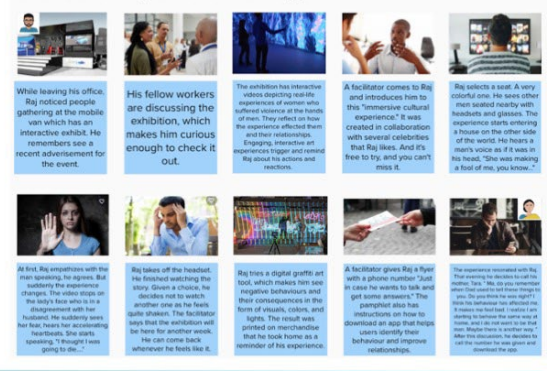

WDO - womeN
Other design ideas: Smartphone / home device app

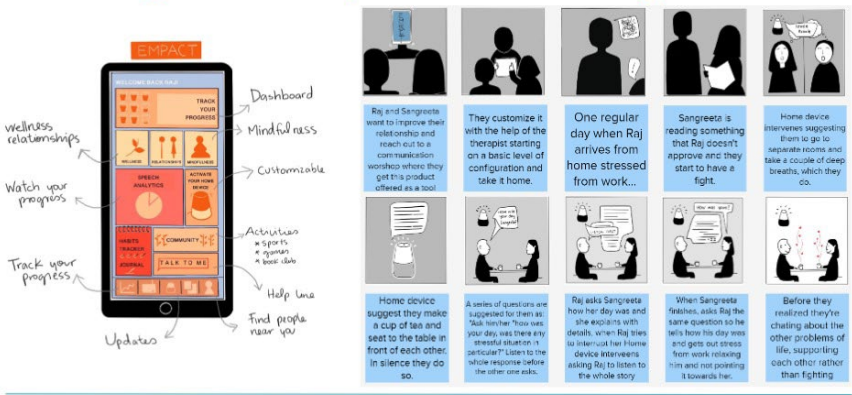

WDO - wOMEN 
Other design ideas: Social media empathy challenge

We suggest integrating a social media empathy challenge parallel to the exhibition. This challenge could also be allocated within the supporting app.

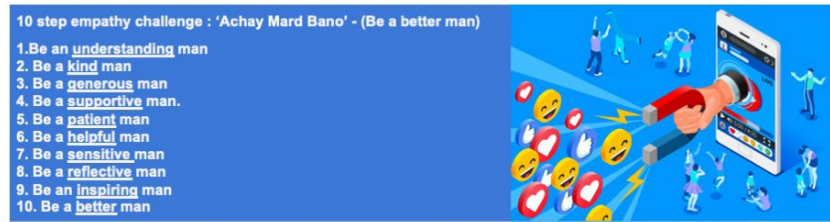

Each step will be supported by push content and user-generated content. Videos and images of average people as well as celebrities, actors, sports-players (non-pald) etc, will provide examples of how to become these kind of marchandise,etc. could be offered as a reward, if budget allows. Re-evaluation of challenge every 2 months $>$ New challenges can be added to keep this campaign going.

WDO - WOMEN

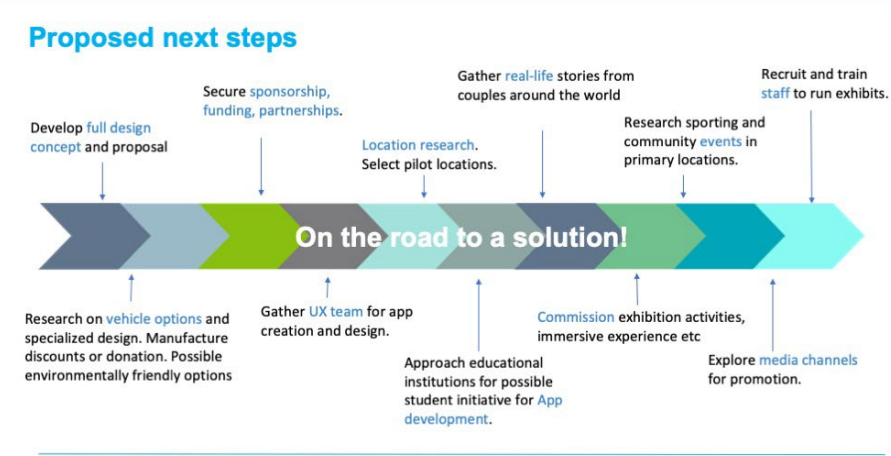

WDO - woMN N
Other design ideas: Empathy workshops

$$
\begin{aligned}
& \text { Workshops -"Pyaar Aur Parivaar" } \\
& \text { (Love and Family). "Kaise kare parivar se pyaar"- } \\
& \text { (How to love your family) }
\end{aligned}
$$
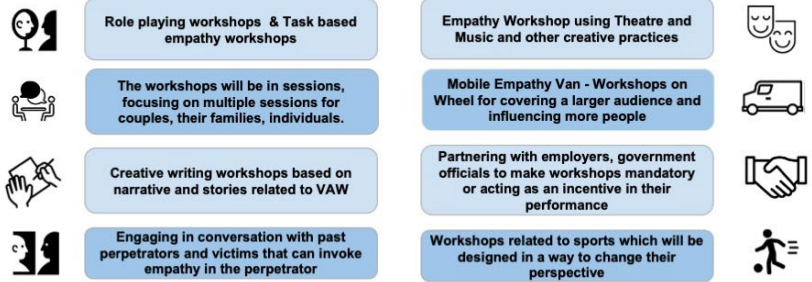

WDO - พOMNANA
Team 3 Participants

\begin{tabular}{ll}
\hline Salomi Christie & New Delhi, India (IST) \\
\hline Saneera Dev & India (IST) \\
\hline Lorena Garcia Giron & Montreal, Canada \\
\hline Triana Gonzalez & CDMX, Mexico (CDT) \\
\hline Piraya Puapanichya & Bangkok, Thailand (ICT) \\
\hline Julie Sane-Pezet & Paris, France (CEST) \\
\hline Nimisha Parab & Mumbai, India (IST) \\
\hline Wajeehah Aayeshah & Melbourne, Australia \\
\hline Betul Sahin & Istanbul, Turkey (GMT+3 \\
\hline Udipti Jaiswal & Bangalore, India (IST) \\
\hline Akanksha Singh & Gujarat, India \\
\hline Kopal Gangrade & Mumbai, India (IST) \\
\hline
\end{tabular}

Bernard J. Canniffe Ames, lowa, USA CST Pragati Shrivastava Lonavla, India (IST) Tugba Celikten $\quad$ Turkey $(\mathrm{GMT}+3)$

Team 3 Facilitators

Lyndsay McLean $\quad$ UK (BST $=$ GMT + 1)
Angie Fahlman Ottawa, Canada EST

Team 3 Thought Leader Sue Garvey Ottawa EST

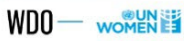

Thank you!

Any Questions?

WDO - woMENi⿺辶

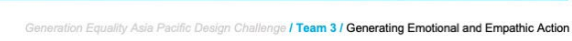




\section{Appendix III DAILY ACTIVITIES \\ Agenda \\ Homework \\ Meeting Notes}



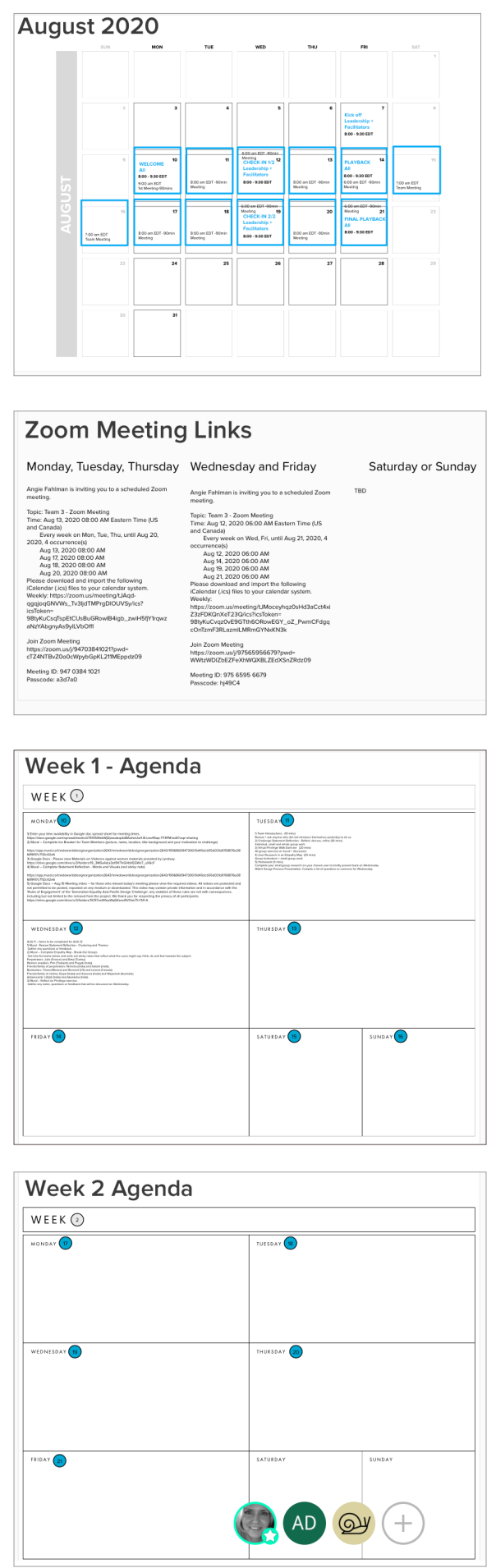

Agenda and homework, in most cases, were created by both facilitators and posted on Slack.

Meeting notes were taken by a volunteer participant and posted on Slack.

\section{AUGUST 10 \\ AGENDA AND TASKS TO COMPLETE}

\section{Agenda}

1) Review statement

2) General rules and guidelines

3) Introduction to leaders and participant.

4) Cover tools - Mural, Slack, Google Docs and Zoom

\section{Homework}

1) Enter your time availability in the Google doc spreadsheet for meeting times. https://docs.google.com/spreadsheets/d/1514SWekW jDpwulaqxtd8AohoUuH-B-Leo45ap-TF4PM/edit?usp=sharing

2) Mural - Complete Ice Breaker for Team Members (picture, name, location, title background and your motivation to challenge) https://app.mural.co/t/wdoworlddesignorganization2643/m/ wdoworlddesignorganization2643/1596860947300/9d45dcb55d 031d0158876a38689f47c71f2c42e6

3) Google Docs - Please view Materials on Violence against women materials provided by Lyndsay. https://drive.google.com/drive/u/3/folders/19_3MSxAdui3of9XThGHb VEGWs7_uX6cF

https://www.youtube.com/watch?v=lhk66LtCLvc\&list=WL\&index $=4 \& \mathrm{t}=0 \mathrm{~s}-$ provided by the participant.

https://drive.google.com/drive/folders/1SfVyrYYFqT7cBCCGu GUiM-zT-CIn6cnJ?usp=sharing

4) Mural - Complete Statement Reflection - Words and Visuals (red sticky note) https://app.mural.co/t/wdoworlddesignorganization2643/m/ wdoworlddesignorganization2643/1596860947300/9d45dcb55d 031d0158876a38689f47c71f2c42e6

5) Google Docs - Aug 10 Meeting video - for those who missed today's meeting please view the required videos. All videos are protected and not permitted to be posted, reposted on any medium or downloaded. This video may contain private information and in accordance with the 'Rules of Engagement' of the 'Generation Equality Asia Pacific Design Challenge', any violation of these rules is not with consequences, including but not limited to the removal from the project. We thank you for respecting the privacy of all participants. https://drive.google.com/drive/u/3/folders/1ICR7sxiN1eyWqGKzeuR VOsk71i-YN1-A 

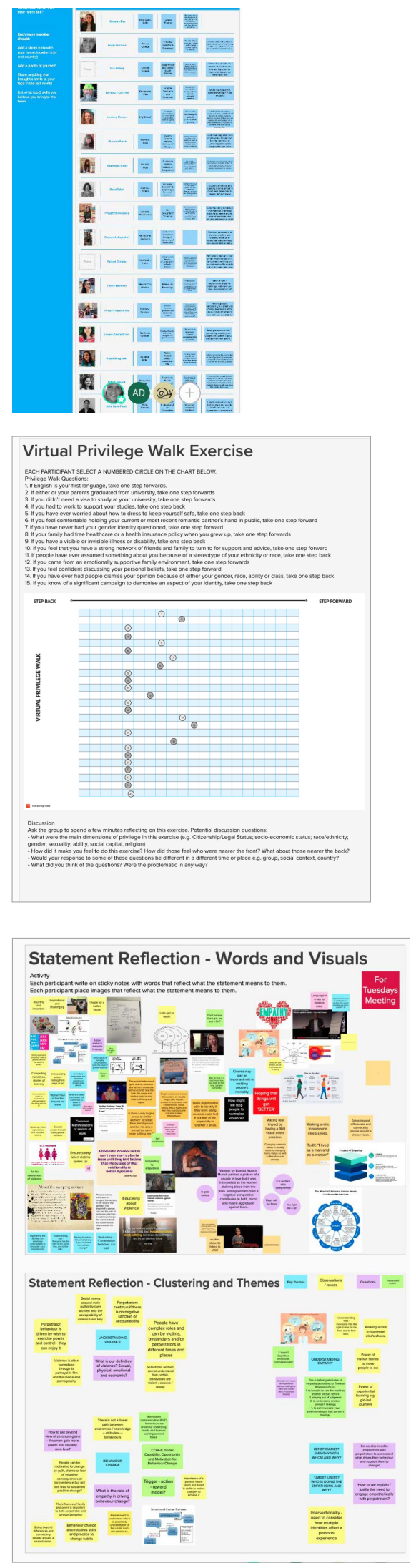

AUGUST 11

\section{AGENDA AND TASKS TO COMPLETE}

\section{Agenda}

Tuesday's Suggested Activities:

1) Review - Ice breaker

2) Discuss the Reflection Activity and everyone's thoughts.

a) The group could continue the process by adding to it if some participants did not get a chance to add to it.

b) Group any related or similar visuals or words into themes.

c) Label the grouped themes

3) Complete the Virtual Privilege Walk Exercise for those who have not done it and then reflect on it.

4) Review - Summarize User Research in an Empathy Map

a) Determine User(s) - State what they would say, think, do and feel towards the subject.

b) Determine problem(s) - State obstacles

5) Homework - Inform participants that they will be receiving a link for the Design Process Presentation, which we will discuss in Wednes day's zoom meeting. They are to compile a list of questions or concerns to be addressed in Thursday's class.

\section{Homework}

1) Mural - Review Statement Reflection - Clustering and Themes Gather any questions or feedback.

2) Mural - Complete Empathy Map - Break-Out Groups Get into the teams below and write out sticky notes that reflect what the users might say, think, do and feel towards the subject.

Perpetrators: Julie (France) and Betul (Turkey) Women enablers: Pim (Thailand) and Pragati (India)

Friends/family of perpetrators: Nimisha (India) and Salomi (India) Bystanders: Triana (Mexico) and Bernard (US) and Lorena (Canada) Friends/family of victims: Kopal (India) and Saneera (India) and Wajeehah (Australia)

Adolescents: Udipti (India) and Akanksha (India)

3) Mural - Reflect on Privilege exercise.

Gather any notes, questions or feedback that will be discussed on Wednesday. AUG 11 - Team 3

\section{Meeting Notes}

Tuesday 11.08 .20

Starting off with a check-up feelings box

Checking the timing for the meetings; Monday, Tuesday, Thursday 8 AM EDT and Wednesday, Friday 6 AM EDT. All good with the timing. $90 \mathrm{~min}$ meetings.

Presentation of Sue Garvey: She's got a background on VAW and homelessness, part of three groups so popping in and out. 
Mural time, checking up the "homework" 5 min.

(Fail)Split up in groups of three to speak about the homework to search for key themes. $15 \mathrm{~min}$.

Talk about the Behavioral change staircase. Empathizing with the predator as well (not justifying).

Three key themes: Blaming the victim, Normalizing VAW, Addressing the problem to Men.

What kind of things lead to acts of violence? Does it bring some sort of satisfaction?

Might be about Power and Control or frustration about not performing well in other areas.

"Is as you're in a dance with society, you take one step forward and you're pushed back.'Salomi- as in for starters you're a woman and then there's the colour of your skin and the social group that you belong to.

Using art as a tool to educate about violence.

Create a safe environment for victims and predators.

How to go from awareness to action? It has to go through discomfort. Sometimes there's a change that comes from shame, not really because there has been an empathy process.

People know what's right and wrong. convenience or inconvenience as a key point to decide how to act.

Skill-building to apply the willingness to change of attitude. Whenever there's been an emotional engagement; people seek those new skills.

We'll do the Privilege Walk as homework to discuss tomorrow.

There's another board made bellow the first mural trying to organize the content that we've got already. We can keep up with adding information. Summarize user user-research in an empathy map.

Perception of who we are talking to.

Open discussion on who should we address to.

Working on the workspace for user research empathy map.

A short discussion on a comparison against speed limit and the system that goes against driving very fast even if it's thrilling.

Proposed persona's: Existing and potential perpetrators, Friends and families of perpetrators, Friends of families/ survivors, Duty bearers, workmates, celebrities and other public figures, adolescents, women enablers, bystanders.

Voting on the top three at the chat. 

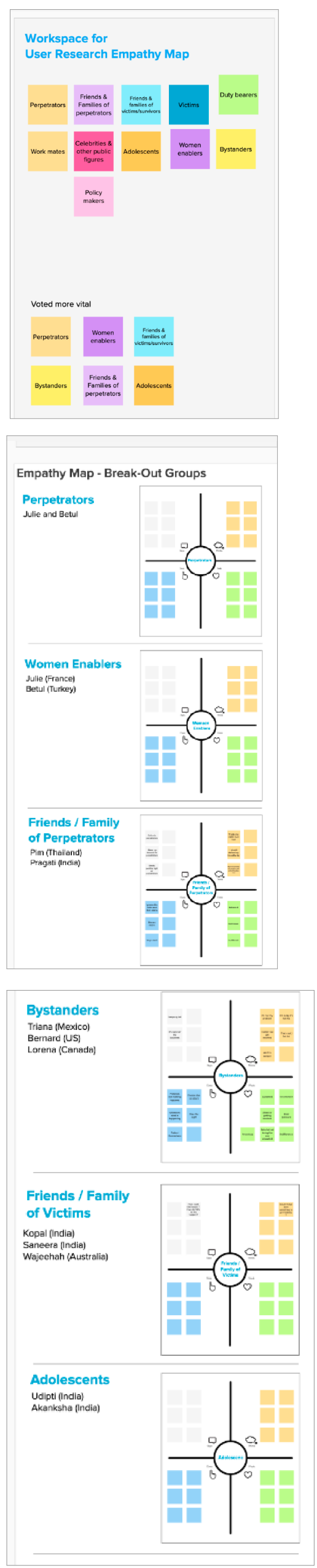

AUGUST 12

\section{AGENDA AND TASKS TO COMPLETE}

\section{Agenda}

Wednesday's Suggested Activities:

Quick check-in (Feelings, questions, note-taker) (5 mins)

Virtual privilege walk - a few reflections (10 mins) (Lyndsay facilitate)

The design process - overview of the design process and timeline

(15 mins) (Angie facilitate)

Challenge statement - reflection on clustering / questions (20 mins)

(Lyndsay facilitate)

User empathy maps - brief 3 minute summary from each team of $2 / 3$, discussion of user profiles, decisions of which to take forwards (30 mins) (Angie facilitate)

Homework and check-out (Research to be done) (Feelings) (5-10 mins)

\section{Homework}

1. Empathy maps of users - please each individually review all 6 maps and add any post-its around the edge of the team's work. Use the same colour post-its for feelings, thoughts etc... If you have another question or comment to add, please add on a different colour post-it.

2. Extending user research - please can the same teams as yesterday do further work on their users and brainstorm what the obstacles are that stop these users acting to prevent violence.... For example, these could be lack of knowledge / understanding, attitudes or beliefs, social norms, practical or logistical etc...

3. Prioritising our user(s) - Tomorrow, we will need to narrow down to one user or a couple of users. Please could you reflect on the work we have done and reflect on which user or couple of users you would like to prioritise and why.

\section{Meeting Notes}

Checking up on feelings; everyone is excited.

Privilege map

- Try to get people to think about the power and privilege they may have in their lives

- Dimensions of privilege can be important in different times and spaces Feedback from people:

- Interesting to compare and confront differences, how I was disadvantages, made me feel uncomfortable

- The feeling was different, in this context of international collaboration, I am quite privileged

- Unexpected, felt some of these privileges are difficult to obtain

- Had to think and reflect a lot about privilege, think about things you may have ignored.

- Had never done it, but did not surprise me, experience this while traveling in other countries.

- The questions are formulated well, try to get to less visible dimensions of privilege (mental health issues, cultural issues, etc).

- Help us reflect on who we are designing for. 

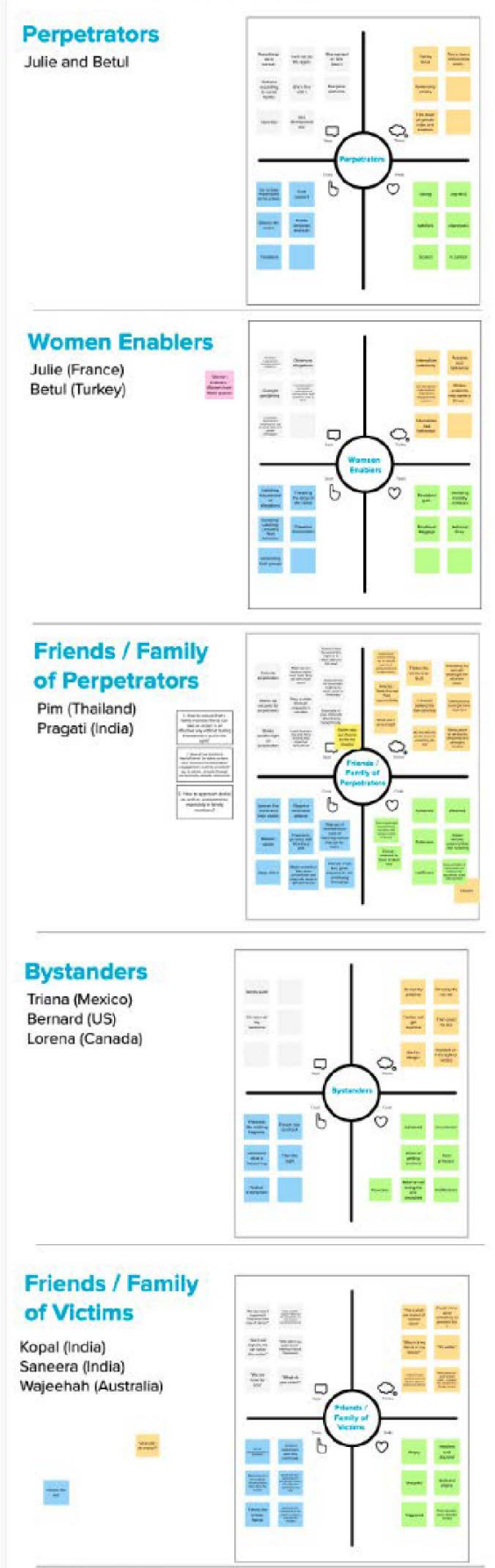

Adolescents Udipti (India) Akanksha (india)

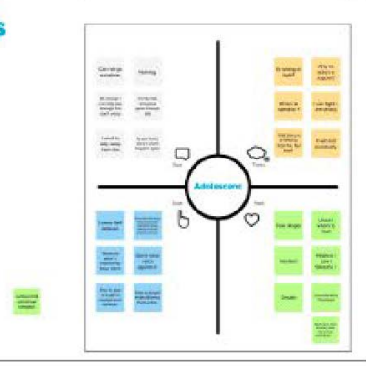

Three main areas and relations to statement

\section{Design challenge process}

- A Wicked problem, complex problem, diverse in nature with multiple facts; government, social, individuals. Very hard to resolve, no one process.

- Process is adopted to the problem, user and any other dynamics.

- Design the problem

- Identify the ones who would have the most impact on creating change, we want to scrape down our persona process a little bit more. Focus in on particular individuals.

- Narrative maps and story boards to make sure we are catching any gaps.

- 5-7 steps process, but try not to put a lot of structure on it. Our structure might evolve. We can go back and reflect

- We don't have the luxury of time, so we should try to move along

- Principles

- Seek out points of exclusion

- Solve for one, extent to many

- Empathy, not sympathy

- Learn from diversity

- No such thing as "normal" human, to our standards of norms, our thinking, that there is no fixed mold

- People are heart of the design process,

- Persona spectrum excludes less people

- Understand personal bias

- Disability is a mismatch, how we frame disability; it is the environment that is the issue

\section{Statement Reflection}

- How we understand violence

- How we understand empathy

- Who are we talking about? Who are our target users? Who do we want them to engage empathetically with?

- Aware that people can be bystanders, victims and perpetrators.

- How some things are driven by patriarchal norms

- What type of violence will we be talking about?

- What is the role of empathy in driving behavioral change?

- Do we need to empathize with perpetrators?

- Which groups do we target to provide the most impact?

- Make sure we approach them

- Example: Give me your hand/Take my hand

\section{Empathy Map}

Please feel free to create another reflection board if it helps with your thought process and critical thinking

\section{Perpetrators}

Two behaviours; people who have strong positions and think they are right, or some people who show remorse.

Have justifications that are more emotional: I love her, she wanted it, use family issues to justify violence.

Action: blame victim, find support.

Feelings: in control, strong or complicated feeling, regretful, can be scared Some perpetrators accept that what they did was wrong, whilst some do 
not. If violence remains the option, you need to consider the whole system There are some perpetrators who are unawar.e

\section{Women enablers}

Understand how we look at them; use basis of women in the work spaces as it is more universal.

Normalizes abuse and bad behaviour and internalize patriarch.y Colleagues might manipulate victim.

How to report to people in a senior position.

We felt a lot of times women colleagues do not want to interfere or get involved with any other problem.s

Many feel guilt.

\section{Friends/Family of Perpetrators}

We need to understand that some friends and family do not know what to do in their position.

We should educate them and help them understand their impact in avoiding such behaviour.

Some might be indifferent, and chose not to take action.

Some might feel ashamed.

Some might defend the perpetrator and defend victim.

All of this is because they don't have an idea of what they can do in their position.

\section{Bystanders}

Assume that it was a person who did not do anything and was not participating Think it is not their problem.

They might try to escape to avoid getting involved.

As women, we might feel we are at risk of getting attacked, but some might feel indifferent.

Peer pressure: someone witness something and would like to intervene but chose not to (self protection).

\section{Friends/Family}

They will start to question you; are you sure it happened? Were you drunk? What were you wearing?

Sort it out internally, keep quiet. Making it about themselves; should have come straight to them, etc.

A lot of fear.

Could I have done something to prevent it? Why my daughter/friend?

Become agents and advocates of awareness, try to make people aware. Some try to solve matters with their owns hands.

High levels of stress and anger.

\section{Adolescents}

How people in general at this age thing; they are unsure if its right or wrong.

Why is no action or support being provided? No action happening. Whom to speak to.

Can they stop this, how?

Some people think it will end eventually?

Feel fear, anger, but also helpless, stressed, unsure of whom to trust, People at this age are easily influenced, it is cool at this age group. A person might not be able to share things with others (not comfortable) 

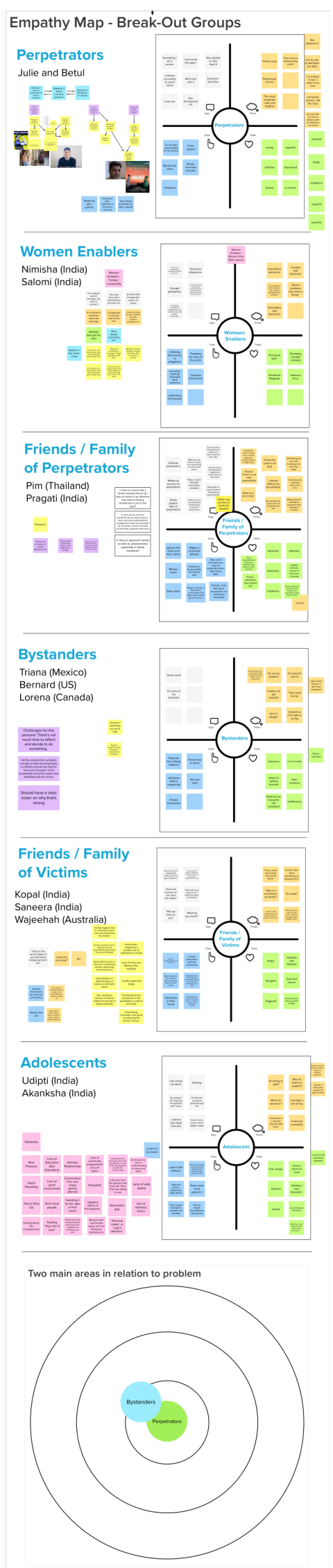

Parking lot

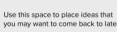

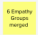

For tomorrow:

How can we narrow this down? Which couple of users do you think we should take forward?

Take a look at the maps, add anything you want.

In your own pairs, do a step further of work, what are the obstacles for the users against violence?

\section{AUGUST 13}

\section{AGENDA AND TASKS TO COMPLETE}

\section{Agenda}

Tuesday's Suggested Activities:

Quick check-in (Feelings, questions, note-taker) (5 mins)(Lyndsay)

User empathy maps: Each pair/three to present for 3 minutes on their empathy map. Comment on any extra inputs since yesterday. Highlight obstacles faced by that user which stops them from acting to prevent violence. Questions / discussion (30 mins)(Angie)

Prioritising our user(s) - narrowing down to one/two users - discussion and decision - who and why? (20 mins)(Lyndsay)

Creating our user(s) persona - Small group brainstorming - 2/3 groups - what do we already know? What more do we need to know? How do we find it out? (20 mins + feedback)(Angie)

Homework and check-out (Team research to be done) (Feelings) (5-10 mins)(Angie)

\section{Homework}

1. Empathy maps of users - please each individually review all 6 maps and add any post-its around the edge of the team's work. Use the same colour post-its for feelings, thoughts etc... If you have another question or comment to add, please add on a different colour post-it.

2. Extending user research - please can the same teams as yesterday do further work on their users and brainstorm what the obstacles are that stop these users acting to prevent violence.... For example, these could be lack of knowledge / understanding, attitudes or beliefs, social norms, practical or logistical etc....

3. Prioritising our user(s) - Tomorrow, we will need to narrow down to one user or a couple of users. Please could you reflect on the work we have done and reflect on which user or couple of users you would like to prioritise and why.

\section{Meeting Notes}

Thursday 13.08.2020

Check ins: everyone is feeling good, Bernard is able to join.

\section{User empathy maps: \\ Perpetrators}

Many limitations and obstacles; cultural ones, etc.

How can we make them realize the effect of their violence; perhaps use art forms (film, etc) and emphasize with the victim/survivor 


\section{Women Enablers}

Obstacles: some internalize patriarchy and feel they are unable to do anything.

Might sometimes blame the victims.

Might see VAW as something women inevitability have to deal with.

\section{Friends and family of perpetrators}

They need to understand the effect they have on the perpetrators and know how to utilize their power to prevent it; most friends/family don't know how to do this.

We should also emphasize with the friends and family as they also do not know how to navigate and deal with the problems they may face Cultural barriers: those from indirect cultures would choose not to do/say anything.

\section{Bystanders}

They don't realize that they can be 'heroes' and can prevent violence from happening.

Need to educate them to speak up and help victims.

Friends and family of victims.

Need to emphasize how important it is for them to support the victims emotionally.

They can help the victims in more ways than one.

Some don't know what to do in their positions to help the victims.

\section{Adolescent}

Lack of (sex) education.

Lack of good environment (where they fully trust people).

For younger people, they might be blinded by the idea that they love a person and use this to justify abuse.

Prioritizing our users.

Most agree that we should prioritize perpetrators.

Must be concise in defining who the perpetrators are.

How are we going to reach out to the.m

Are they potential perpetrators or those that have engaged in VAW?

Should we target and empathize with victims as well?

We should target people surround the perpetrators as well, because they have a large influence.

Perhaps group the following users we listed into a larger group.

So we have 2 users we are targeting.

\section{Homework}

Due to the time limit, we will be creating the users persona individually, this means we will be putting ideas onto the post its by the personas and creating a visual image of the target persona

We will further discuss tomorrow. 


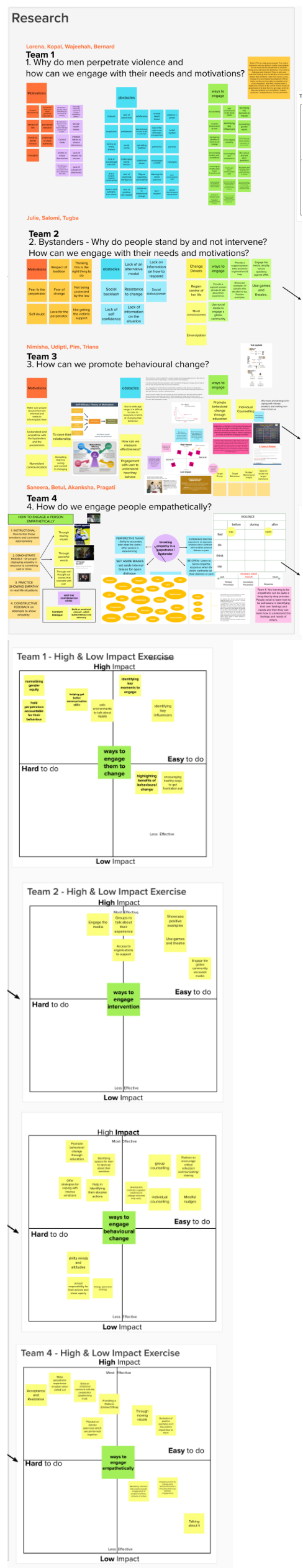

\section{AUGUST 14 \\ AGENDA AND TASKS TO COMPLETE}

\section{Agenda}

Suggested Activities:

Quick check-in (Feelings, questions, note-taker) (5 mins)(Angie)

Personas: 2 Personas - finishing 1 and working on 2. Start to create background stories. (40 mins)(Angie)

\section{Homework \\ Empathy: What is empathy and how do we engage people empathetically? (Saneera, Betul, Akanksha, Pragati)}

2. Behaviour change: What are some useful models of behaviour change that we can apply to our challenge? (Nimisha, Udipti, Pim, Triana)

3. User 1: Perpetrator - deepen research on motivations, obstacles to change, how to engage with them (Lorena, Kopal, Wajeehah, Bernard)

4. User 2: Bystanders - deepen research on motivations, obstacles to change, how to engage with them (Julie, Salomi, Tugba)

\section{Meeting Notes}

The Playback meeting was so useful today. We had a presentation from each team on where they are at in their design and thinking process.

The recording of the session will be posted on the general channel later. A few takeaways from my perspective:

We are on track in terms of the design process as well as the depth of our thinking

Next time, we will share more of our in-depth content which is of comparable quality to other teams

There are some team with some overlap and complementarity with us and Angie and I will stay in touch with them and exchange insights. In particular these are team 4 (working on transforming men's sense of entitlement) and team 6 (working on the gender socialisation of children in the home).

It is super helpful to really narrow down to focused / concrete personas. Team 6 has done this (maternal, paternal and other male family member personas) and it was really powerful. Their personas have names, back stories, thoughts, feelings... Although this narrows things down I think it really, really helps to develop empathy and find solutions. I also think those solutions will work for a wider number of users in the end anyway. Those who took also part, please feel free to add your insights. 
Workspace for

Persona Profile

USER - Prepetrator

Defining Perpetrator as one who as commit

and one who might possibly commit.

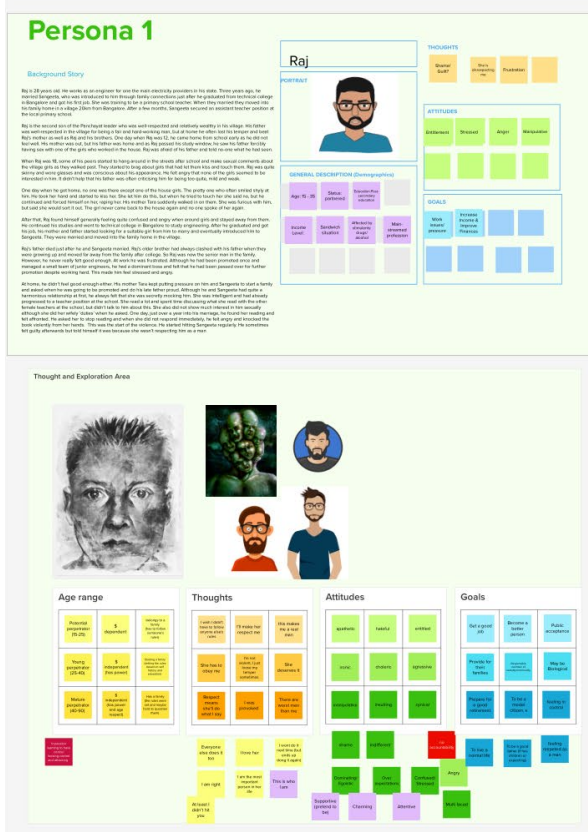

USER - Bystander

Defining Bystander as anyone who facilitates, enables, witnesses, has awareness of
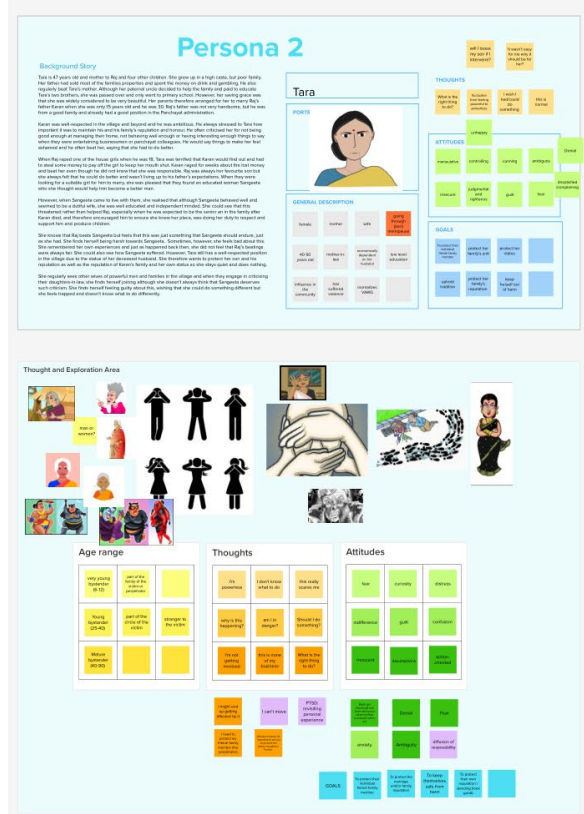

\section{AUGUST 15}

\section{AGENDA AND TASKS TO COMPLETE}

\section{Agenda}

Suggested Activities:

Quick check-in (Feelings, questions, note-taker) (5 mins)(Angie)

Personas: 2 Personas - finishing 1 and working on 2. Start to create backgroud stories. (40 mins)(Angie)

\section{Homework}

Working on research 4 question in teams - Small group brainstorming 2/3 groups - what do we already.

\section{Meeting Notes}

\section{Persona - name?}

Feeling something for the persona, Group 6 did it perfectly in the playback Lyndsay will great a background story and everyone else will review it.

Give human qualities to our persona.

Team 6 Shazia Usman (Wajeehah's friend) graphic book - "Kaluti” for young girls.

\section{Persona for bystander}

Age range of bystander?

Mother-in law is a very important bystander?

Female bystander?

Younger age of bystanders - their ability to make decisions isn't formulated yet and they take longer to process things.

Someone who can intervene?

We want to choose a bystander that could intervene positively, have influence and make a difference.

Female-40 to50 yo - has influence and can make decisions

She could be still married, she is a mother.

\section{Education level?}

Matriarchal power in some cultures - controlling and manipulative females. "Don't confront him - just say yes and then do what you want to do". Mothers are biased towards their sons.

Learned behaviour passed down through generations.

Financially dependent on a ma.n

When we engage with Mother-in-law, we have potential to influence her behaviour towards her son and daughter-in-law as well as the behaviour of other Mother-in-laws of the community.

Switches between being in power and being powerless consciousl. Maybe she thinks her power comes from her specific ability to perform as a woman?

She has some ambigious feelings. She occasionally feels compassion towards her daughter-in-law as a woman and remembering what she suffered. At the same time she wants to uphold the family, her husband's and son's position.

She has a strong sense of insecurity because her daughter in law is well educated, more independent woman. 
Maybe there is some anger also. She feels she had to comply to a certain amount of things in her life. She had to make sacrifices. Now she feels it's her daughter in law's turn. So she is not ready to see her having more freedom.

So there is also a link between her lack of self-empathy for what she suffered and her lack of empathy for her daughter in law or she is just normalised with the idea.

She says 'it's just part of marriage'. I endured it so she has to endure it On the other hand she can show off her daughter in law to the society as well. So there are fleeting moments of pride.

She may think that society's attitude toward her family will change if they divorce.

One of her goals can be to uphold tradition in favour of upholding the family's reputatio.

Social comparison and dissatisfied attitude.

She is unhappy and feeling guilty perhaps sometimes wishing she had / could do something different.

When she is with other women, they are often complaining about their daughters-in-laws. She joins in, but sometimes feels guilty as she knows he daughter-in-law is actually a good person.

\section{Some Thoughts:}

Maybe: this is normal in a relationship.

«Raj is not a bad person ».

It wasn't easy for me, why should it be easy for her and the mother-in-law hasn't had the chance to get out of her environment to get different ideas and see people doing things differently.

I think to change behaviour people need an alternative vision and to believe they have the power to change to achieve that vision.

Even if the person is 'typical' or 'stereotype', we will reach a broader range of people with our solution and we can broaden out from this person.

For teams 1 and 2, they will continue to work on our two users and look more at their motivations, obstacles and how to engage them.

Team 3 will look at models of behaviour change and suggest a vision for how we visualise the behaviour changes needed and how we can visualise this behaviour change process.

Team 4 will research on how we engage people empathetically and support them to engage empathetically... so it looking at some of the literature as well as some ideas e.g. stories of change, encouraging them to empathise with themselves so they can empathise with others etc/ I will share a couple of examples for all groups.

So for example, I think it is hard to get a perpetrator to engage with a survivor's experience, unless we try to understand his experience and perspective. However hard that is...

Find a portrait - put more images in next 24 hours - someone can volunteer to create a cartoon - we should get it ready by Sunday. Ending note - "If you are not kind to yourself, you cannot be kind to others". 


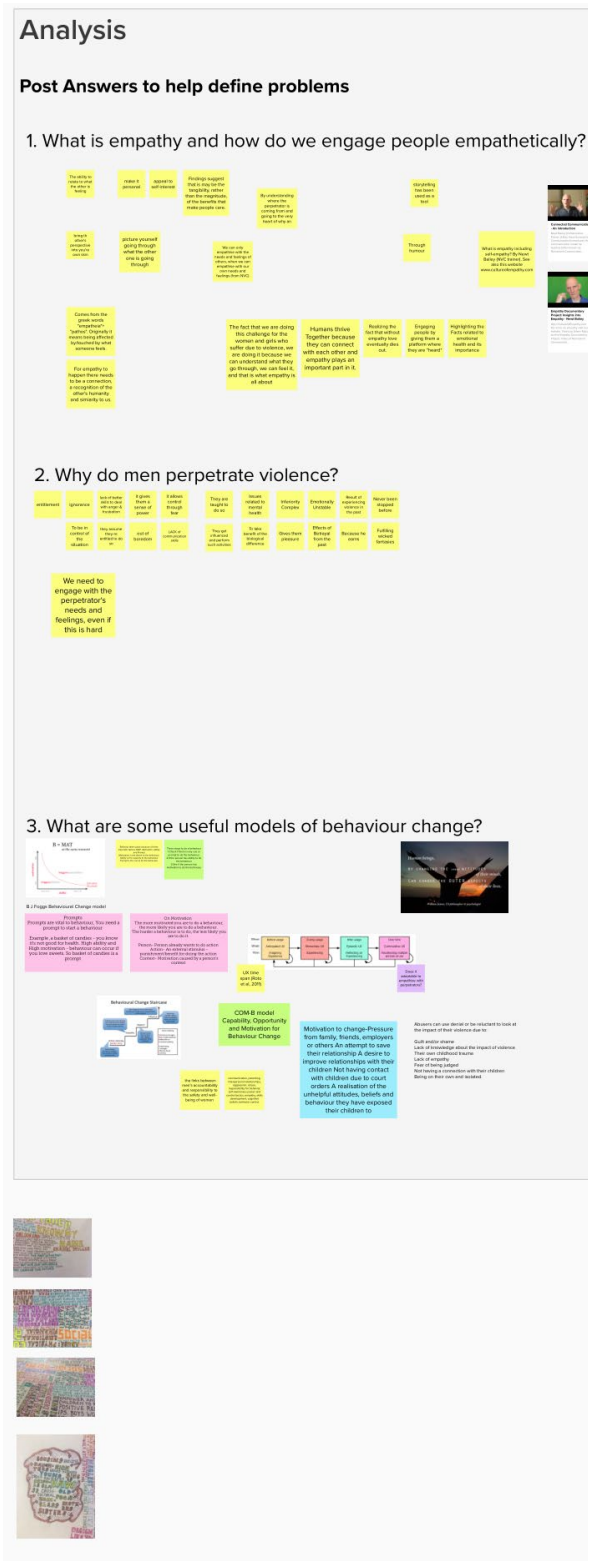

AUGUST 17

\section{AGENDA AND TASKS TO COMPLETE}

Agenda

Suggested Activities:

Check-in (feelings, notetaker)(5 mins)(Lyndsay)

Overview of the week's design process, $Q+A$ (Angie)(10 mins)

Team 1: Behaviour change - presentation, $Q+A$ (15 mins)

Team 2: Empathy - - presentation, $Q+A$ (15 mins)

Team 3: Perpetrators - presentation, $Q+A$ (15 mins)

Team 4: Bystanders - presentation, $Q+A$ (15 mins)

Check out - decisions on homework, next steps, feelings (Lyndsay, Angie)

(10 mins

\section{Homework}

Working on research 4 question in teams - work on addition boards 1) cool and hot 2) Low and High and Low impact.

\section{Meeting Notes}

Checking on the feelings

Introduction to Scenario mapping by our users: Raj and Tera.

The goal is to set our persona into a specific contextual situation and have a reflection around how would they behave under those circumstances. Before moving forward, checking the backgrounds of the personas. Team one: Why do men perpetrate violence and how can we engage with their needs and motivations?

They might have been abused too, sometimes they feel challenged by their partner, could be mental health issue, they act as they've learned how "being a man is". Some of the obstacles are: lack of awareness, norms on family privacy, lack of positive role models, lack of tangible negative consequences, they try to put themselves as the victim, poor communication skills.

Ways to engage: be sure the victim is safe, encouraging empathy, be curious and ask open tables, identifying key moments to engage, begin by being empathetic with the perpetrator.

Team two: Bystanders-why do people stand by and not intervene? How can we engage with their needs and motivations?

Motivations: Respect of tradition, thinking is the right thing to do, self doubt, fear of change, care for the perpetrator, not being protected by the law.

Obstacles: lack of an alternative model, social status or power, social backlash, resistance to change, lack of self confidence, lack of information on the situation. Safety of the bystanders is critical.

Ways to engage: provide a support system, easy access to organizations and help, use games and theatre, use social media to engage global community, engage the media: amplify voices speaking against VAW. Lorena shared the story of her mom and the critical paper that bystanders had to not support her while being mistreated by her dad.

Bringing up the conversation about pre-menopause and menopause and how that effect in the bystander persona Tara. 


\section{Team 3:}

Motivations, to begin a lifestyle change, motivation has to be clear but also have a trigger. In this case, the motivation should be trying to save the relationship or the family (which is interesting if applies to both personas). Motivation sometimes is not enough is the context doesn't help. Motivation might be the start to look for the tools to get to the change. Obstacles, there's a very wide range of age, also how could we measure effectiveness?,

Which could be the pinpoint to trigger the motivation? So, there is a map about the hard to do activities and easy to do activities against the amount of impact that they'd have.

Categorizing the behaviours could be a path to find the key behaviours that are easy to do and cause a high impact.

\section{Team 4:}

\section{How do we engage people empathetically?}

How de we make feel those emotions, first identify them and look for other people going through that emotion. Keep the conversation going to build a connection.

Perspective taking, set aside biases, belief that other people ought to be respected and treated with compassion, experience emotion, be open. Learning to be empathetic can be quite a long step by step process. The first step is to learn to be self-aware.Tthe next step is to work on the scenarios.

They could be detailed or just an idea picture of the user experience. Like a story.

We want to look at what SHOULD happen and then how do we GET THERE?

We should have in mind the background story of the personas so we infer what might trigger the violent responses and the steps that should follow. Looking for volunteers for making the scenario map for tomorrow. Should we do it as a group?

Two groups to make the two map scenarios. Team 1\&3 would work together and $2 \& 4$ together. Lorena will make the slack group for 1 and 3 and Saneera will do for teams 2 and 4.

Angie will create the other boards.

Thank you everyone! See you tomorrow!

\section{AUGUST 18}

\section{AGENDA AND TASKS TO COMPLETE}

\section{Agenda}

\section{Suggested Activities:}

Thanks for all the work and brainstorming you have done on the board. I have spent some time reviewing the inputs since yesterday and have created two big yellow stickies.

The first 'key ingredients' tries to summarise the conclusions of our group on the key elements of a solution designed to engage people emotionally and emphatically. The other sticky tries to summarise and 
Workspace for Scenario Mapping

User Research scenario mapping helps you see the experience that the

Persona 1

Perpetrator

Raj

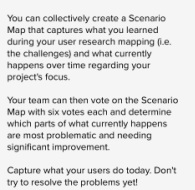

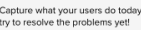

PROBLEM

Idenify problem to solve. We are only

examining it here

NEEDS

What needs to be addressed to help sove the

Alim

Team A

Team 1 - Lorena, Kopal, Wajeehah, Bernard

Team 3 - Nimisha, Udipti, Pim, Triar

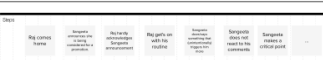

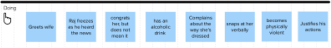

$\bar{s} \equiv \equiv \equiv \equiv$

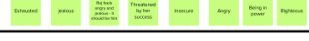

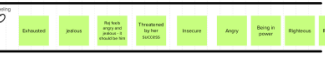

User Research scenario mapping helps you see the experience that the

persona is having as they travel through their activies.

Team B

Team 2 - Juile, Salomi, Tugba

Team 4 - Saneera, Betul. Akanksha. Prage

Bystander

Tara

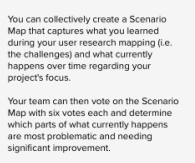

圆

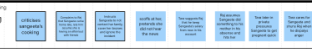

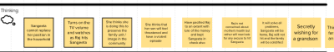

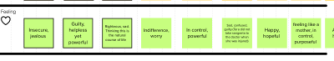

PROBLEM COMMENTS

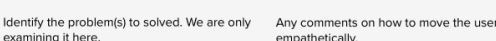

NEEDS

What needs to be adcressed to help solve the THOUGHTS

AIM

Identify the thoughts that need to change in
order to categorise the big ideas / solutions I see on the boards. We can update these as I know you are still adding ideas.

In terms of today's team meeting at 8.00 EDT / 12 GMT / 17.30 IST, given the time we have left, Angie and I propose the following agenda.

Check-in (feelings, note-taker) (Lyndsay facilitate)-(5 mins)

Design process and meeting the deadline - plan for today, tomorrow and playback (Angie facilitate)(10 mins)

Review and finalise 'key ingredients' list (Lyndsay facilitate)(10 mins) Review big ideas list - quick 1 minute summary of each idea from the originator + add any others missing (Angie facilitate)(20 mins)

Review evaluation criteria - and agree on how to make our decision on which idea to take forwards (Lyndsay facilitate)(10 mins)

Decide on which idea to take forward (all)(20 mins)

Explanation of Storyboards (Angie)(10 mins)

\section{Homework}

Storyboards, structure of presentation (Lyndsay and Angie)-(5 mins)

\section{Summary}

We reviewed the Tara character picture kindly designed by Saneera. We liked it and thought it captured her personality well. If you have any further comments, please post them here in Slack.

We reviewed the work the team did on the perpetrator scenario map. There was consensus that the team had done well to capture this unfolding scenario and sequence of events that seemed very believable.

A few other comments were made:

This captures a behavioural dynamic / pattern which is common and which tends to recur time and time again.

It is about how Raj is dealing with his emotions and about poor communication in the family. When he is triggered and feels frustrated, insecure etc, he is not able to talk about his emotions and receive empathy and instead has negative coping strategies and tries to get attention and regain control, autonomy and respect through abusing Sangeeta emotionally and physically.

We need to remember the social norms around manhood and the pressures on Raj from his friends and family to behave a certain way e.g. succeed in his career, provide for his family, control his emotions, 'be a man' etc.

Some of the research shows that it is hard for someone to empathise with another if they cannot empathise with themselves and their own feelings and needs.

There have been some previous programmes working with couples to support them to improve their communication, engage in more gender equitable behaviours and avoid violence e.g. indashyikirwa programme in Rwanda was a 20 week transformative couples curriculum where 15 couples worked together in participatory workshops around power, 

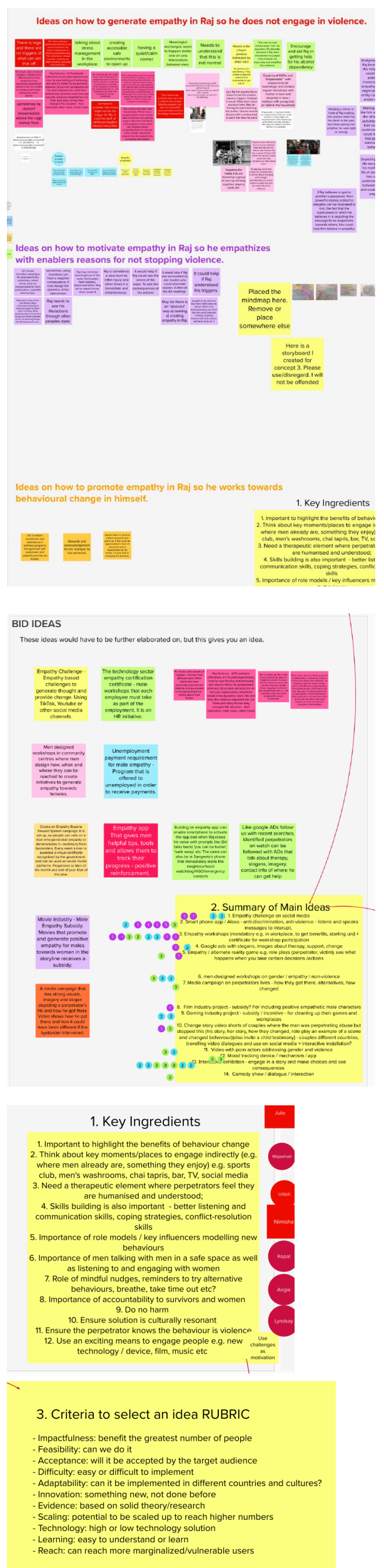

gender roles and stereotypes, communication skills, conflict management skills ect.

Key question: What is stopping Raj from engaging emotionally and expressing his own emotions?

2. We reviewed the work the team did on the bystander scenario map (Tara). Again, there was consensus that the team had done well to capture a number of events that seem realistic and common.

\section{A few other comments were made:}

This shows the importance again of the family dynamic and the multiple relationships. The fluctuation of emotions and behaviours of Tara seems very believable. Sometimes she wants to punish Sangeeta, sometimes protect her.

3. Primary persona: We agreed on the perpetrator (Raj) as the primary persona for our solution, but that we need to see him clearly as part of this family dynamic in which his mother Tara plays a key role.

\section{Homework}

Fill in the High and Low impact grid for some interventions

Brainstorm ideas for solutions on mural

\section{AUGUST 19 \\ AGENDA AND TASKS TO COMPLETE}

\section{Agenda}

Suggested Activities:

Thanks for all the work and brainstorming you have done on the board. I have spent some time reviewing the inputs since yesterday and have created two big yellow stickies.

The first 'key ingredients' tries to summarise the conclusions of our group on the key elements of a solution designed to engage people emotionally and emphatically. The other sticky tries to summarise and categorise the big ideas / solutions I see on the boards. We can update these as I know you are still adding ideas.

In terms of today's team meeting at 8.00 EDT / 12 GMT / 17.30 IST, given the time we have left, Angie and I propose the following agenda.

Check-in (feelings, note-taker) (Lyndsay facilitate)-(5 mins) Design process and meeting the deadline - plan for today, tomorrow and playback (Angie facilitate)(10 mins)

Review and finalise 'key ingredients' list (Lyndsay facilitate)(10 mins) Review big ideas list - quick 1 minute summary of each idea from the originator + add any others missing (Angie facilitate)(20 mins)

Review evaluation criteria - and agree on how to make our decision on which idea to take forwards (Lyndsay facilitate)(10 mins)

Decide on which idea to take forward (all)(20 mins)

Explanation of Storyboards (Angie)(10 mins) 


\section{Homework}

Fabulous work today team - the input and collaboration were result generating - Way to go!!

For homework, we need to complete the following to hit our deadline: In your teams, create a storyboard based on your team's concept. Remember, this is Raj's journey with the concept. The result should be him using the concept that generates empathy, which initiates change in him not to commit violence.

\section{Teams are as follows:}

Storyboard 1

(empathy challenge, social media): Kopal, Wajeehah, Tugba, Pragati Storyboard 2

(Smartphone/siri/alexa type app on Empathy): Saneera, Pim, Betul Storyboard 3

(Empathy workshops): Nimisha, Akanksha, Salomi, Bernard

Storyboard 4

(Interactive / video travelling exhibition): Udipti, Lorena, Julie, Triana Summary of Ideas \& Key Ingredients - visual depicting all concepts and Ingredients (Udipti/Saneera)

\section{$12: 39$}

I failed to mention that all the storyboards are ready to go. Thank again Team!

\section{Meeting Notes}

The meeting's aim was to select the ideas we will move forward with. However, we will account for all ideas in our final presentation.

1. Emotions check in: Overall, most of us are excited about this session.

\section{Today's plan:}

- Design process and meeting the deadline - plan for today, tomorrow and playback (Angie facilitate)(10 mins)

- Review and finalise 'key ingredients' list (Lyndsay facilitate)(10 mins)

- Review big ideas list - quick 1 minute summary of each idea from the originator + add any others missing (Angie facilitate)(20 mins)

- Review evaluation criteria - and agree on how to make our decision on which idea to take forwards (Lyndsay facilitate)(10 mins)

- Decide on which idea to take forward (all)(20 mins)

- Explanation of Storyboards (Angie)(10 mins)

- Homework - storyboards, structure of presentation (Lyndsay and Angie)-(5 mins)

We want to have the storyboard fleshed in today so that we can make tomorrow's presentation as tangible as possible.

3. Reviewing the key ingredients with Lyndsay: elements that felt really important to change Raj's behaviour.

- Benefits of behavioral change to the person

- Think about the key moments to engage with the person

- Need to humanize the perpetrator and have a therapeutic element

- Skills building is important

- Importance of role models to encourage new behaviours

- Men need to be able to talk with men in a safe space but they need to ${ }_{29}$. 
talk to women and listen to women as well.

- Mindful nudges: ways to remind people to mind their behaviours

- Accountability to survivors and victims

Added:

- Do not harm

- Make sure the solution is culturally relevant

The team felt that overall this list encompasses all the ideas that we had so far. If ever anyone thinks about anything to add, they will add a sticky note nearby the main one Lyndsay made and it will be incorporated.

4. Reviewing the big ideas with Angie - 3 main categories: empathy focused/ men focused/ family focused

\section{EMPATHY}

1. Empathy challenge on social media

2. Employer Empathy certificate

3. Mandatory empathy workshops

4. Google ads with slogan and access to therapy and support

5. Empathy game

\section{MEN}

6. Workshop on gender/empathy/non-violence for men

7. Media campaign on perpetrators' lives

FAMILY/COUPLE

8. Film industry project: subsidy for including positive male characters

9. Gaming industry project - incentives for cleaning up their games and workplaces

10. Change story videos: a perpetrator who decided to change. Showcase different countries.

Challenging the idea of the empathy app: will people with no or little empathy download it? One way to « sell » it would be to market it as a benefit: « improve your sex life » for example.

Mix of ideas that involve the government/public institutions and ideas that involve private industries.

A lot of industries have unions that we can reach out to and motivate with tax exemptions for example.

Developing a game might not be the right way to go but « cleaning » games from toxic images and behaviours could be an interesting path to explore. Most of the time, money is the only motivation as it's nearly impossible to change people's mindsets in these organizations.

Exploring the idea of the game: it would be interesting to explore role playing. Maybe the perpetrator could look at a situation through the eyes of a victim. Problems: how do we have people actually playing? How do we make sure that people are touched by the game and feel motivated to change their behaviour? 


\section{Additional ideas:}

- Replace the woman/victim by another character that they would connect more with. Would it be a pet?

- Involve authorities?

- What if we have videos that look like porn but when you go in you con front violence? The most watched categories on porn websites, are the ones that showcase violence against women.

- An average person spends more than 5 hours on their phone. The phone could keep track of key words that would activate the app and send an alert (neighbourhood, police, family). The phone's search engine could also then target the adds sent to the perpetrator.

- Mood tracking device/app/tool. Maybe part of a smart watch?

- Videos from all around the world showing how couples have overcome a violent relationships

- Using comedy or humour to challenge ideas about what is okay or not in a relationship

Final lists to be found on Mural.

\section{Idea selection}

Criteria to select an idea

- Impactfulness: benefit the greatest number of people

- Feasibility: can we do it

- Acceptance: will it be accepted by the target audience

- Difficulty: easy or difficult to implement

- Adaptability: can it be implemented in different countries and cultures?

- Innovation: something new, not done before

- Evidence: based on solid theory/research

- Scaling: potential to be scaled up to reach higher numbers

- Technology: high or low technology solution

- Learning: easy to understand or learn

- Reach: can reach more marginalized/vulnerable users

We need to select 4 ideas to move forward with. The group decided to vote using Mural.

Final selection: 1, 2, 3, 13

\section{Things to consider:}

How to engage people efficiently? If we « trap » them while they are trying to have good time it won't really work. (Example of porn websites)

- Hard to onboard governments and employers

- We can combine some ideas based on the ones we have listed

\section{Storyboarding process}



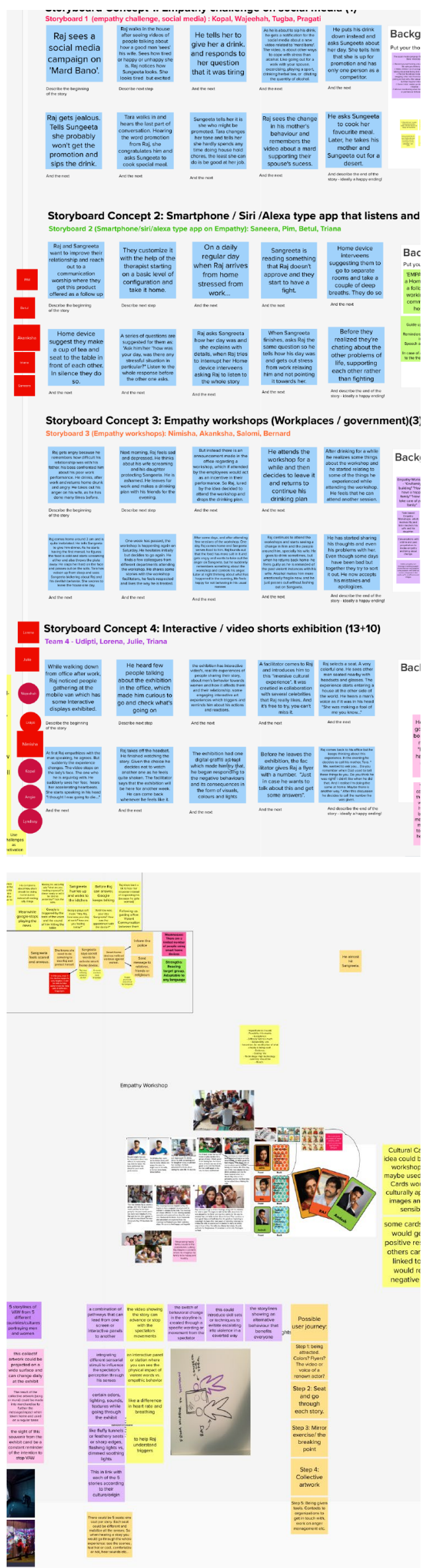

\section{AUGUST 20 \\ AGENDA AND TASKS TO COMPLETE}

\section{Agenda}

Amazing Team 3 - Homework

1. Each team make adjustments to their Storyboards in new space.

Please make sure to tighten up written part.

\section{Each team please add visuals above each sticky note.}

The visual only needs to relate to a key point on that sticky note.

3. Please make sure to have boards done by deadline provided by Lyndsay.

4. Lyndsay and I agreed that the presented Final Storyboard will mention 2 and how the others can be supporting tools.So they are all part of the solution in some capacity - Great work! Your hard work made this approach feasible.

\section{Can someone form teams 2 and 4 please volunteer to present a slide.}

So sorry I had to leave early for my other meeting. I wold have preferred to stay with you and listen to the end of idea 4 and then the discussion. So exciting - you have all done such good creative work!

I have voted. I was torn between idea 4 and 2, as were all of you. I voted for 4 in the end, but I am hoping that both 2 and 4 can be taken forward (with also integrating elements of 1 and 3 !). It looks like 4 has the most votes with 2 as the close second.

I know that you are all now tidying up the concepts, visuals etc for tomorrow. I will do the next draft of the presentation when I get up tomorrow morning UK time, ready for our meeting at 6 EDT. We can then go through it, agree how to improve it and leave time for someone to make it visually more beautiful than I can and for us to practice before the Playback at 8 EDT. Can I kindly therefore ask that all teams finish their work on their ideas on mural before 8am UK time /12.30 IST / 3am EDT? If you want to prepare any visuals for the powerpoint to help out, then please do so and attach the design files here or email to me on lyndsay@ msukumo.uk.

Angie will write and confirm the homework, but for the presentation for each of the four ideas, we will need:

A visual for the design idea, some short bullet point text to capture the key features of the concept + a completed storyboard

For ideas 2 and 4, it would be good to have a few more bullets and visuals to elaborate features of the concept.

Remember we only have space for two slides for the main design idea and two slides to summarise the other three, so try to be concise in your words and visuals!!! You can say more when you present. 


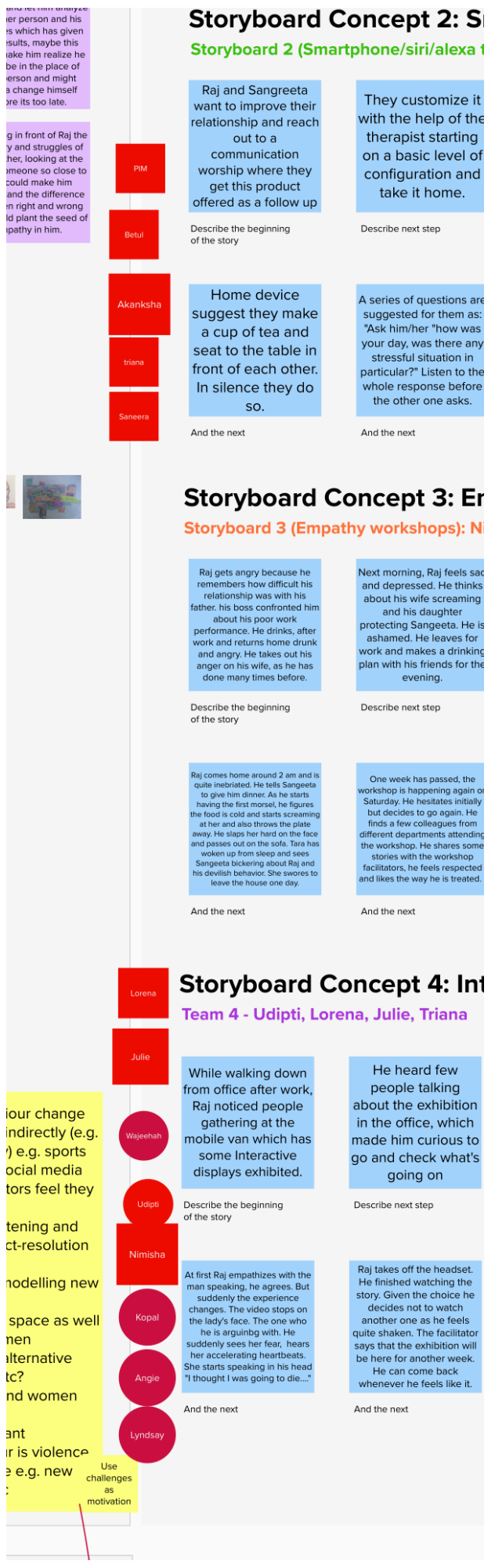

In terms of the presentation, as I said earlier, we would really like this to be a team presentation. It would be great to have $2 / 3$ volunteers from among you to present a couple of slides. Ideally, we need one person from team 4 (to present concept), one from team 2 (to present 1, 2 and 3). If someone else would like to speak, I am sure we can figure it out. Please chat and let us know here who is volunteering.

We will need to be clear who is doing what in the meeting at 6 EDT / 10 GMT, 15.30 IST tomorrow and set time limits for each slide as we will strictly have 10 minutes! Here is the link for our team meeting tomorrow:

\section{Meeting Notes}

Check in and going over what needs to be done for tomorrow's plays back.

Everyone is feeling excited, hopeful, energized about tomorrow.

\section{Presentation of 4 ideas/storyboards:}

Great work has been done. Very good team synergy.

Keeping our minds open to combine elements from other ideas to the idea that will be chosen.

Reviewing the depth of the story, review the criteria to make an educated choice.

\section{Concept1: Empathy challenge on social media}

\#MardBano (be a man)

Role based local contextual narratives to identify what behaviour change needs to happen.

Putting forth the benefits of such changes in the couple dynamic.

This initiative would benefit from the viral factor of sharing the videos and the popularity of challenges on social media.

Combination of Push Content and User generated content.

How do we moderate the user generated content?

What about intensity? How much exposure does Raj need? Time needed for change?

Maximum and intense exposure could help behaviour change.

The content could translate to TV and radio to reach a larger audience. Questioning the Be a Man slogan, versus Be a (adjective) Man.

How does Raj take part of this challenge on social media?

Making it a 10 Step challenge.

Concept2: Smartphone/Siri/Alexa: Empact app

The app can be installed by the perpetrator or by the bystander

Different Modes available: Wellness, relationships, mindfulness, stress

management

Safety tools, enable Alexa with safety words

Habit tracker and journal

Support group available through the community using the app.

A safety word is programmed to trigger support in a potentially violent situation happening at home.

To download the app means he already recognized he needs to change his behaviour.

The app helps Raj identify triggers and helps de-escalate the situation through providing tools. 
Storyboard Concept 1: Empathy challenge on social media (1)

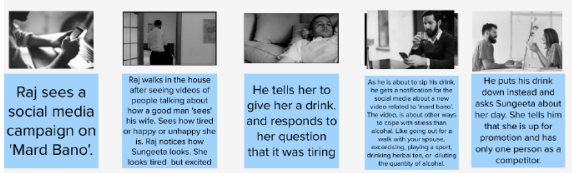

Storyboard 2 (Smartphone/siri/alexa type app on Empathy): Saneera, Pim, Betul, Trian

Storyboard Concept 2: Smartphone / Siri /Alexa type app that listen

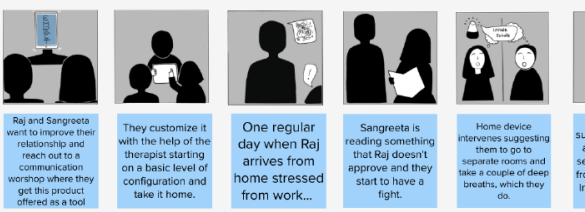

Storyboard Concept 3: Empathy workshops (Workplaces / governm

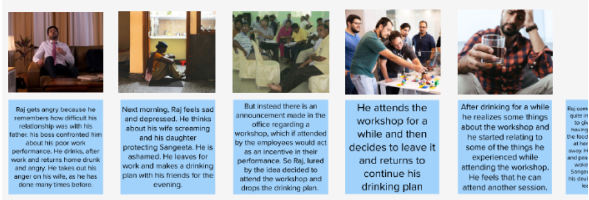

Storyboard Concept 3: Empathy workshops (Workplaces / governm

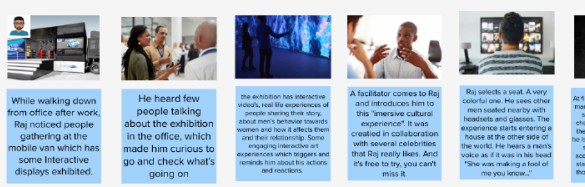

Interactive / video shorts exhibition: Mirrors and Windows and relationship enhancement app

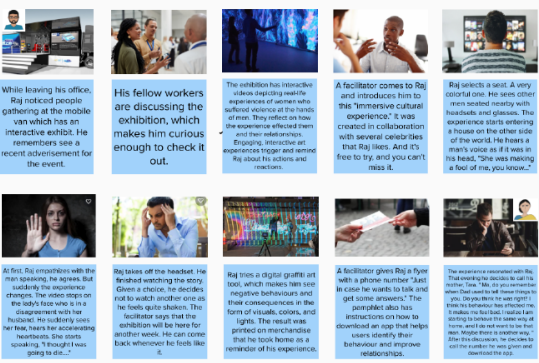

An app to have healthy relationships. Relationship improvement App. A follow up tool to maintain the good habits after he realized the problem. Questions around how to market it so that Raj will install and use it. Questioning the secret word that activates it, when it comes to safety. The idea of the app listening, tracking the patterns of the conversations to be able to pinpoint triggering moments. Identifying moments when things escalate, and ways to rephrase the conversations.

Verbal abuse analytics and feedback

Concept 3: Empathy workshop (Workplace/gouverment)

How to love your family

Health and happiness of your family

Workshop happening at a time when Raj would normally go drinking to replace that activity.

Using incentives to make Raj participate in the workshop.

Aiming at small victories in acquiring awareness and changing

his behaviour.

Positive reinforcement is needed for him to come back and keep assisting the workshops.

Role playing.

Gamification of the workshop.

Conversations with victims and past perpetrators to promote better

awareness and empathy.

Challenges: how do we recruit the most violent men to this workshop?

Scaling: how do we reach the most people?

Tax cuts for institutions as incentive to finance this initiatives.

\section{Concept4}

Immersive cultural experience.

A travelling interactive Movie Van Exhibition.

Showcasing 5 stories of VAW from 5 different cultural backgrounds.

Allowing for empathy through experiencing content from victim and former perpetrator.

Curiosity fueled.

Facilitators will be there to engage with the public and provide sources of information or support to both perpetrators and bystanders as well as victims/survivors.

It is an attractive idea for the general public but aiming at the perpetrator as the main target of the push content.

I can spark conversation.

It allows for collaboration (in a collective interactive digital graffiti artwork) that can be made into merchandise to take home and serves as a reminder of the experience and core message. It can be interconnected with the Wellness and healthy relationship app of idea \#2.

The team feels its very attractive and unique.

How do we choose one idea or integrate and blend several storyboards?

The team feels idea $2+4$ can be complementary.

Idea 4 can be the launch for all ideas. 
Accessibility for idea 2 shouldn't be a problem since smartphones and internet are widely available in India.

\section{Taking a vote}

Team is thorn between the App and the travelling exhibition ideas

Each team needs to copy their storyboard to the side of mural to clean up and update it for the leadership organization to be able to come back to them even if the idea is not chosen.

And add an image per sticky note in the storyboard (photo or sketch) for the viewer to better understand the idea visually.

The final vote will be announced on slack.

We will meet tomorrow at 6EDT to prepare for the 8EDT Playback. 


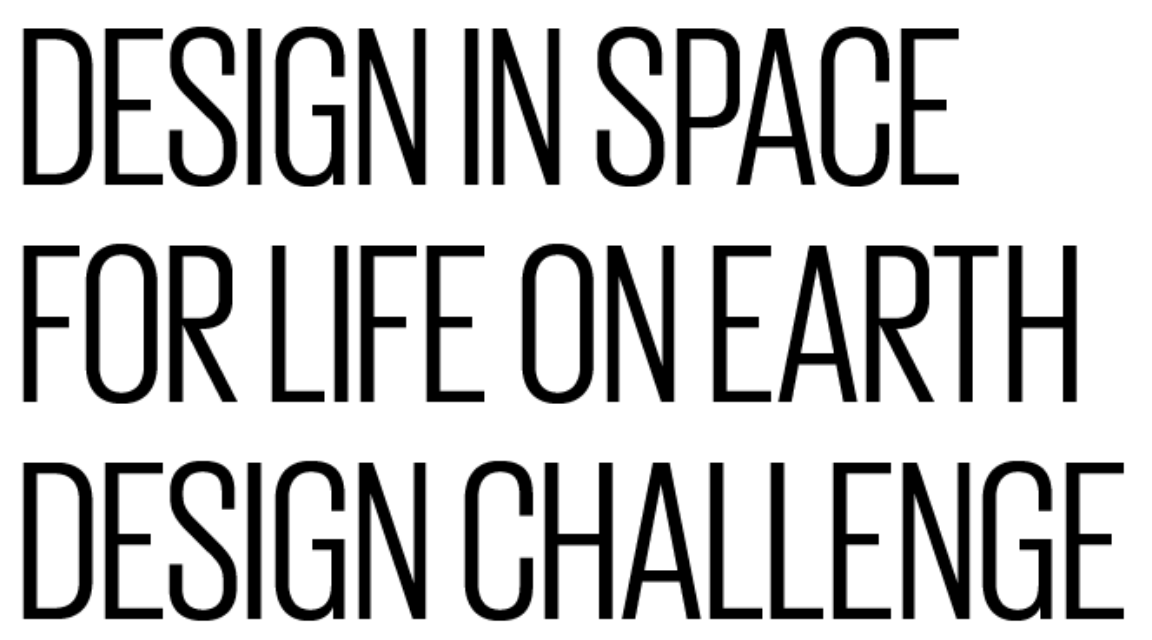

Carleton

School of Industrial Design

Appendix K

Professor Thomas Garvey - Supervisor

Angie Fahlman - Student 


\section{Tables of Contents}

Preface and Summary of experience

Space opportunity visionaries

Objective and three challenge statements

Roles and responsibilities

TEAM 1

Team 1 names and titles

Timeline, creative process and progress diagram

Appendix I - Team 1 Playback 1 presentation

Appendix II - Team 1 Playback 2 presentation

Appendix III - Daily activities

(agenda, homework and meeting notes)

TEAM 2

Team 2 names and titles

Timeline, creative process and progress diagram

Appendix I - Team 2 Playback 1 presentation

Appendix II - Team 2 Playback 2 presentation

Appendix III - Daily activities

(agenda, homework and meeting notes) 
The International Space Station's Design in Space for Life on Earth Challenge provided an optimal glance of research beyond this planet for this planet. At the onset, it became clear that I had minimal understanding of the UN SDGs and how they relate to research opportunities in space. I was also not aware of the impact that space research could have on Earth. Two days into challenge, I discovered that the ISS has three unique selling benefits over the other 3000 satellites presently in space. I stressed this factor to the teams repeatedly to ensure we were narrowing the market.

For this particular challenge, I was the Design Thought Leader for two SDG teams. Due to the dual leadership opportunity, I observed and analysed how two diverse teams with the same Design and Topic Thought Leaders uniquely navigated the design process and generated entirely different results.

The challenge allowed me to view the design process from different perspectives, which has piqued my interest in design sprint processes and whether it should be less structured with minimal guidance or more structured with a defined path. The challenge has allowed me to grow as a design facilitator and has enriched my understanding of the design

\section{Experience Summary}

This summary statement will provide insight into the International Space Station's Design in Space for Life on Earth Challenge. The summary will begin by giving an overview of the challenge and the role of the stakeholders.

A timeline and design process structure will be discussed, which was initially introduced to increase and track progress but took a different route during this challenge for both groups. The Facilitator and participant's predetermined expectations and knowledge base will be explored to establish why some of the distractions occurred. Finally, fostering creative flow and the minimalist approach of planting seeds for creative inspiration will be reviewed.

The challenge began with stakeholders and associates from the World Design Organization and International Space Station (see figures 1 and 2) who streamlined a vast amount directives into three challenges statements. The three challenge statements (See page 4) set the dynamics for an exploratory plan in the three areas of interest. Two of the challenge statements had two teams each, equalling five teams in total. There were two teams for the SDG statement, two teams for the university statement and one team for the business incubators.

A challenge statement team structure was created so that each of the three teams included two thought leaders (a topic and a design thought leader). Each team had one facilitator and a limited amount of participants. 
One facilitator and the two thought leaders created a well-balanced information hierarchy structure. Participates utilized both thought leaders for their areas of expertise. It took time for the facilitators to feel comfortable in their roles, which may be due to their lack of knowledge in the design sprint process, SDGs and ISS as a topic. Both facilitators expressed the importance of being educated before the beginning of the challenge.

It was also difficult for the facilitators and thought leaders to direct the participants through the SDGs' complexity. Both facilitators expressed being at a disadvantage due to the SDG challenge statements' nature compared to the other two challenge statements.

Both facilitators were given the same creative process guidance and instructions. It was interesting to observe that each facilitator took different approaches. While one followed some of the protocol and another choose different aspects to utilize. However, it would have been a better process if both adopted all the requirements to minimize confusion and generate a better structure.

Some of these instructions included:

1) Creating regular meeting times

2) Post on Slack an agenda prior to each meeting

3) Post on Slack clearly written homework instructions after every session

4) Video each meeting and post on Google Docs

5) Take meeting notes each meeting completed by a different participate (in addition to chat messages)

6) Export Miro after each day to use as artifacts and ensure miro maintains the design integrity

The challenge presented a unique and complicated scenario due to the nature of the topic. Participants needed to be continuously redirected from their areas of interest. Most participants felt they were trying to generate a research project on ISS to solve an SDG. The thought leaders and facilitators tried not to derail the disruptive thinking process by giving examples of possible direction alternatives (planting creative seeds). This approach proved fruitful but also was time-consuming as they had to change their lines of thought.

A timeline and design process structure (See figure 5 and 7) for both teams played a vital role in understanding expectations. However, even with the structure, some participants became influenced by other team directions and processes, which may have affected their concentration area or the end product. Although both leaders and the facilitators listened, nurtured and inspired the participants, only a few remained to answer the call to produced a finished product. At the end of the sprint, both teams were excited and eager to make a product that could provide a possible solution that may benefit the planet and ISS's longevity. The teams felt proud of the products they produced, and most are excited for phase two.

Finally, International Space Station's Design in Space for Life on Earth Challenge allowed teams to come together and produce a process and plan that can be broken apart or used as a whole to potentially solve an SDG goal. The well-structured challenge platform allowed teams to concentrate on solving the design goal and be part of the solution. 


\title{
Space Opportunity Visionaries \\ WDO AND ISS NL
}

\author{
Leadership Teams \\ Creative and Topic Thought Leaders \\ Facilitators \\ Participants
}

Together generating opportunities for the future.

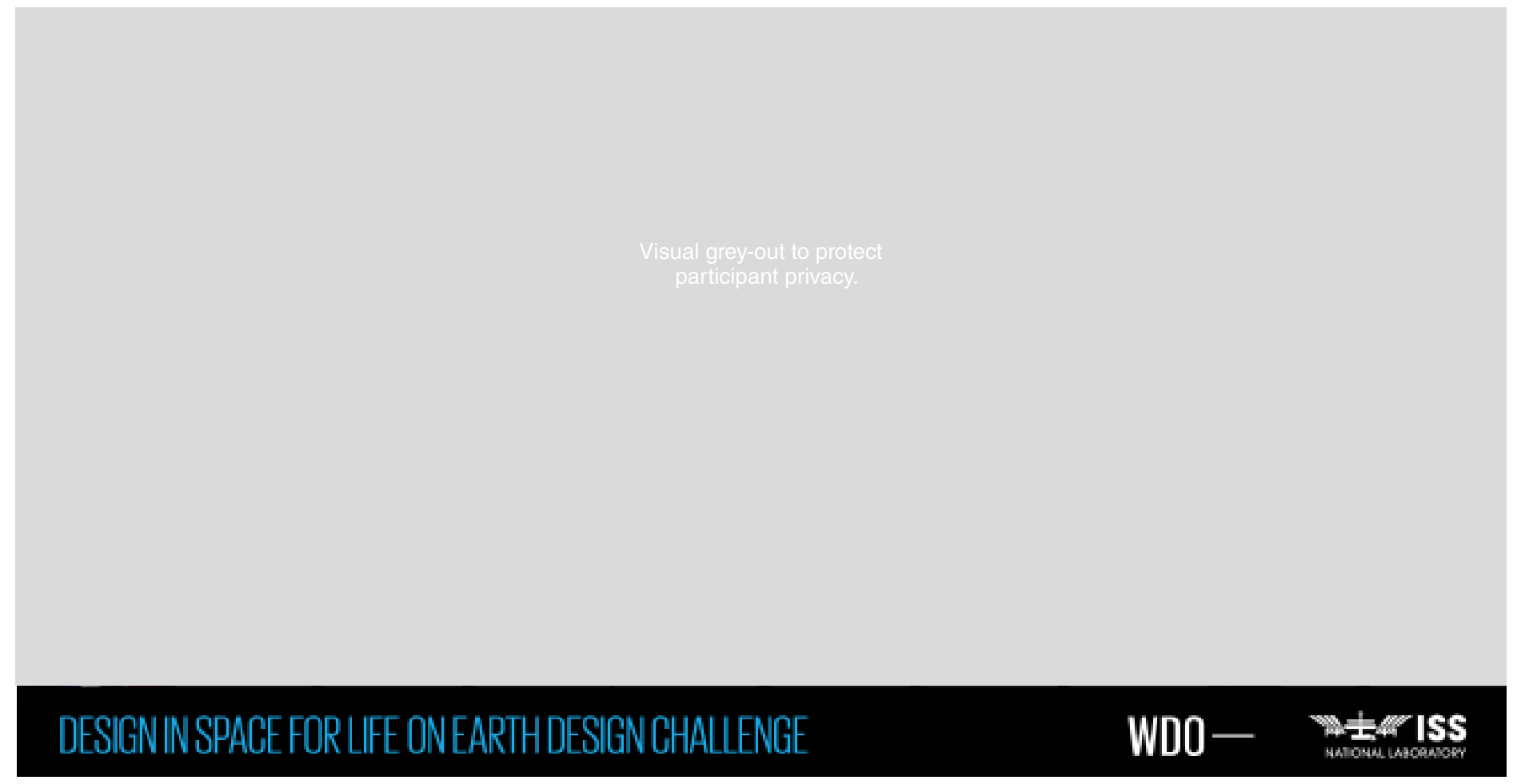

Visual taken by WDO of Zoom Meeting Participants. 


\section{Three Challenge Statements}

\section{Objective}

To create options for ISS to provide opportunities for research to benefit life on earth.

\section{Three Challenge Statements}

1) How can space based research address UN Sustainable Development Goals

2) How can we build an orbital university?

3) How can the ISS become a business incubator?

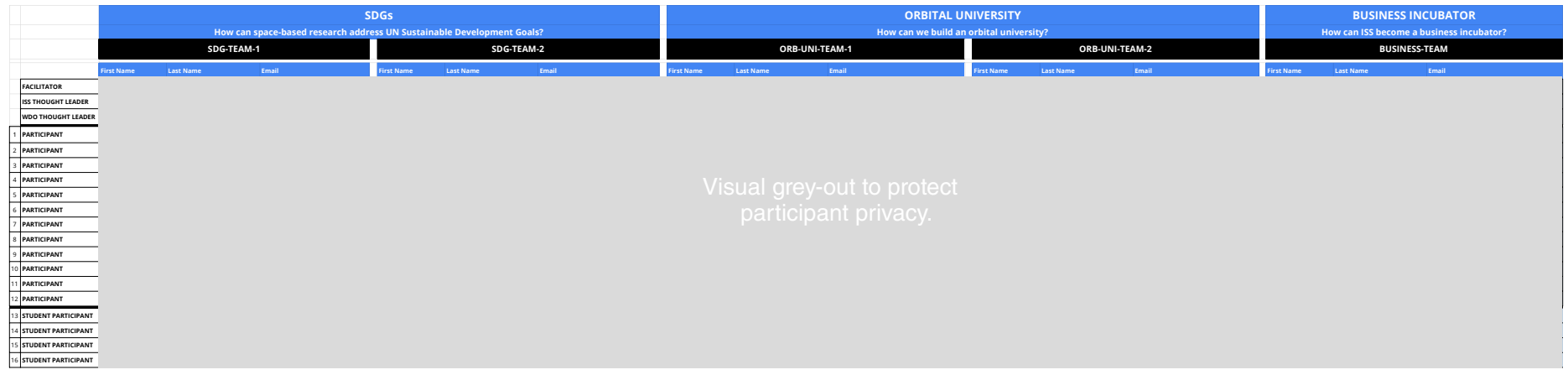

Figure`2. (Spread Sheet Supplied by WDO)

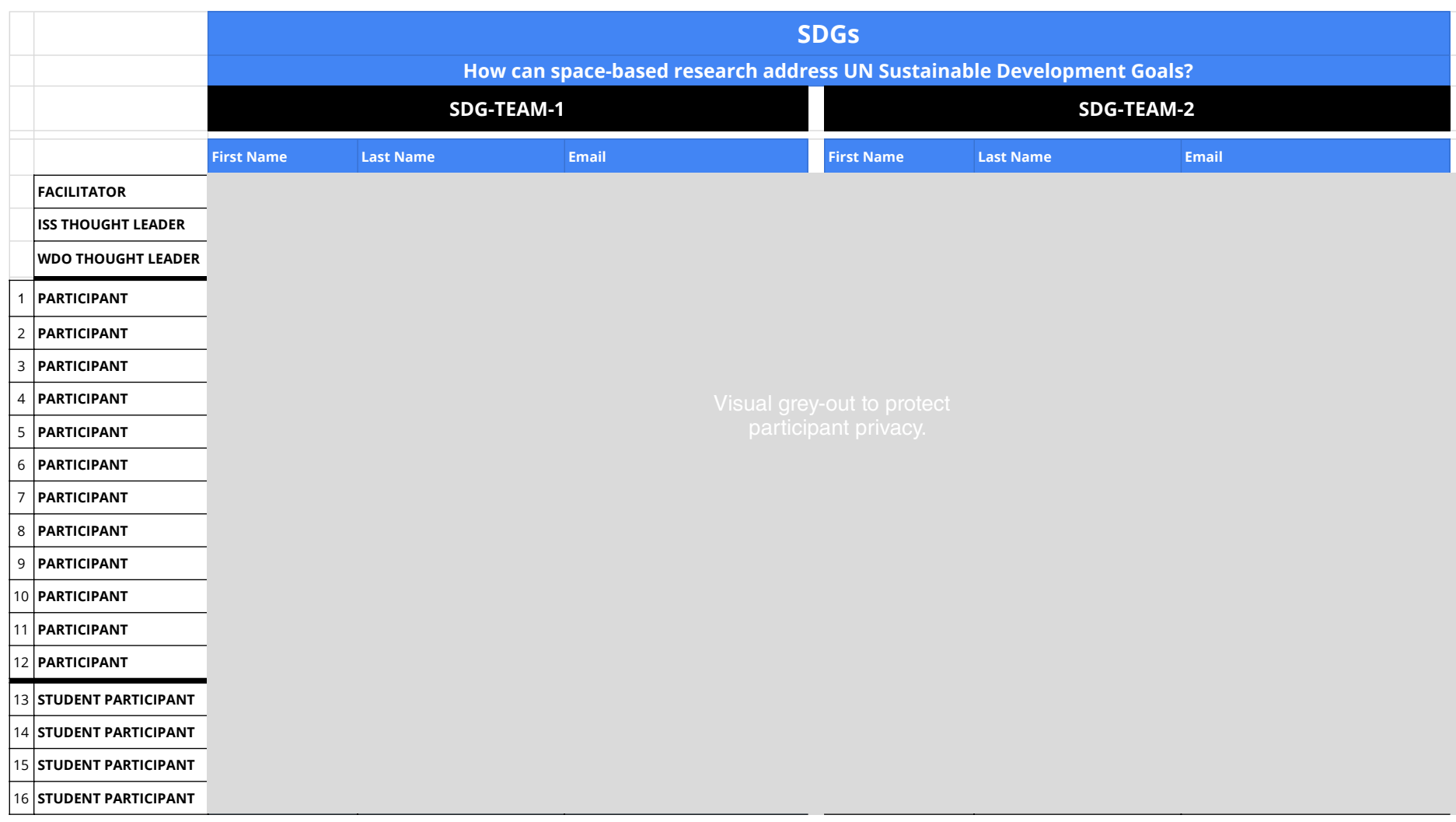

Figure`2. (Spread Sheet Supplied by WDO - only SDGs ) 


\section{Remote collaboration}

\section{Leadership Team}

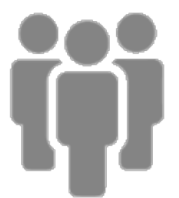

WDO-

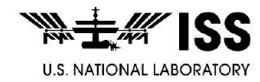

UO U. National LaDoratory U.S. NATONAL LABORATORY

\section{Facilitators}
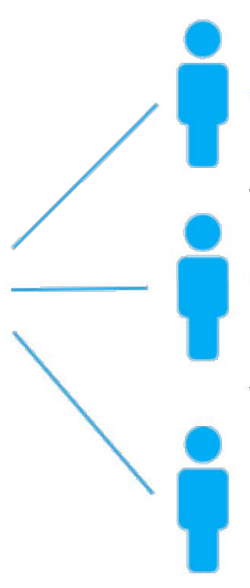

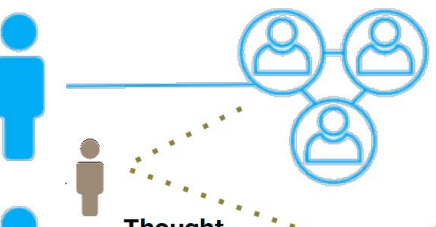

Thought $\cdots$

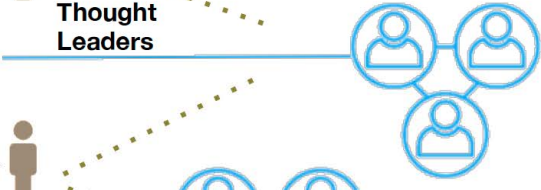

A number of software will be the disposal of all stakeholde including: Miro, Slack, Zoom, TeamUp Calendar and GoogleDrive.

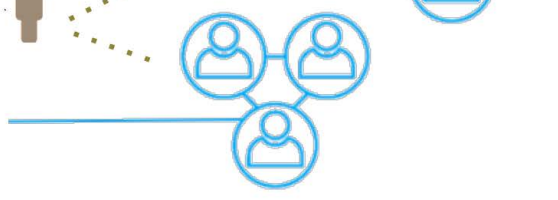

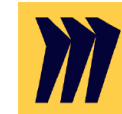

ZoOm

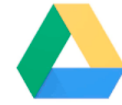

\% slack

\section{Leadership Team}

- Provides overall direction to the project development and management

- Identified facilitators and oversaw participant selection process

- Convene Zoom check-in meetings with team facilitators (Wednesdays)

- Oversee Mural boards

- Serve as a point of contact to facilitators and thought leaders on Slack

- Attend playbacks (Fridays)

- Drafts and circulates all material related to project
Thought Leaders

Provide expert input to team project development

- Provide relevant direction/guidance to the team/facilitators

- Encourage team to push boundaries and explore

- Attend team meetings and playbacks as time allows

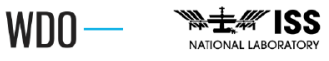

Facilitators

- At least one facilitator per team

- Facilitators will be assigned to team and given the email addresses of team members

- Convene meetings (daily or other as determined by team)

- Oversee the team Miro board, online workshopping and collaboration

- Serve as a point of contact for team members on Slack channels

- Manage work assignments between calls

- Relay progress reports to leadership team (Mondays and Wednesdays)

- Access Slack Channel for Facilitators

- Attend playbacks (Fridays)

Commitment

4 hours daily on average (including weekends) 


\section{SDG - Team 1}




\section{SDG - Team 1}

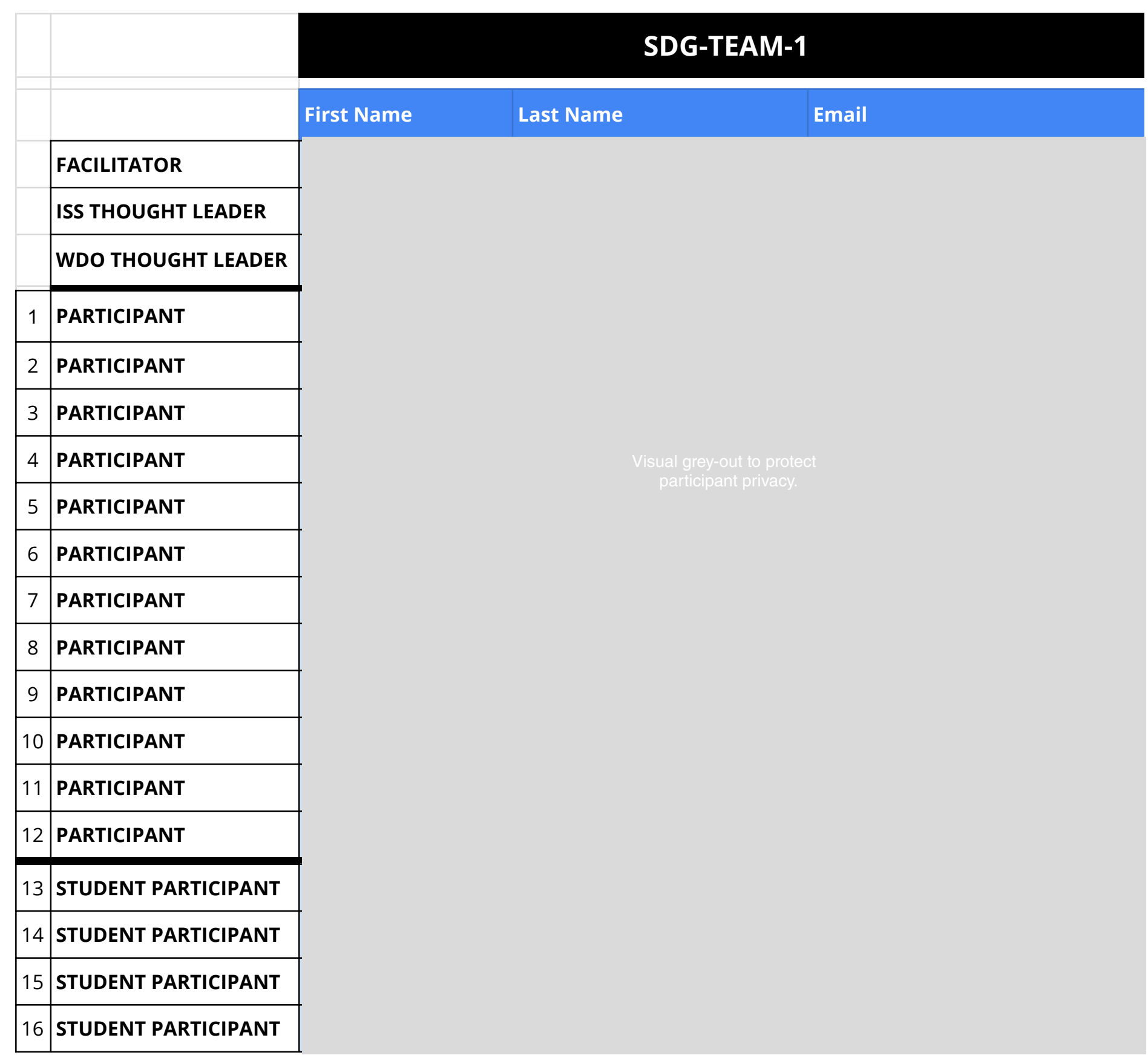




\section{SDG - Team 1 - Timeline, Creative Process and Progress}
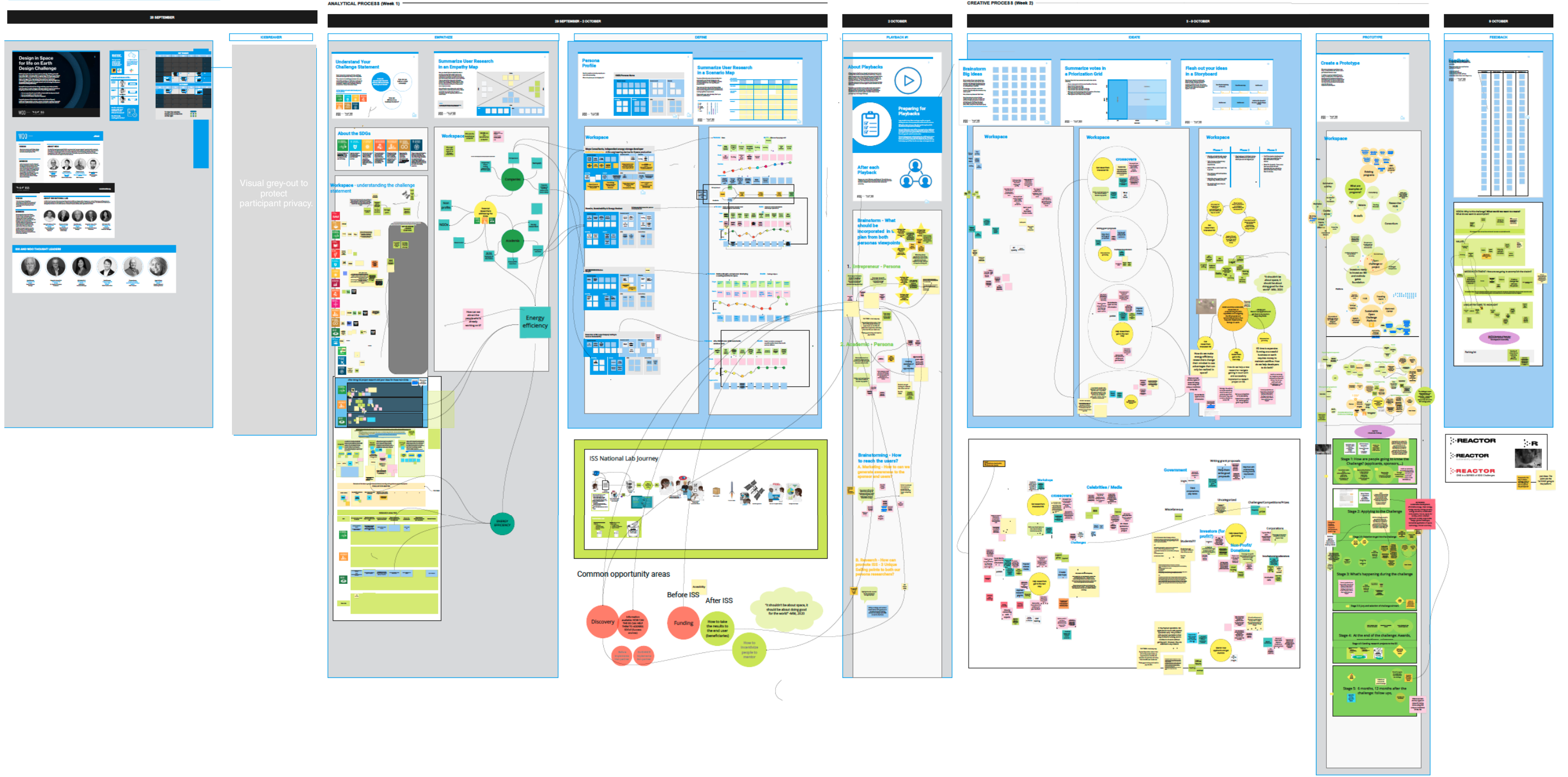


\section{Appendix I TEAM 1 PLAYBACK 1 \\ Presentation}




\section{Appendix I}

\section{TEAM 1 PLAYBACK 1}

Presentation

\section{Design in Space for life on Earth Design Challenge}

\section{Team 2}

SDG Team 2

How can space based research address UN

Sustainable Development Goals?

WDO-

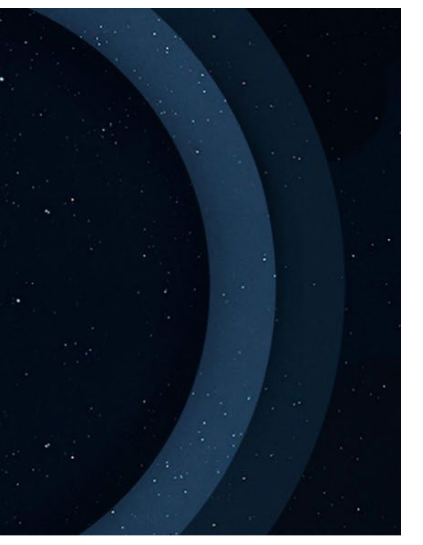

Structure

Context

Design Goal

Opportunity

What's Next

Meet The Team

WDO - Mt丝 ISS

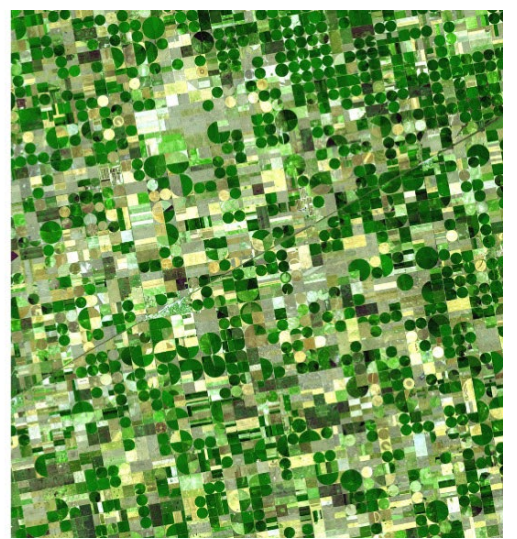

Exploring the SDGs

We chose the SDGs that would be impacted most by space-based research.

Team members offered lots of ideas to start and were inspired to begin working together.

We decided to take a satelite view and to focus on what the ISS has to offer as a unique laboratory

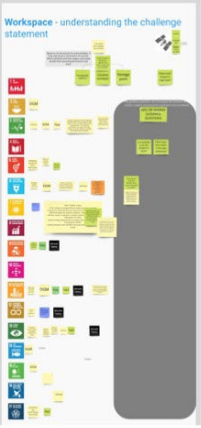

WDO Mter ISS
High Focus SDGs

- 3-Good health and well-being

11 - Sustainable cities and communities

- 13 - Climate action

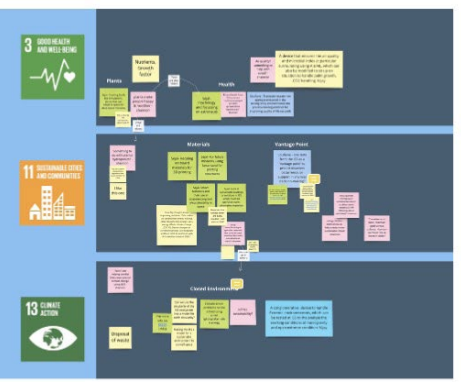

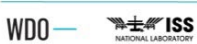

ISS Unique Experimental Conditions

Our team then broke out into
research focus groups in the
areas where ISs provides areas where ISS provides unique opportunities:

\section{Microgravity}

Extreme Conditions

Unique Vantage Point
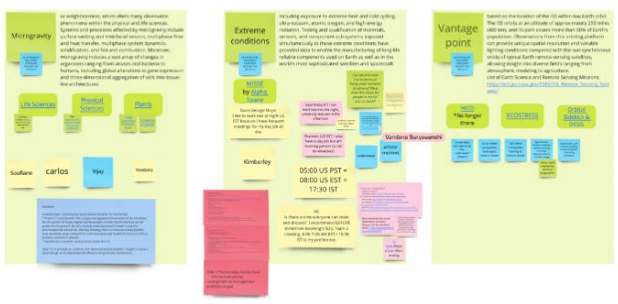

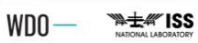

(Team 2 / SDG Team 2

\section{Next Steps}

Now that our team has focused in on which SDGs we are interested in looking at, and done some background research into the unique aspects of
working with the ISS, we have defined the following next steps:

We would like to spend more time defining the problem and understanding who our project impacts before proposing a solution

Identifying the stakenolders for this project, including: End beneficiaries here on Eart

Potential partnerships (governments, institutions, etc)

We are plotting out our research findings based on relevance to the SDGs,

Evaluating each of our idea themes across:
Is it possible to do it on Earth?

Is it possible to do it on Earth?
How many main SDGs are addressed?

How many main SDGs are addressed?
Which qualities make space-based rese

technology transter officece?
Or more useful to a high-impact spinoff?

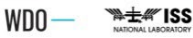

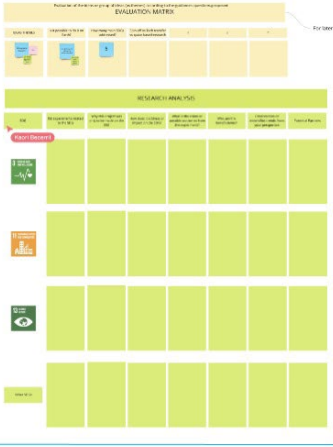

SDG Team 2 Participants

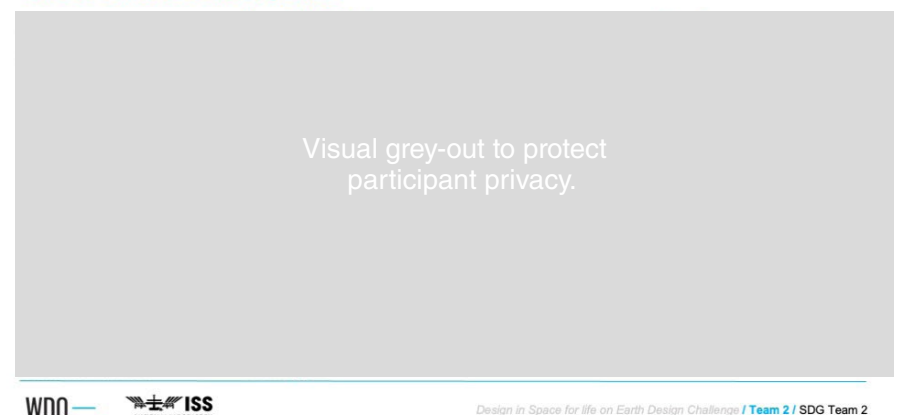




\section{Appendix II}

TEAM 1 PLAYBACK 2

Presentation 


\section{Appendix II}

\section{TEAM 1 PLAYBACK 2}

Presentation

\section{Design in Space for life on Earth Design Challenge}

Team 2

SDG Team 2

How can space based research address UN

Sustainable Development Goals?

WDO-

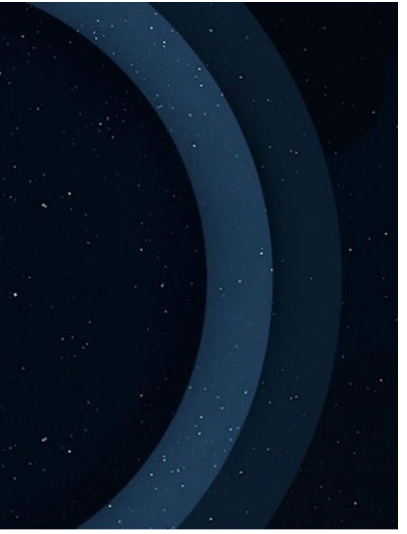

Structure

Context

Design Goal

Opportunity

What's Next

Meet The Team

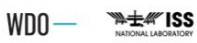

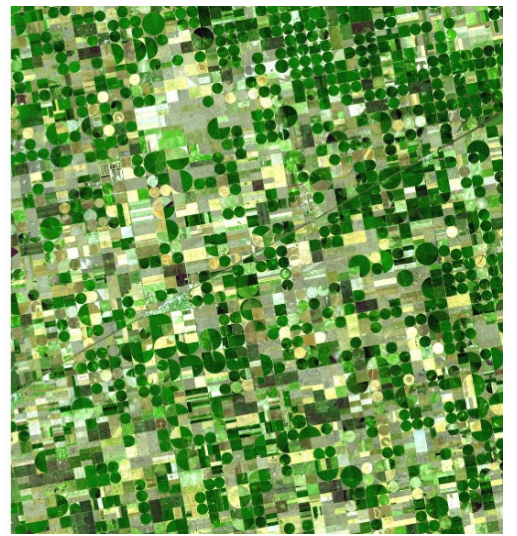

Exploring the SDGs

We chose the SDGs that would be impacted most by space-based research.

Team members offered lots of ideas to start and were inspired to begin working together.

We decided to take a satellite view and to focus on what the ISS has to offer as a unique laboratory.

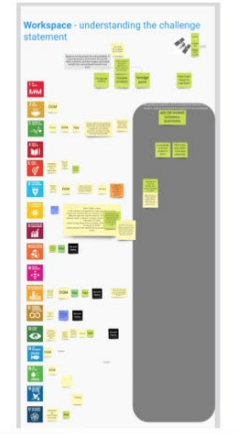

WDO - MDEISS
High Focus SDGs

3-Good health and well-being

- 11 - Sustainable cities and communities

- 13 - Climate action

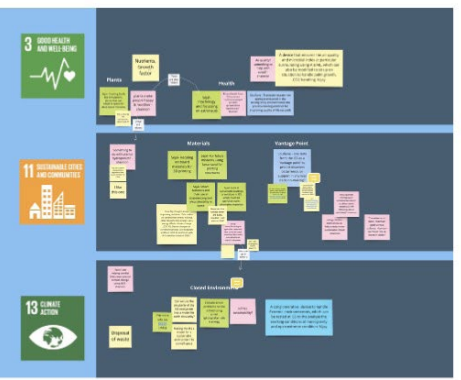

WDO - m.terISs
ISS Unique Experimental Conditions

Our team then broke out into areas where ISS provides unique opportunities:

\section{Microgravity}

Extreme Conditions

Unique Vantage Point
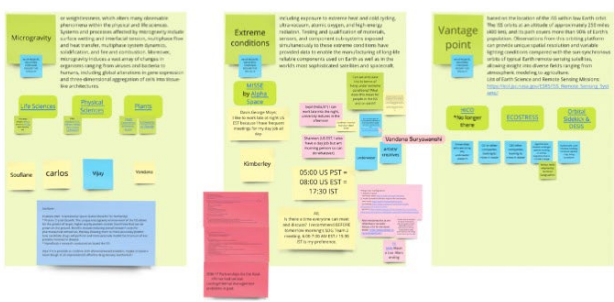

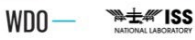

Team 2/ SDG Team 2

\section{Next Steps}

Now that our team has focused in on which SDGs we are interested in looking at, and done some background research into the unique aspects of
working with the ISS, we have defined the following next steps:

We would like to spend more time defining the problem and understanding who our project impacts before proposing a solution

Identifying the stakeholders for this project, including. End beneficiaries here on Eart

Potential partnerships (governments, institutions, etc)

We are plotting out our research findings based on relevance to the SDGs, possible outcomes of the experiment, and who are the beneficiaries.

Evaluating each of our idea themes acros:

Is it possible to do it on Earth?
How many main SDGs are addressed?

How many main SDGs are addressed?
Which qualities make space-based rese

technology transter officece?
Or more useful to a high-impact spinoff?

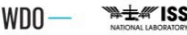

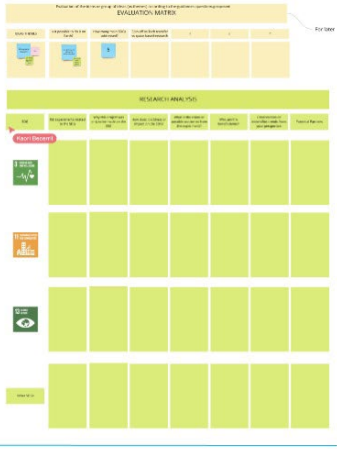

High Focus SDGs

\begin{tabular}{ll}
\hline Stephan Reckie & City, Country \\
\hline Vandana Suryawanshi & Pune, India \\
\hline Vijayakomagan M S & Chennai, India \\
\hline \hline \\
\hline \\
\hline \\
\hline \\
\hline \\
\hline \\
\hline
\end{tabular}

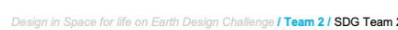

\begin{tabular}{ll}
\hline Abdul Rahman & Islamabad, Pakistan \\
\hline Angie Fahlman & Ottawa, Canada \\
\hline Carlos Balderas & Puebla, Mexico \\
\hline Davis George Moye & Florida, USA \\
\hline Kaori Becerril & Mexico City, USA \\
\hline Kimberly Miner & Washington DC, USA \\
\hline Klara Anna Capova & Cily, Country \\
\hline Mark Vanderbeeken & Turin, Italy \\
\hline Melodie Yashar & Los Angeles, USA \\
\hline Miki Sode & San Jose, USA \\
\hline Sejal Budholiya & Bangalore, India \\
\hline Shannon Case & Boston, USA \\
\hline Soufiane El Fassi & Bedford, UK \\
\hline WDO- & \\
\hline
\end{tabular}

WDO -

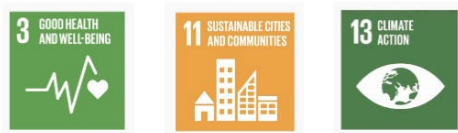

WDO- m士 Iss 
High Focus SDGs
- 3 - Good health and well-being
- 11 - Sustainable cities and communities
- 13 - Climate action

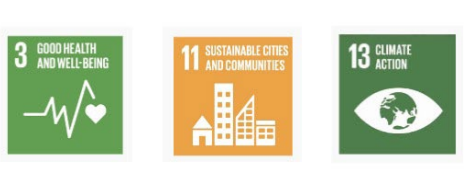

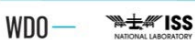

Title
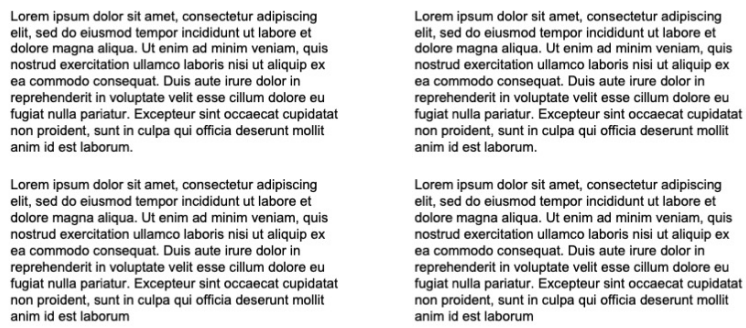

WDO-
Bridge the Gap between Sustainability and Space

$$
\begin{aligned}
& \text { Begin with SDG } 7 \text { researchers: } \\
& \text { Photooltaics } \\
& \vdots \text { Energy storage } \\
& \text { Power distribution } \\
& \text { HVAC }
\end{aligned}
$$

\section{E曰г।}

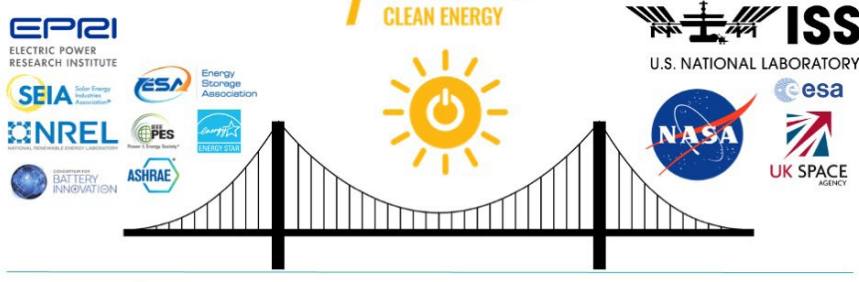

WDO-

\section{AFFORDABIEAND CLEAN ENERGY}

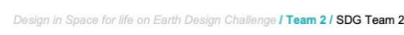

Build Community

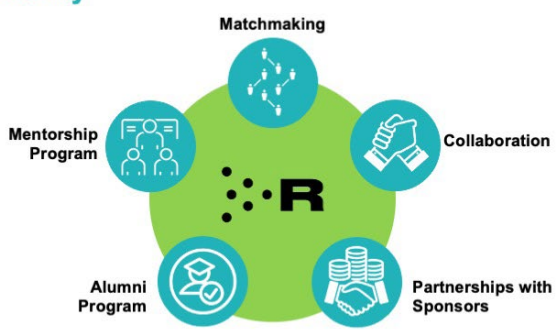

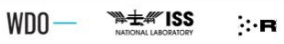

\section{Next Steps}

To understand the gap and delivering values to meet SDG targets \& indicators:

- Direct tie between space-based research and SDG targets \& indicators.

- Deepening understanding of stakeholder needs.

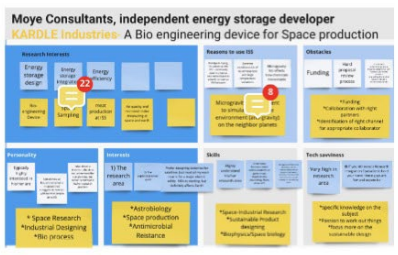

WDO-

\section{Conclusion}

- Proposed REACTOR Sustainability Challenge to use space-based research to address UN SDGs Sustainable Development Goals.

$\circ 6$ stages

- Bridges gap between Sustainability and Space

- Builds community of Sustainability and Space

- Celebrates achievements: Successful and Failed

- Next Step: Understand gaps and how to meet SDG

WDO-
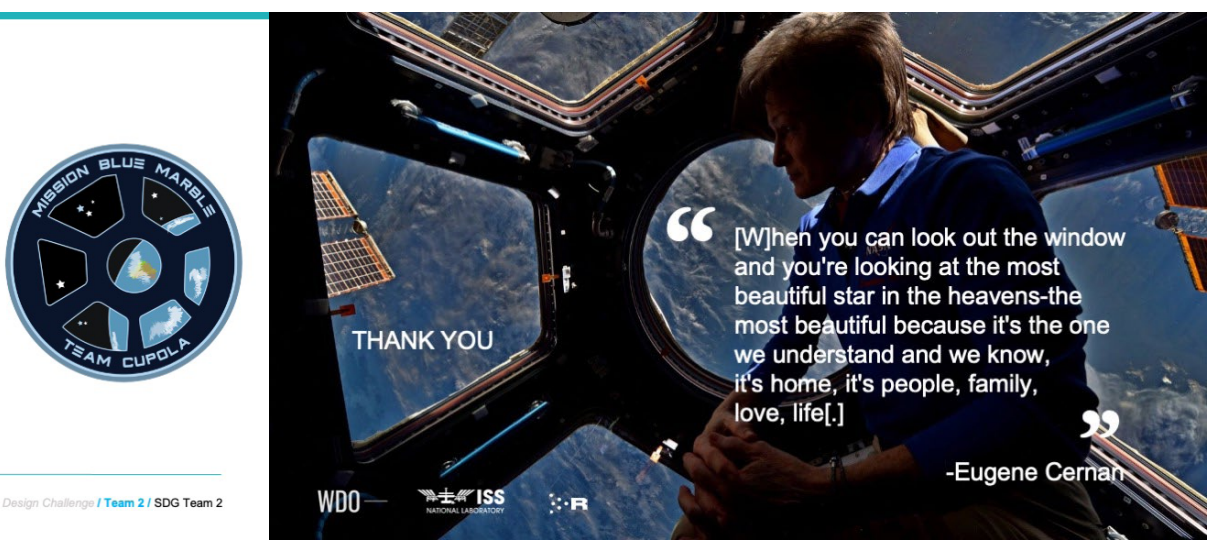


\section{SDG7 Affordable and Clean Energy}

SDG7 Ensure access to affordable, reliable, sustainable and modern energy for all

7.1 By 2030, ensure universal access to affordable, reliable, and modern energy services 7.2 Increase substantially the share of renewable energy in the global energy mix by

.3 double the global rate of improvement in energy efficiency by 2030

7.a By 2030, enhance international cooperation to facilitate access to clean energy

research and technologies, including renewable energy, energy efficiency, and advanced

and cleaner fossil fuel technologies, and promote investment in energy infrastructure and

clean energy technologies

7.b By 2030, expand infrastructure and upgrade technology for supplying modern and

sustainable energy services for all in developing countries, particularly LDCs and SIDS

WDO - "IDEIISS

Descign in Space for life an Earth Design Challengo / Team 2 / SDG Team 2

iCARE

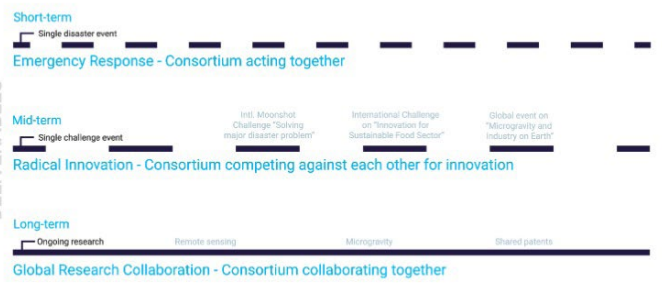

WDO- Mt MISS

\section{iCARE Prototype plan}

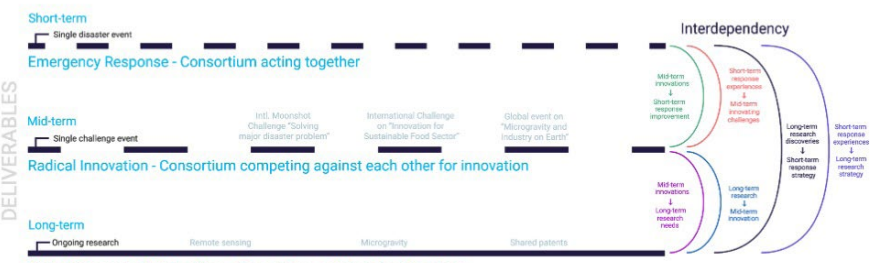

Global Research Collaboration - Consortium collaborating together

WDO - M士EIISS

Design in Space for lite on Earh Design challenge / Team 1 / C CARE

iCARE Prototype plan

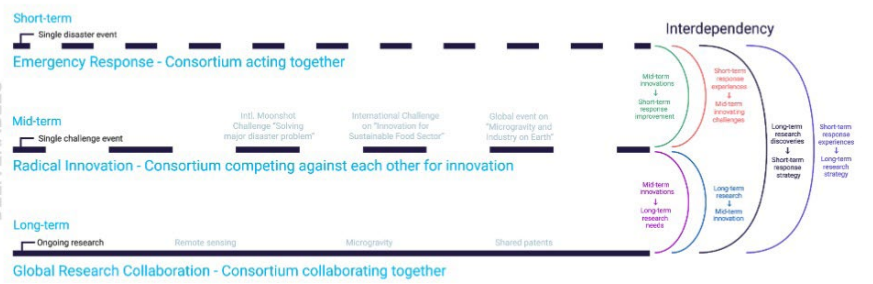

WDO

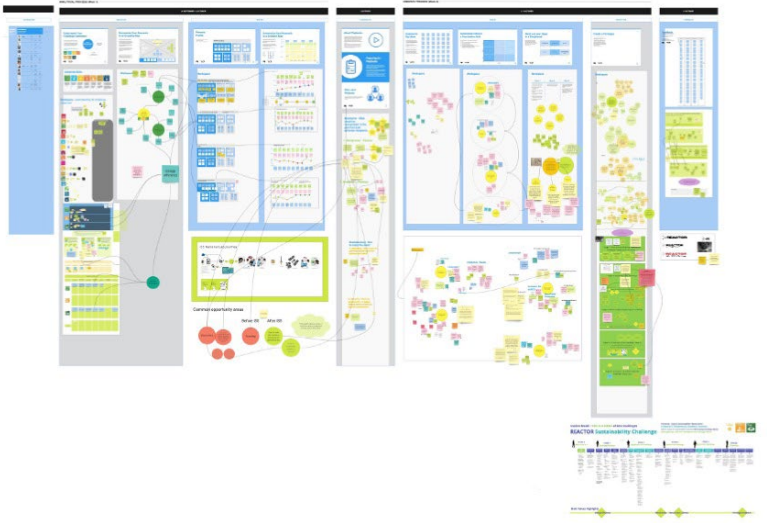

iCARE

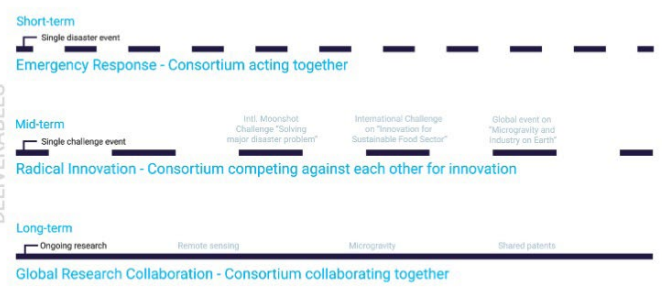

WDO- Mt:

Design in Space for life on Earth Design Challenge / Team 1 / ICARE

iCARE Prototype plan
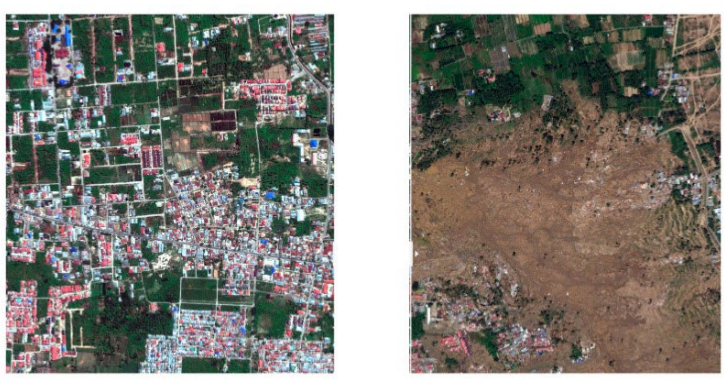

WDO

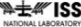

Design in Space for life on Earth Design Challenge / Team $1 /$ / CAPE 
Monitor Interventions

and Track KPIs to

ISS Objectives

Value Privers Success Measures

Measure Outcomes

As we integrate learning from

space research on earth and create

to closely track the progress of

these interventions to ensure

maximum value and al
strategic goals of ISS.

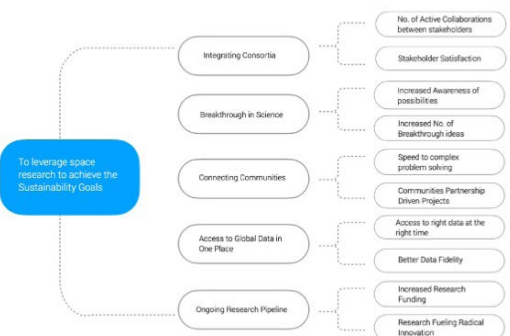

WDO - MIUIISS

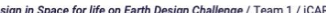

Team Members

Thank You!
WDO - M\#世ISS

Team Members

Future Plans
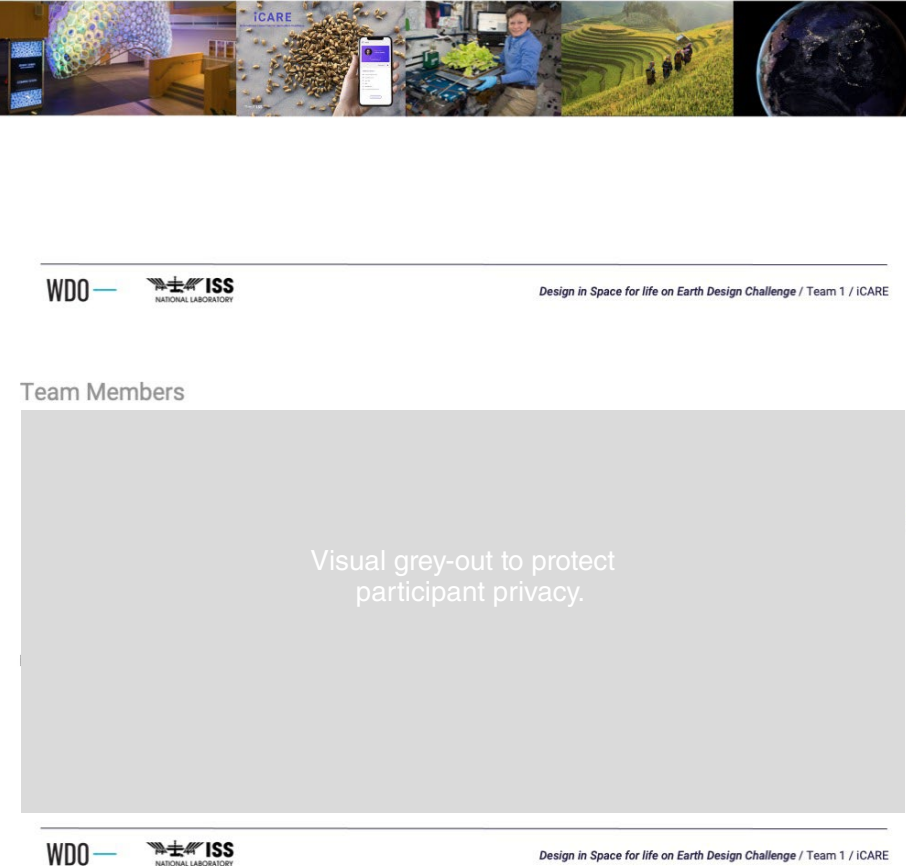


\section{Appendix III \\ TEAM 1 DAILY ACTIVITIES}

Agenda

Homework

Meeting Notes 

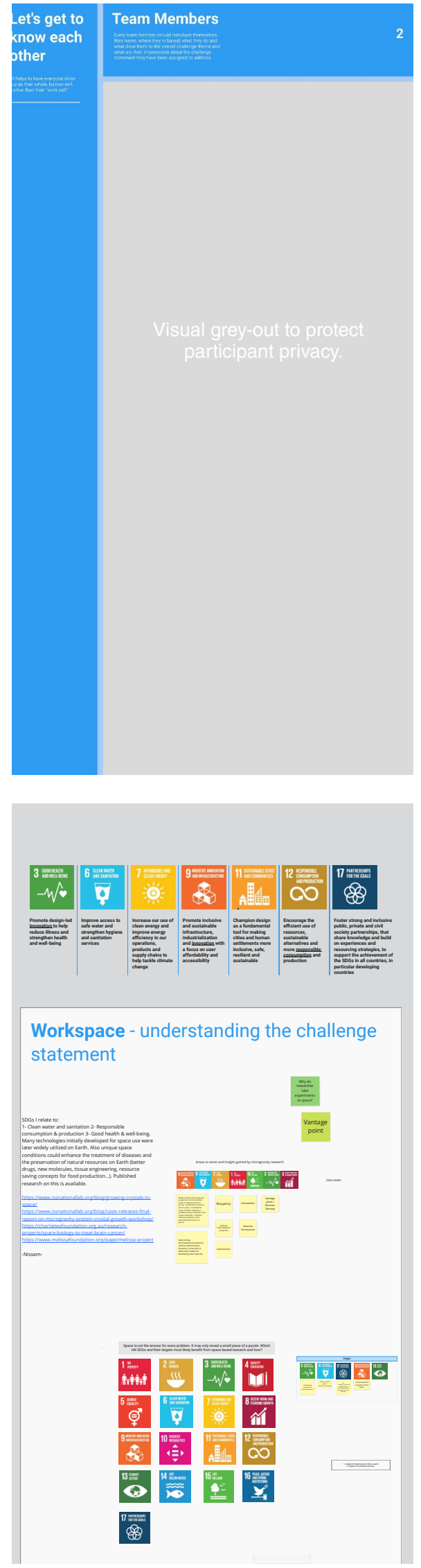

\section{SEPTEMBER 28}

\section{AGENDA AND RECORDINGS}

\section{MEETINGS Recordings}

Mon, 28 Sept 2020, 18:55

Meeting Recording:

https://eu01web.zoom.us/rec/share/-r3yCwRJ9ftb8IU2agHdZvmMNI1L5AolxdjxJ3xuuNLo_Cp_ny53SvW8jKUZ15VR._qV3dO1JsSK87NJe

\section{Agenda}

1) Review statement

2) General rules and guidelines

3) Introduction to leaders and participant.

\section{Homework}

1) Enter your time availability Slack Polly Pole.

2) Miro - Complete Ice Breaker for Team Members (picture, name, location, title background and your motivation to challenge)

3) Google Docs - Review Miki's two papers.

\section{SEPTEMBER 29 \\ AGENDA AND RECORDING}

\section{MEETING Recordings}

Tue, 29 Sept 2020, 16:57

Meeting Recording:

https://eu01web.zoom.us/rec/share/YEbLrDLX3y20XvyqApwYHGnavjU7h19esjOiWvWT79RWUbMkZp3gerXDp-RGalh7.L-XWPFHMGs8qJ_j5

\section{Agenda}

1) Review SDGs

2) Explore what the SDGs mean to statement.

Homework

1) Enter thought on SDGs

2) Miro - Completed exercise. 

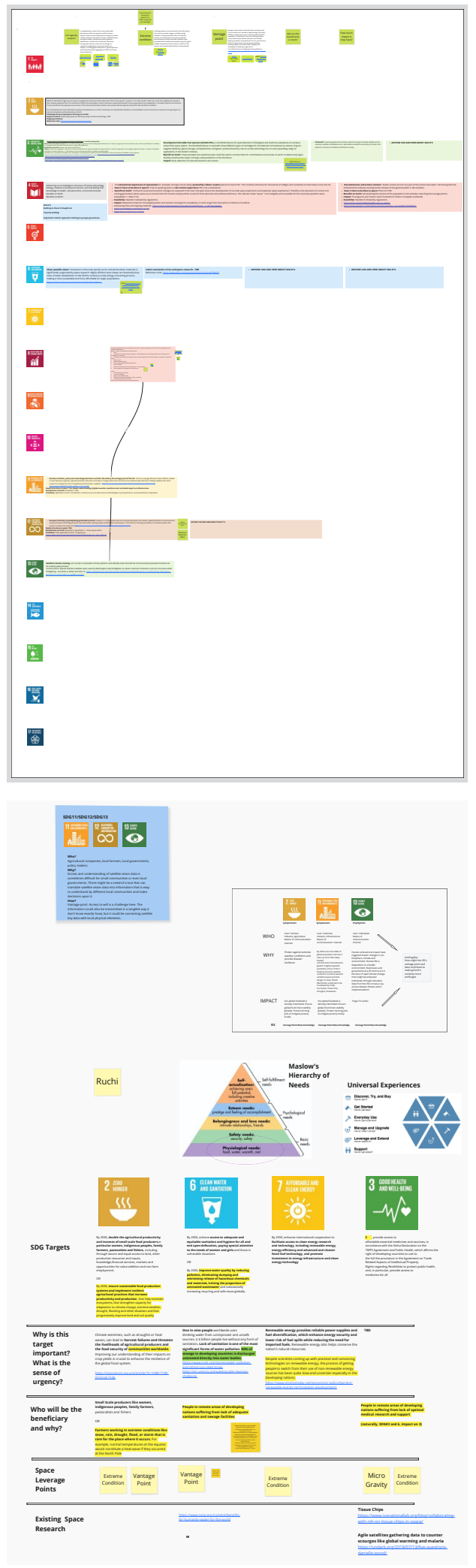

Persona

Profile

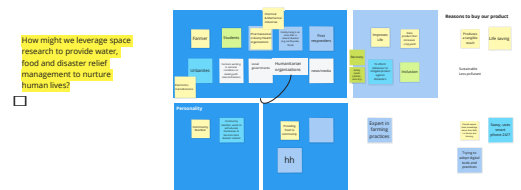

SEPTEMBER 30

AGENDA AND RECORDINGS

\section{MEETING Recordings}

Wed, 30 Sept 2020, 19:01

Meeting Recording:

https://eu01 web.zoom.us/rec/share/SQS1W8z6eyyz1DnwvrAQsg1d4ZCzStvcbC-HAM1a9ksdrBv_p2L0Bn6Ue7UkH7LL.GSG1WYifFSMTPWdc

\section{Agenda}

1) VOTE on SDGs and their importance.

2) Explore what the SDGs mean to statement.

Homework

1) Explore in-depth SDGs

2) Answer Who, Why and the Impact of the winning SDGs

\section{OCTOBER 1}

\section{AGENDA AND RECORDINGS}

\section{MEETINGS Recordings}

Thu, 01 Oct 2020, 17:06:

Meeting Recording:

https://eu01web.zoom.us/rec/share/dzU2BaZyMOM5y05pPKN-mVMsn-

vhURKFUeZYpjL9utsnHMk_a-HI9q4KxBahWfWtU.Q6OJQorihp0FBOiC

\section{Agenda}

1) Review the targets for SDGs 2, 3, 6, 7 and 4 main questions.

Homework

1) Explore Persona - The end user and beneficiary.

\section{OCTOBER 2}

\section{AGENDA AND RECORDINGS}

\section{MEETINGS Recordings}

Fri, 2 Oct 2020, 17:08:

Meeting Recording: https://eu01web.zoom.us/rec/share/cKud09AAuya2v2ubS5QFBmxm2fcFyWWjiPQu2hYc4DFhwR322Z9Qx1hwuKkJybMs.gcdObQOkcilVDYB_

Agenda

1) Review Persona 

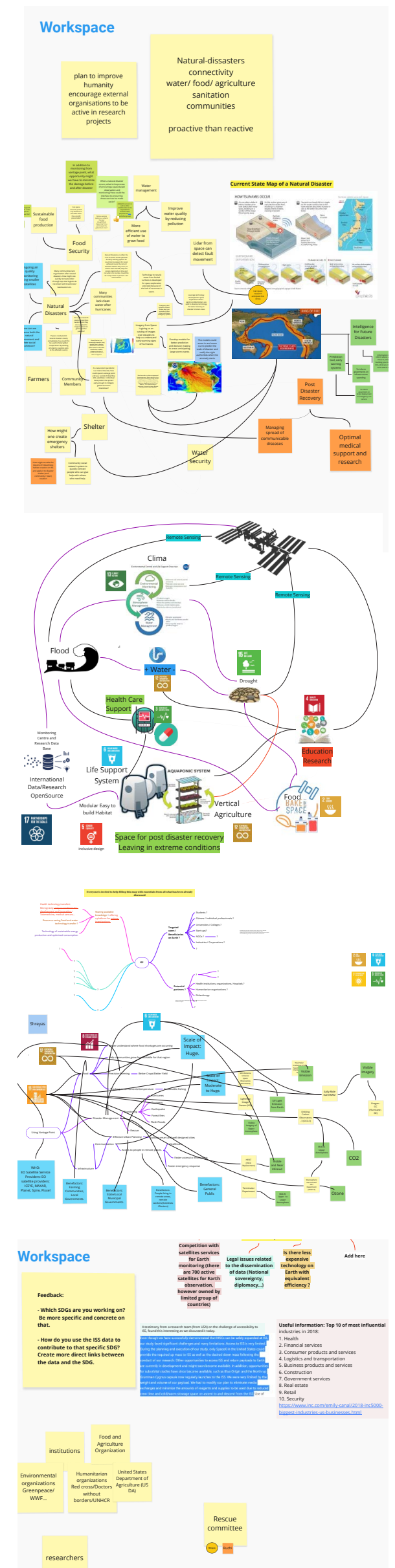

Homework

1) Enter thoughts on Natural Disaster, who responds to them, who benefits from research from the disasters.

\section{OCTOBER 4}

\section{AGENDA AND RECORDINGS}

\section{MEETINGS Recordings}

Sun, 04 Oct 2020, 16:59

Meeting Recording:

https://eu01web.zoom.us/rec/share/0uDwnQzW5Yybcg_8z8YC-O3t6fH-

6BF_NC4b_rVADAb4sJV_IR9gzkrszrmdkrFAb.xXG-0qWqvyv6LUzS

\section{Agenda}

1) Review Natural Disaster network

2) Complete disruptive thinking

Homework

1) Examine ISS network in collaboration with disaster network

2) Miro - Completed exercise.

\section{OCTOBER 5-7}

\section{AGENDA AND RECORDINGS}

Agenda

1) Restructed thinking to examined SDGs again and see if anything missing

2) Examine other satellite competitors

3) Examine food industry

4) Global disaster resilience

5) Disaster management

Homework

1) Establish design goals, end user, determine plan or product.

2) Look at storyboard. 

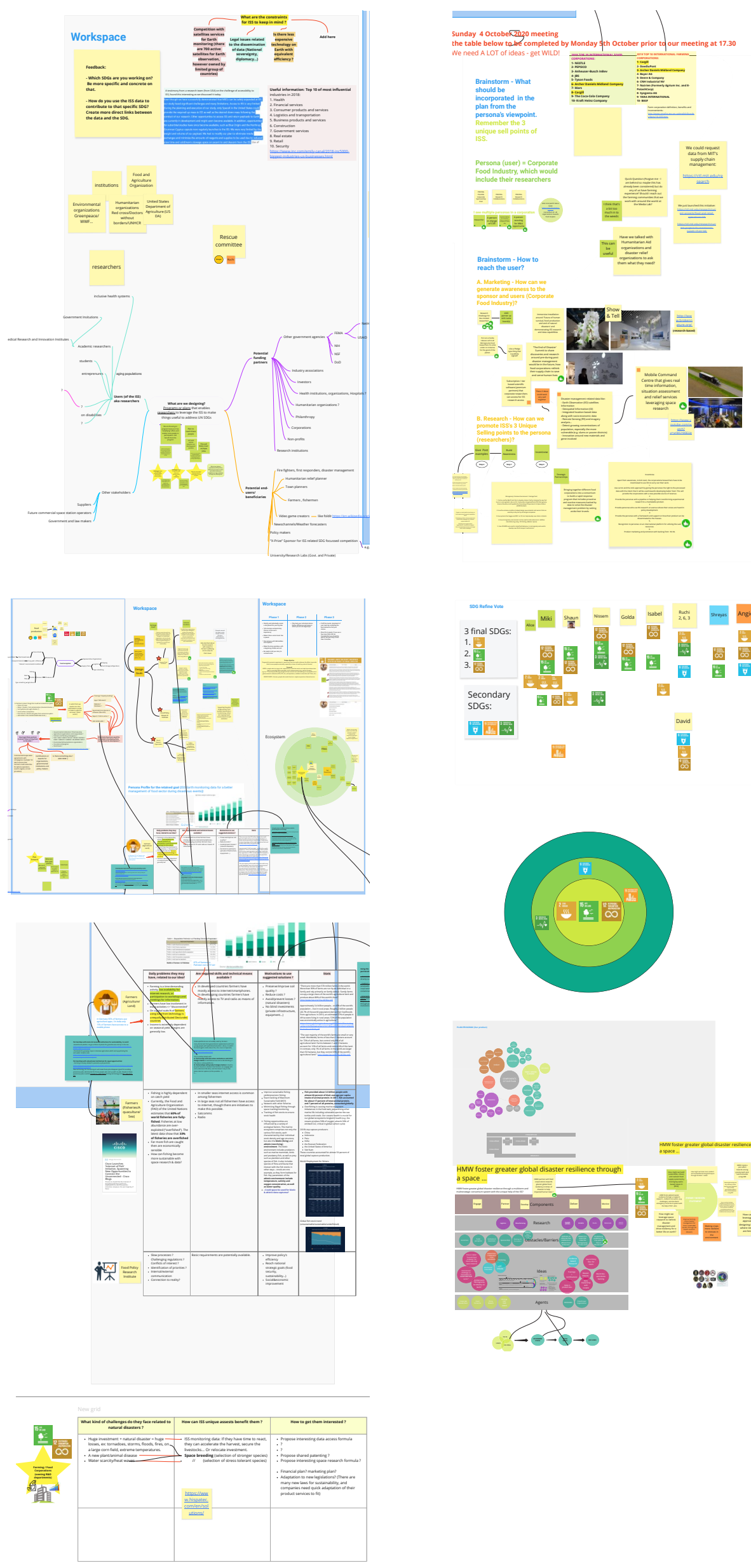

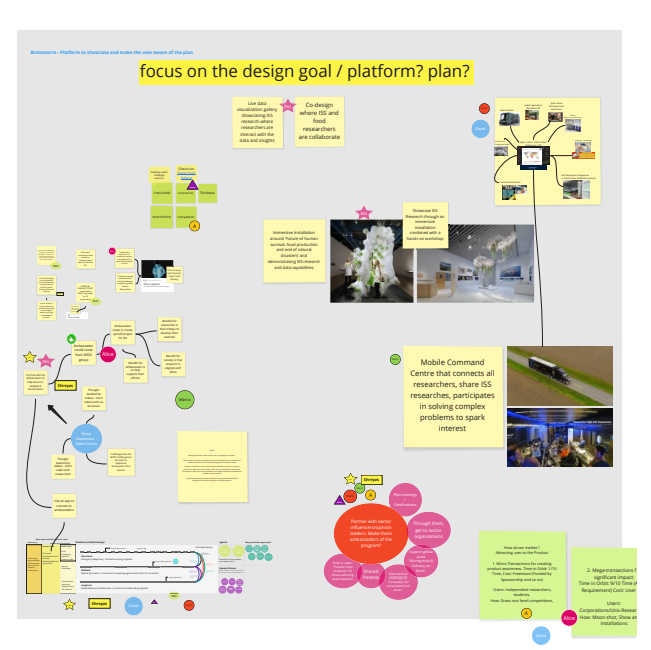

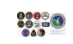

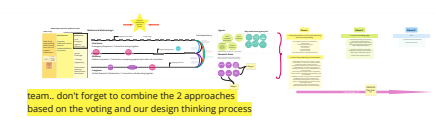

Approach Model
Long-term CONSORTIUMM

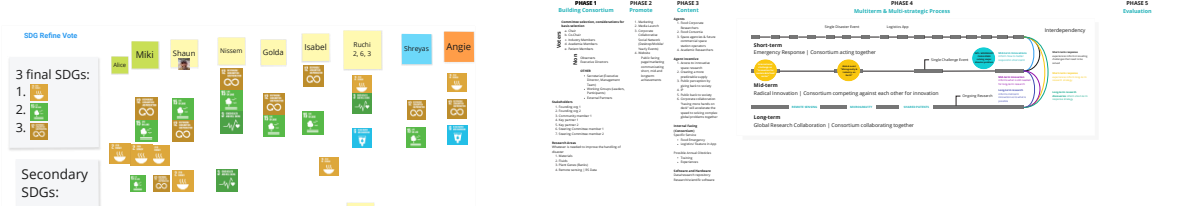

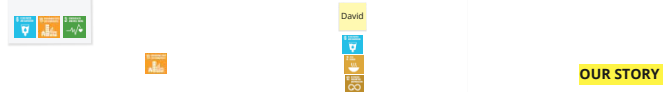

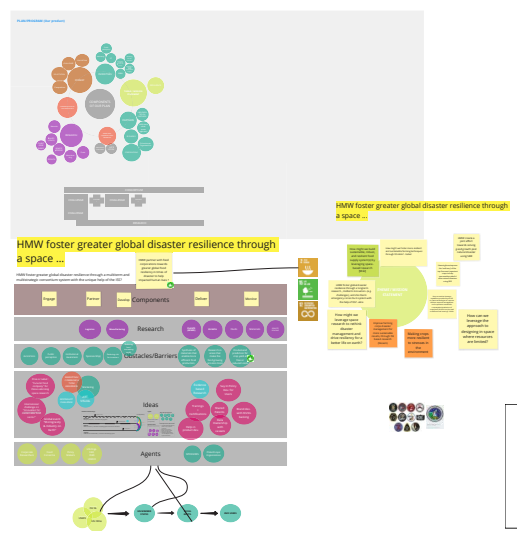

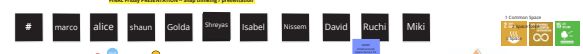

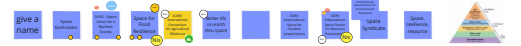

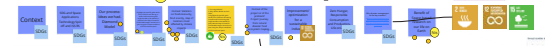

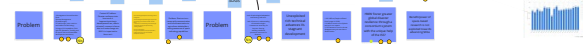

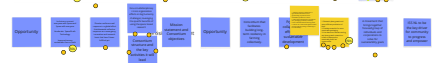

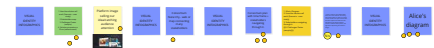

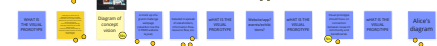

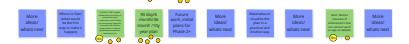

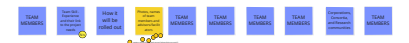

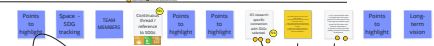

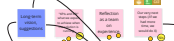
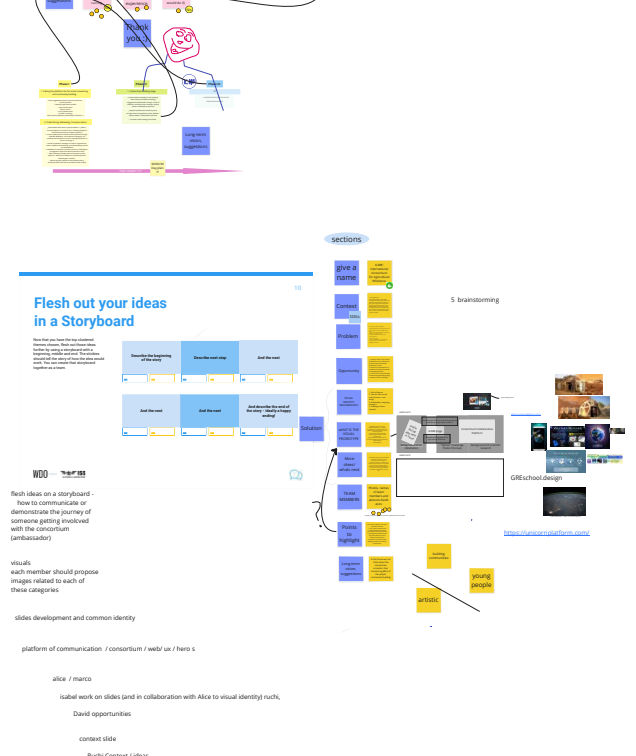


\section{SDG - Team 2}




\section{SDG - Team 2}

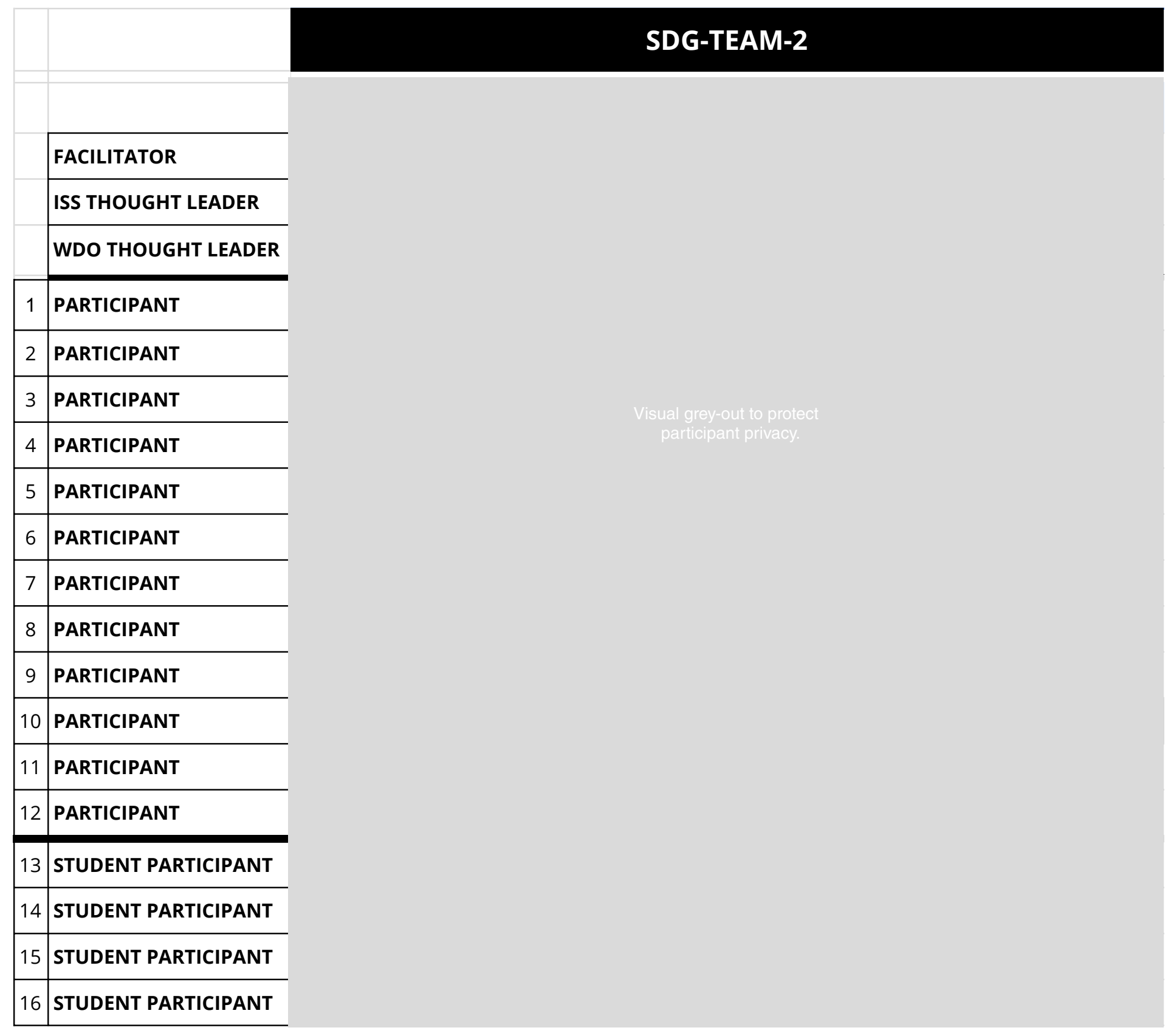




\section{SDG - Team 2 - Timeline, Creative Process and Progress}

Figure 7. - Team 21 Miro Board
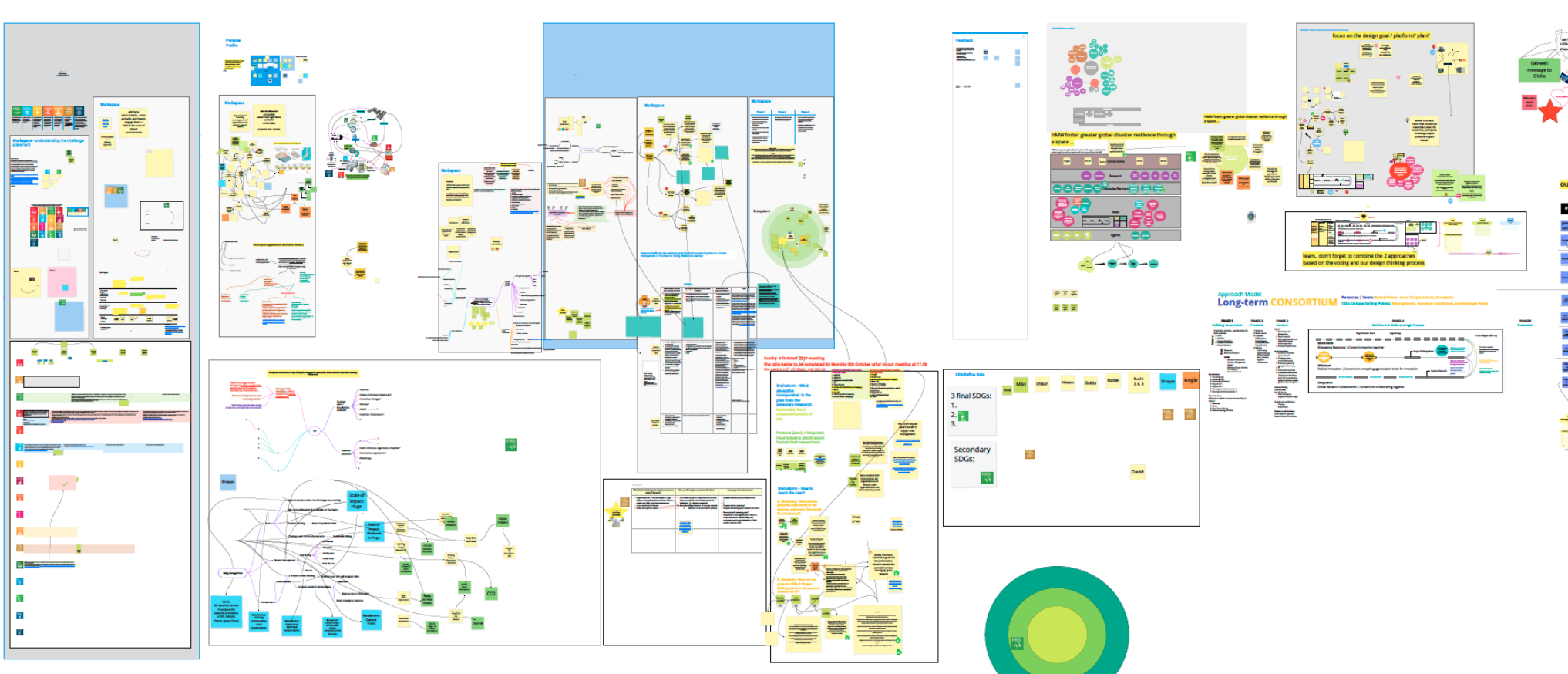

$=$

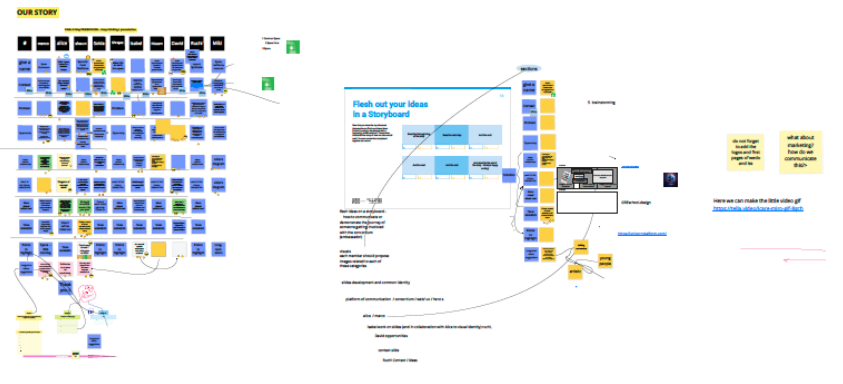




\section{Appendix IV \\ TEAM 2 PLAYBACK 1}

Presentation 


\section{Appendix IV}

\section{TEAM 2 PLAYBACK 1}

Presentation

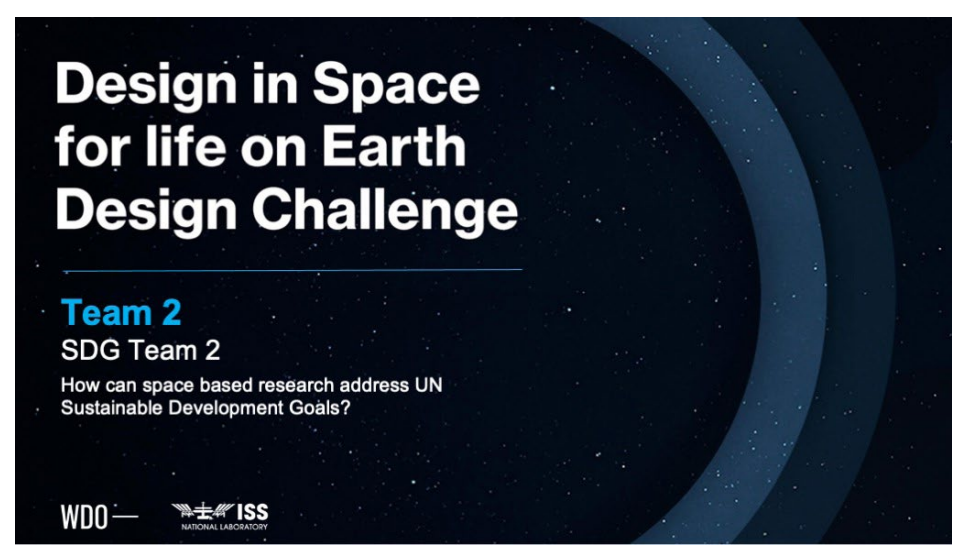

Structure

Context

Design Goal

Opportunity

What's Next

Meet The Team

WDO- Mtyris

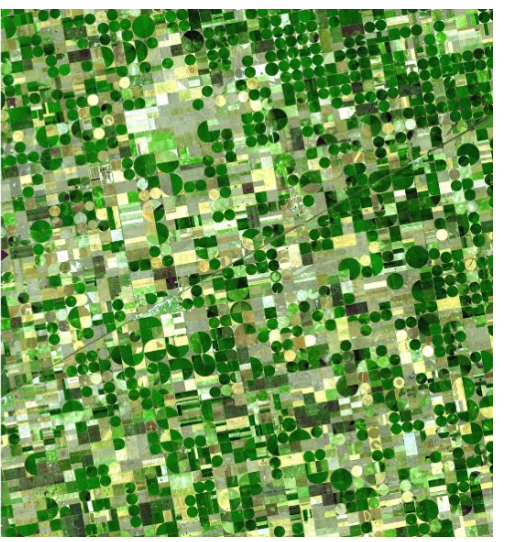

Exploring the SDGs

We chose the SDGs that would be impacted most by space-based research. inspired to begin working together.

We decided to take a satellite view and to focus on what the ISS has to offer as a unique laboratory
Team members offered lots of ideas to start and were

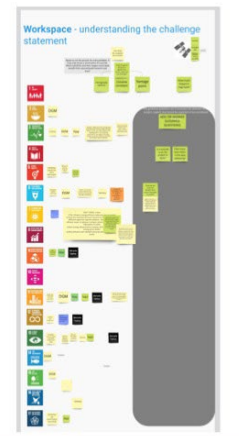

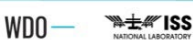

High Focus SDGs

- 3-Good health and well-being

- 11 - Sustainable cities and communities

- 13 - Climate action

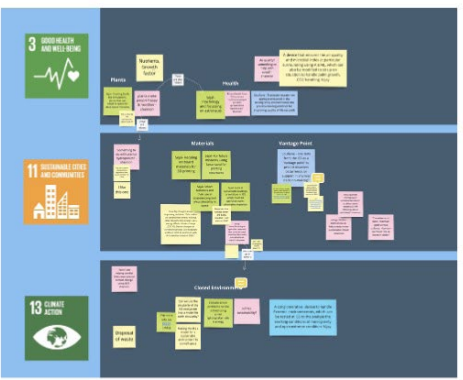

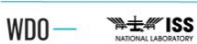

\section{ISS Unique Experimental Conditions}

\section{Our team then broke out into areas where ISS provides} unique opportunities:

\section{Microgravity}

Extreme Conditions

Unique Vantage Point
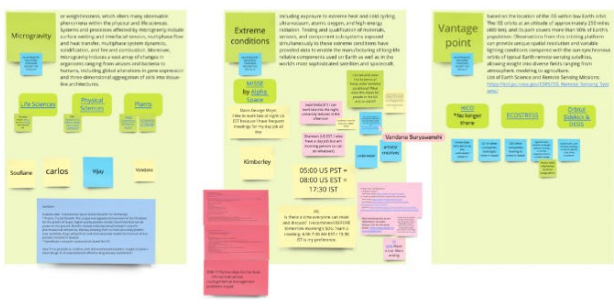

WDO- "

eam 2 / SDG Team 2

\section{Next Steps}

Now that our team has focused in on which SDGs we are interested in

We would like to spend more time defining the problem and understanding who our project impacis be

Identifying the stakeholders for this project, including: Astronauts themselves
End beneiciciaries here on Eart

Enc beneicicaries here on Earth
Potential partnerships (governments, institutions, etc)

We are plotting out our research findings based on relevance to the SDGs, possible outcomes of the experiment, and who are the beneficiaries.

Evaluating each of our idea themes acros:

Is it possible to do it on Earth?
How many main SDGs are addressed?

How many main SDGs are addressed?
Which qualities make space-based rese

technology transfer officece?
Or more useful to a high-impact spinoff?

WDO- M looking at, and done some background research into the unique aspects of
working with the ISS, we have defined the following next steps:

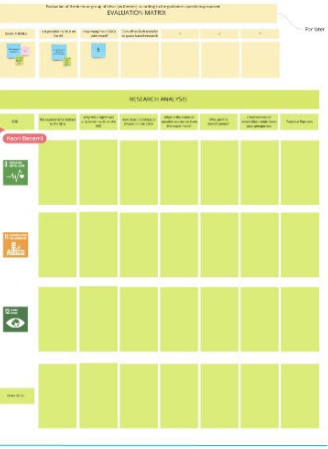

Visual grey-out to protect participant privacy.
High Focus SDGs

\section{3-Good health and well-being \\ 11 - Sustainable cities and communities \\ 13 - Climate action}




\section{Appendix IV}

\section{TEAM 2 PLAYBACK 1}

\section{Presentation}

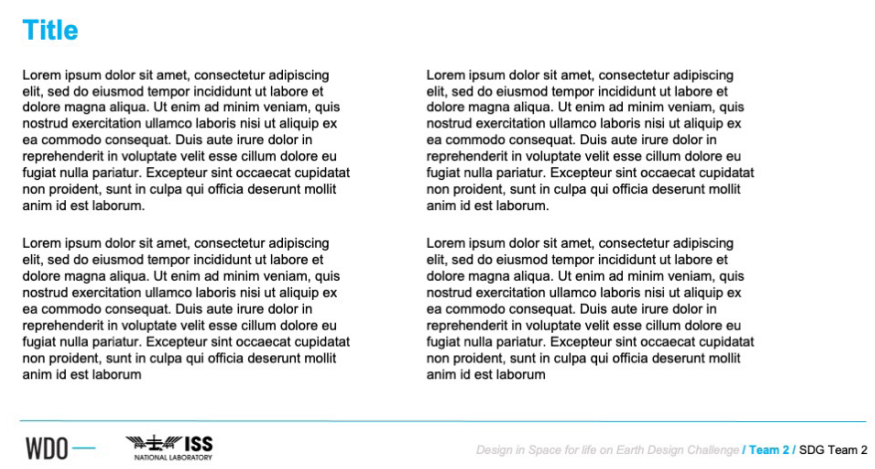




\section{Appendix V}

TEAM 2 PLAYBACK 2

Presentation 


\section{Appendix V}

\section{TEAM 2 PLAYBACK 1}

Presentation

\section{Design in Space for life on Earth Design Challenge}

\section{Team 2}

Cupola

WDO-

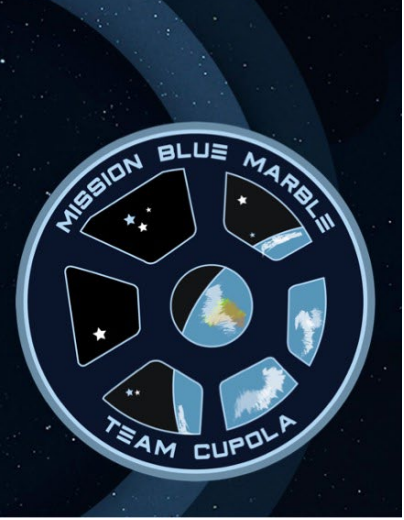

Contents

- Challenge

- Vision and Mission

- Proposed Solution

- Next Steps

- Conclusion

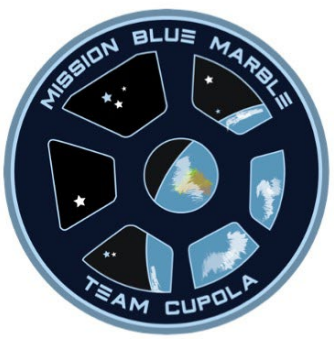

WDO - M:Em ISS

\section{SC}

Space is not only the boost of technological development and knowledge pursuit, but it is also precisely the idea to imagine something novel and completely diverse. That is what drives the great human explorer's spirit.

\section{Challenge Statement}

How can space-based research address UN Sustainable

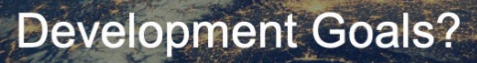

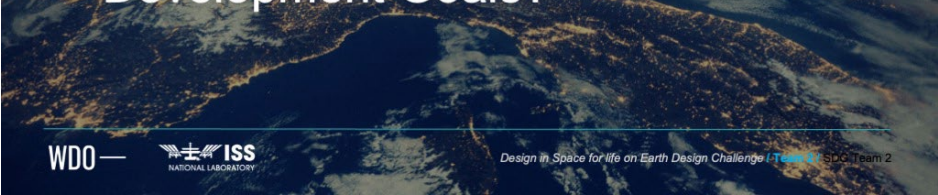

\section{Vision Statement}

We empower and connect those who work to create a sustainable world.

\section{Mission Statement}

We provide a platform to facilitate connections between people who want to directly address the United Nations' Sustainable Development Goals (SDGs) with space-based research.

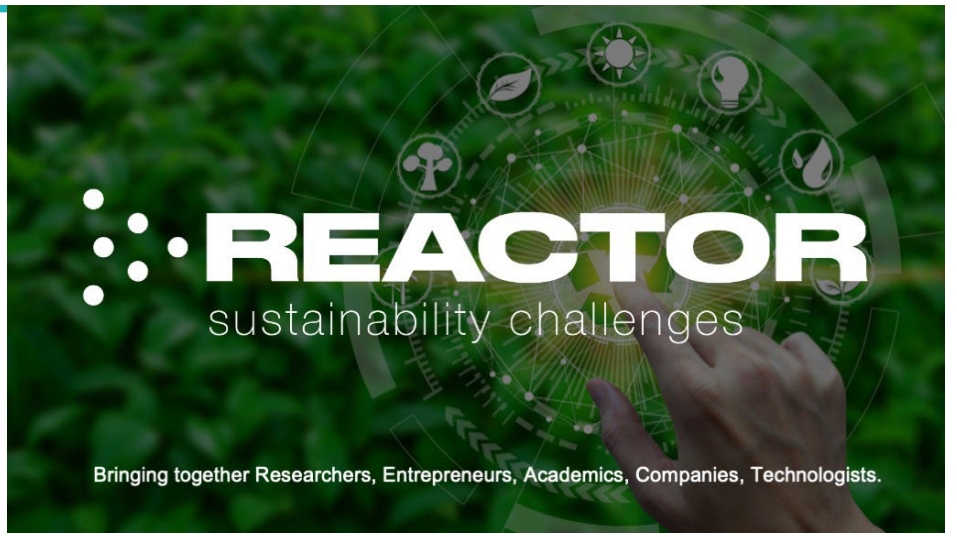

\section{$\because$ REACTOR}

sustainability challenges

Enable collaboration among sustainability researchers, space community and industry partners to develop and scale their technology on Earth.

\section{$\because:$ REACTOR}

Bridge the gap between sustainability and space research communities.

Build community throughout all stages to support each other towards common goal.

Celebrate achievement - both successes \& failures 


\section{Appendix V}

\section{TEAM 2 PLAYBACK 1}

\section{Presentation}

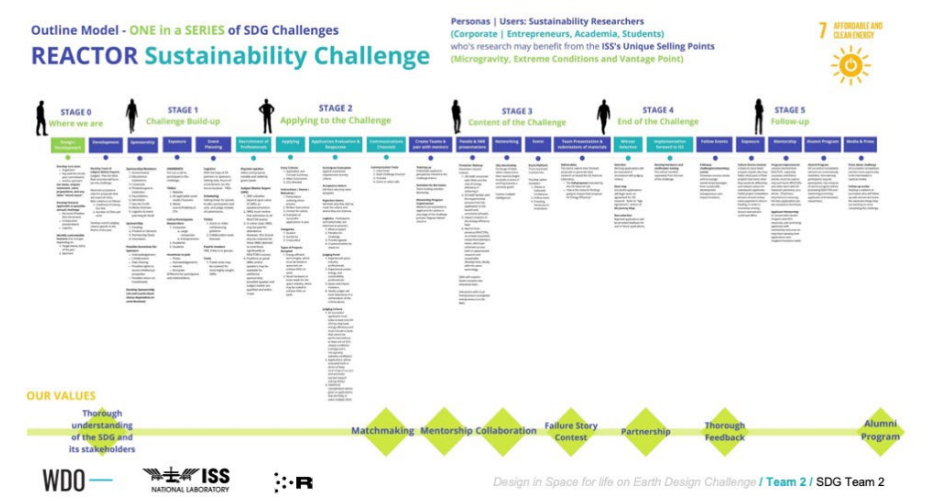

Bridge the Gap between Sustainability and Space

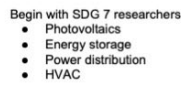
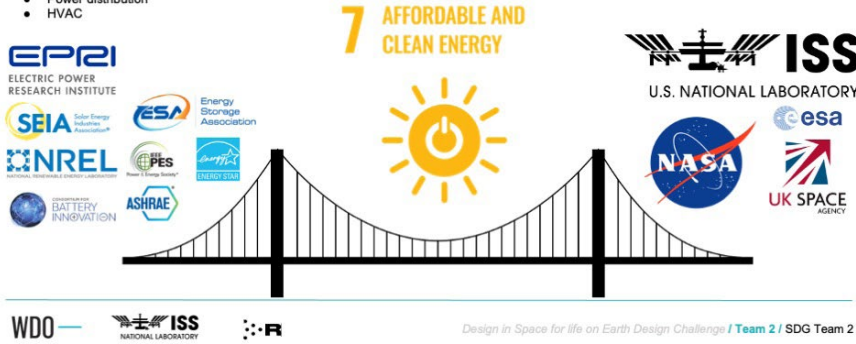

Build Community

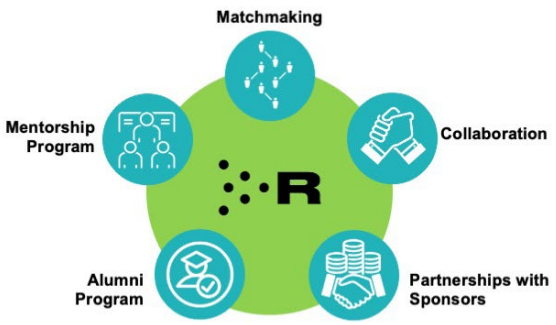

WDO

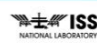

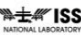

$\because \cdot \mathbf{R}$
Celebrate Achievement

Share success stories and failure stories
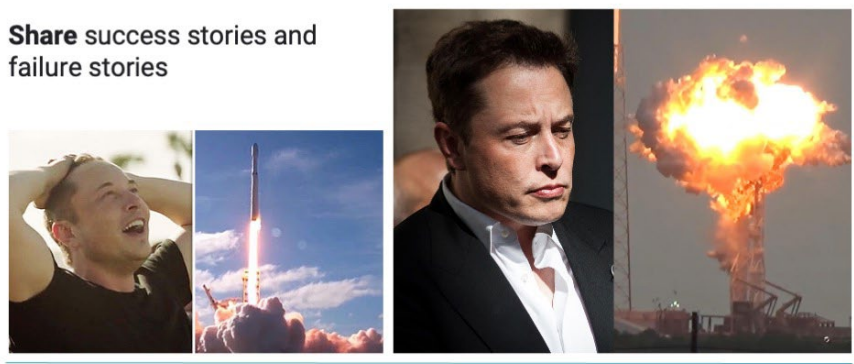

WDO - M:ArISS $\quad \because \cdot \mathbf{R}$
Next Steps

To understand the gap and delivering values to meet SDG targets \& indicators:

- Direct tie between space-based research and SDG targets \& indicators.

- Deepening understanding of stakeholder needs.

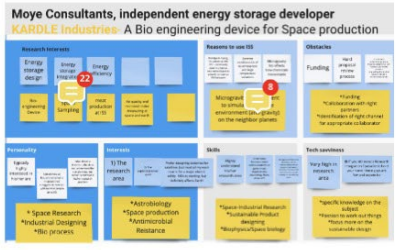

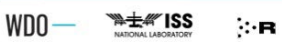

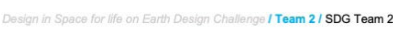

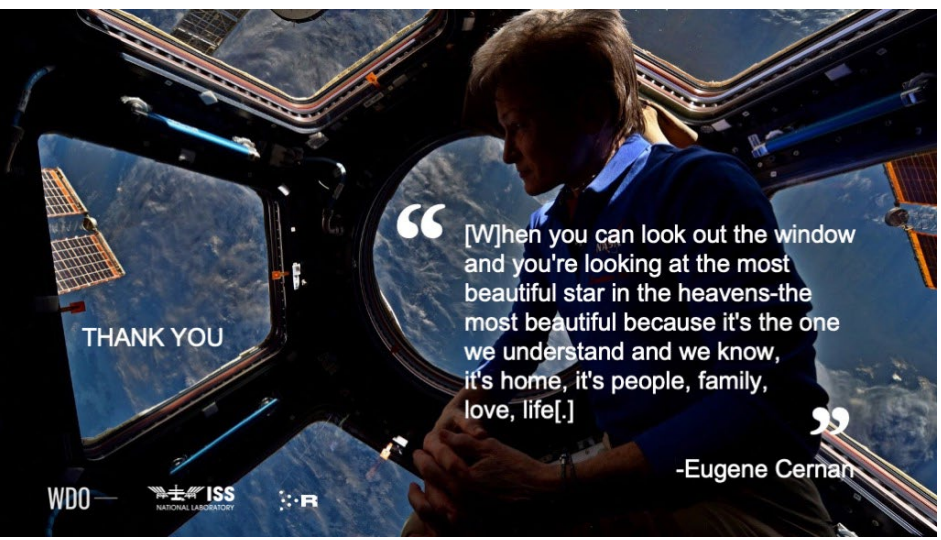

\section{Conclusion}

- Proposed REACTOR Sustainability Challenge to use space-based research to address UN SDGs Sustainable Development Goals.

o 6 stages

- Bridges gap between Sustainability and Space

- Builds community of Sustainability and Space

- Celebrates achievements: Successful and Failed

- Next Step: Understand gaps and how to meet SDG

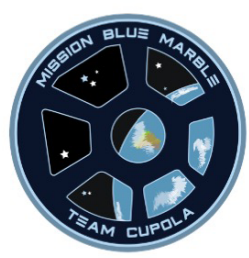

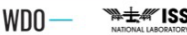

\section{SDG7 Affordable and Clean Energy}

SDG7 Ensure access to affordable, reliable, sustainable, and modern energy for all

7.1 By 2030, ensure universal access to affordable, reliable, and modern energy services 7.2 Increase substantially the share of renewable energy in the global energy mix by 2030

7.3 double the global rate of improvement in energy efficiency by 2030

7.a By 2030, enhance international cooperation to facilitate access to clean energy
. 7.a By 2030, enance and chenced clean energy technologies

frastructure and upgrade technology for supplying modern and sustainable energy services for all in developing countries, particularly LDCs and SIDS

WDO - MIÁlss

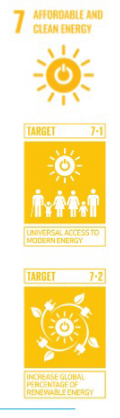




\section{Appendix V}

\section{TEAM 2 PLAYBACK 1}

\section{Presentation}

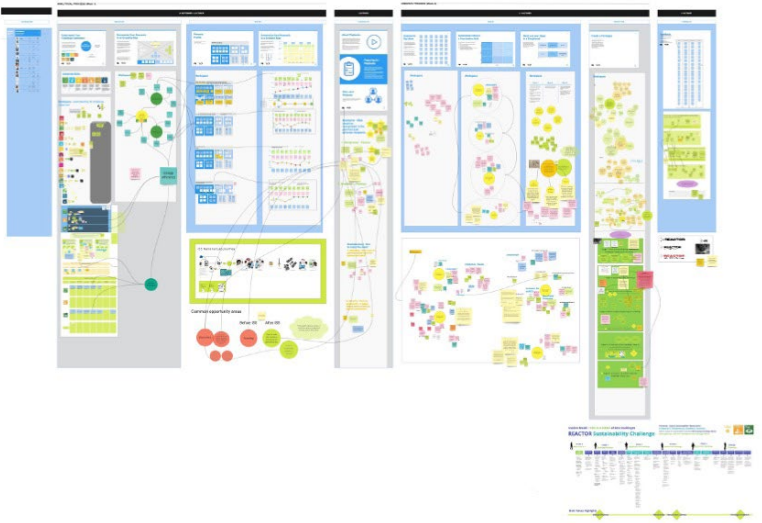




\section{Appendix VI \\ TEAM 2 DAILY ACTIVITIES}

Agenda

Homework

Meeting Notes 
Agenda and homework in most cases, were created by both facilitators and posted on Slack.

Meeting notes were taken by a volunteer participant and posted on Slack.

Meeting video recordings were not saved because the facilitator did not have access to a paid account.

\section{SEPTEMBER 29}

\section{AGENDA AND TASKS TO COMPLETE}

\section{Agenda}

\section{1) Introductions of the team:}

Attendance: 8 team members, 2 thought leaders and 1 team facilitator During this first meeting introductions were made: Name, experiences and background.

\section{2) SDGs review:}

An overview of the SDGs was presented in order to so that we are all in context for the discussion for the direction of the project.

You can find the presentation on the Session 1 folder: https://drive. google.com/drive/u/O/folders/1fF9WJ96feNH9fP_BPGTpPeivq_ m6RCvu

\section{3) SDGs exchange of ideas:}

As a follow-up to the review, the team members discussed their concerns and ideas for the direction for the project. It was explained that the interest of the group can focus on any of the 17SDGs.

For the inquiries of ISS experiments Miki Sode, thought leader, solved, explained the context and gave an overview of what is happening on the ISS.

For the Design Sprint and creative process Angie Fahlman, thought leader, indicated the recommendations and suggestions to follow throughout the process.

As the meeting progressed a poll was made on miro board on the first work space "understanding the challenge" so the team members vote on the SDGs they were most interested in solving, along with their ideas.

You can find some topics of the discussion on the "Meeting notes" : https://docs.google.com/document/d/1c0zhjliW9wQPocQbnpc1zhrlGPmLNuNr4cckFoTz5SE/edit that were extracted from the chat.

\section{Homework}

1) Fill your data on the Ice-breaker

2) Vote for the SDGs you are interested in solving on miro board.

3) If you have an idea, as crazy as it might seem, write it on the miro board first workspace, so that we can come back later.

\section{Next steps:}

1) On Wednesday $30 / 09 / 2020$ the direction of the project (SDGs we are focusing on the team) will be selected. 
2) Most of the participants on the call agree to have meetings at 08:00 am EST.

3) Miki proposed to have casual chats for questions and ideas discussions every day at 18:00 EST, for those who are available and interested.

Challenge, any violation of these rules is not with consequences, including but not limited to the removal from the project. We thank you for respecting the privacy of all participants.

https://drive.google.com/drive/u/3/folders/1/CR7sxiN1eyWqGKzeuR VOsk71i-YN1-A

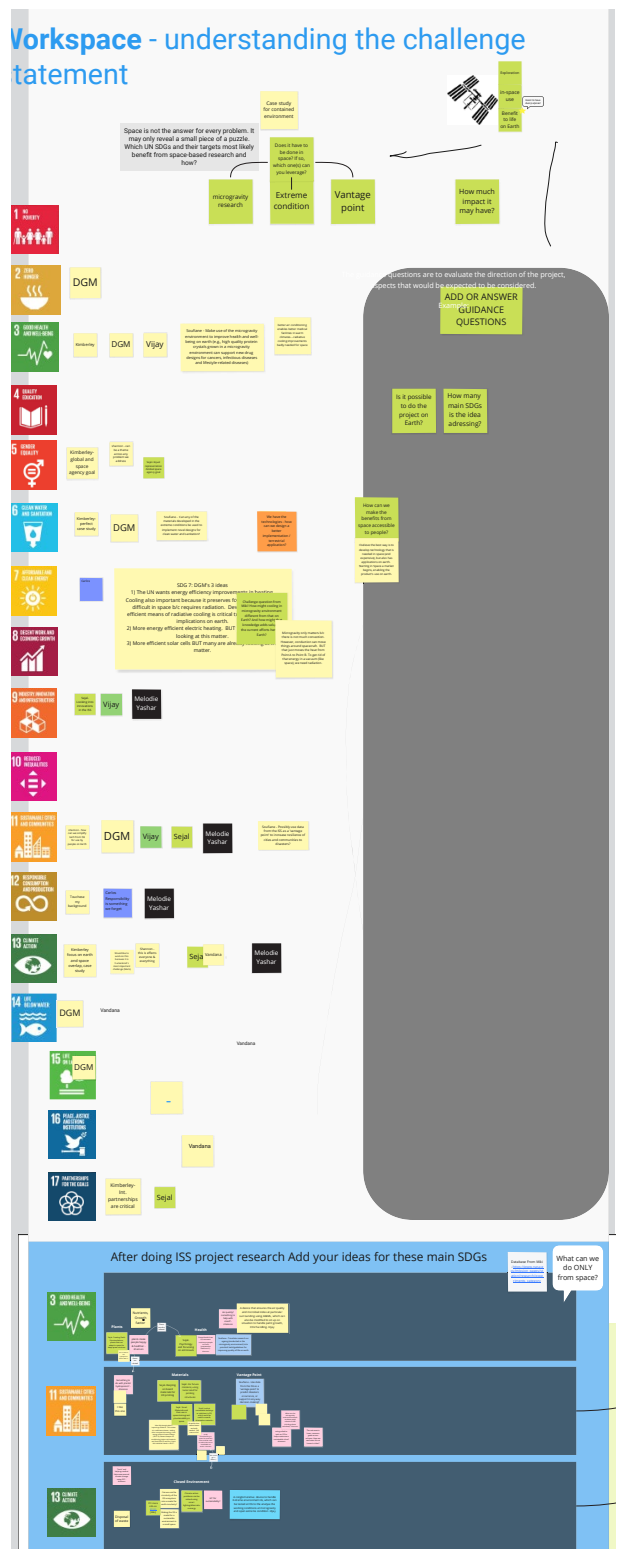

\section{SEPTEMBER 30 \\ AGENDA AND TASKS TO COMPLETE}

\section{Agenda}

1) Review of the work done:

Attendance: 11 team members, 2 thought leaders and 1 team facilitator During the meeting we made a quick review of the first session and what was talked about at the office hour.

\section{2) Narrowing down the SDGs}

By counting the votes of the team interests, 3 main SDGs were selected as the main focus of the team:
a) SDG 3
b) SDG 11
c) SDG 13

Take into consideration that the project proposal can address other SDGs but in a secondary plane.

\section{3) Creating and discussing ideas.}

A section was created to add ideas concerning the 3 main SDGs. There was an exchange of ideas and concerns to take into account, the notes of the chat commentary can be found on "Notes on session 2" https://docs.google.com/document/d/1vdZtOdHYm9ZrG1NLLMmX d4GZThFPOmTVfac9gumSQJE/edit

\section{4) Defining a structure to propose ideas}

It was build an structure to follow to better propose inform ideas, under standing the context of the ISS and to see what's already been done:

The team will divide into 3 research groups, to learn what has been done on the ISS? According to the 3 points of why space-based experiments are done:
a) Microgravity
b) Extreme conditions
c) Vantage points

The subjects of research are in a section of the miroboard so you could put a sticker with your name and reach to your partners to work 
together. At the top of the section Miki included some links as a starting point to research. To share your findings with the team, you can posted on the miro board or please post them on this google doc: https://docs.google.com/document/d/15qtv42yYghs/lF5LuwFRUjlpk1bSzOLqoMu0w0_E9yo/edit

5) Once done your research and understanding of the context of what has been done, you can add your ideas into the SDGs ideas section and if you already post some ideas before your research, allow yourself to evaluate them after your new take.

6) Group the ideas into common themes.

7) On another hand, after your research is done, propose guidance questions, those questions are to evaluate the direction of the project, aspects that would be expected to be considered and to create an evaluation matrix.

8) Once the ideas are grouped and the evaluation matrix is ready with the guidance questions we will proceed to select the best theme to solve

\section{Homework}

1) Select your research team and contact them to organized a quick search

2) Post your findings

3) Propose new informed ideas and guidance questions

4) Group the similar ideas into themes

5) As a group we will later evaluate the ideas with our matrix to select the theme to work on.

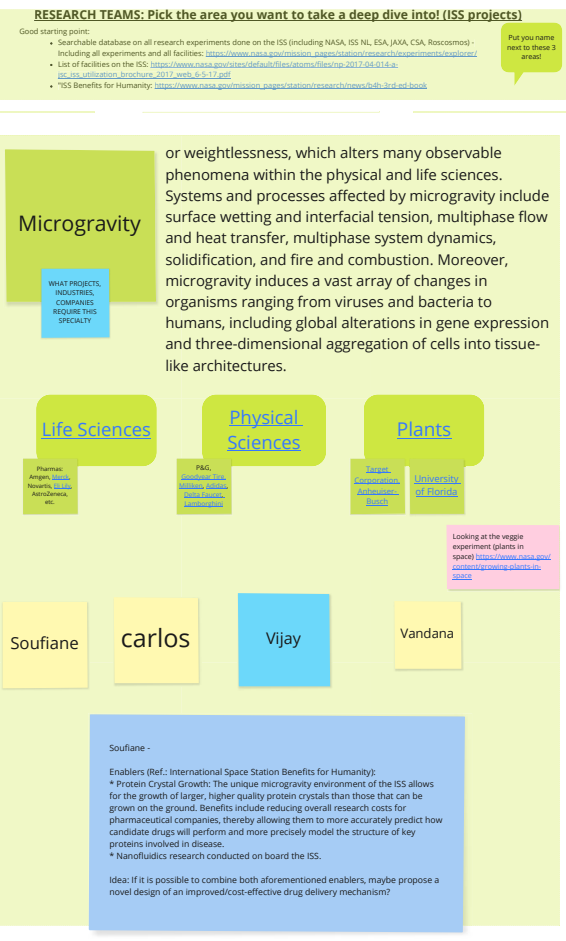

\section{SEPTEMBER 30 PM \\ AGENDA AND TASKS TO COMPLETE}

\section{Agenda}

1) How's everyone doing or feeling?

It was proposed to take into consideration when ideation happens the overview effect while thinking to make an impact on the beneficiaries detected and the overall people.

The team members expressed a concern about understanding the problem, some of them feel that we were on a rush to get ideas without understanding this next points:

a) Understanding the context of the problem

b) Understanding who are the users and the beneficiaries

c) Understanding the need of the stakeholders

So about this insight it was proposed to take a pause on ideation to review and take the time to understand the overall context so that we can better point out the objectives for the project.

Other questions that were made:

2) Who benefits from the SDGs?

3) How can we combine a balanced approach from humanistic under standing and engineering and science understanding? 

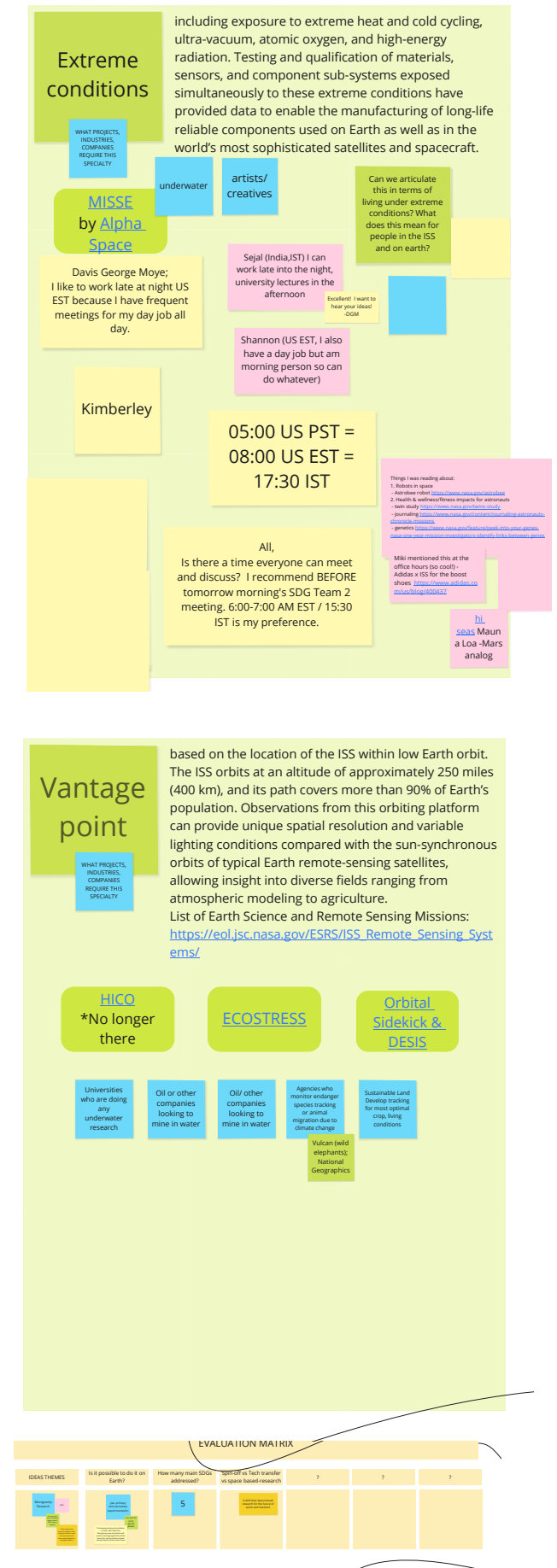

RESEARCH ANALYSIS
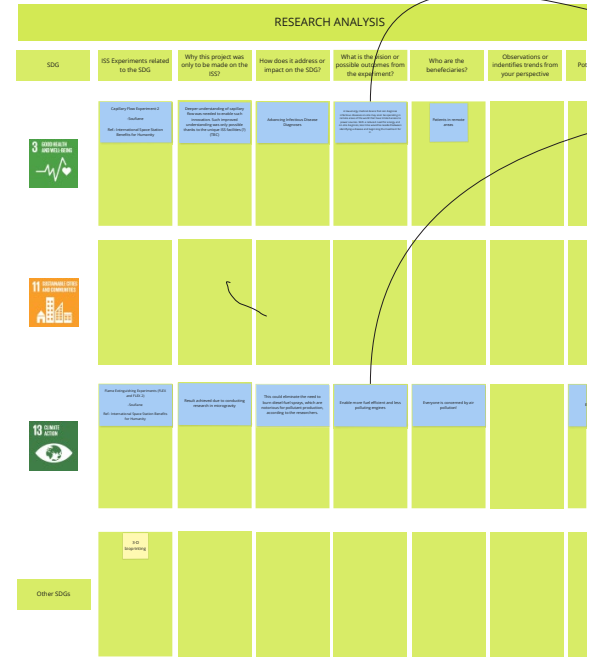

4) What are the environmental impacts that relate to the SDG and who comes out as a beneficiary of that?

After sharing the concerns it was decided to take a pause from ideation and proceed to share the insights about the research assignment.

5) Review of the work done:

Insights of the research and new ideas were shared.

For the new ideas of a concrete project, as we agree to take a pause, it was advice to pin those thoughts for a moment so that we could come back to that later.

As for the research done, the team members shared their findings, which you can check on the miro board.

You can find notes on the conversation on the chat during the meeting at the link: https://docs.google.com/document/d/14dpf74LknUNkCa994Y8BX4O0K5n43k14xG7UnXgPluE/edit

While discussing experiments on the ISS of drugs, during the conversation it was suggested to review the impact of the projects of the pharmaceutical industry, from that it was suggested to also consider different possible industries that may address a problem related to the SDGs selected.

After sharing findings, the discussion took a turn to understand basic concepts to understand and consider while doing this specific challenge.

6) Concepts for the design process to consider:

7) Stakeholders:

We can find two main stakeholders for this challenge:

USERS: Since the experiments are done on the ISS National Lab, those are done by the astronauts, considering them as direct users.

BENEFICIARIES: As the challenge says, we are focusing on results done in space that help the Earth, so inevitably the beneficiaries are the people on Earth.

8) What are the applications for things done on the ISS?:

While discussing some ideas it was necessary to point out the differences of the objectives of the projects done aboard on the ISS:

SPINOFFS: Systems, products, etc., that were created to use in space that might have an application later on Earth. Like Teflon or Spandex

TECHTRANSFER: It might be similar to the Spinoffs, but this one can go both ways. A technology developed on Earth for Earth could be used for an application in space or vice versa.

SPACE BASED: What concerns us, is this direction. Something only could be done in space that we can bring its benefits to Earth.

\section{Homework}

After continuing the discussion about how can we connect the points of what can be done on the ISS lab, how can impact the SDGs to Earth beneficiaries, and raising more questions like:

- How can we communicate the impact of the ISS development to Earth beneficiaries?

- What's the common ground for the SDGs? 
We came to the conclusion to create an analysis map for the research done and organized the insights of the conversation and other possible findings. In the framework of responding to the initial concern of the group for understanding the overall context, this map can help us to proceed to the next steps. Each of the column respond to a theme question made on this session:

SDG: In this you can find the selected SDGs and if you found projects related to other SDGs you can share the findings on the last line.

ISS EXPERIMENTS RELATED: In this column you categorize the ISS projects in relation to the SDGs

WHY THE PROJECT WAS MADE IN SPACE?: Addressing the direction of the project about Space Based Research. Why was it only possible to do it on the ISS?

HOW DOES IT ADDRESS THE SDG? Even Though you already categorized the project according to the SDGs, here you explain exactly how it is involved or related to the specific SDG.

WHAT ARE THE POSSIBLE OUTCOMES ON EARTH FOR THE PROJECT? Addressing the possible future or impact that could have on Earth as a result, it doesn't have to be an immediate result.

WHO ARE THE BENEFICIARIES OF THE PROJECT? Not the users, but who is beneficiary on Earth from that?

SHARE YOUR OBSERVATIONS In here you are encouraged to review a finding after reading the analysis, please review the other projects post in it, not only yours.

\section{OCTOBER 2}

\section{AGENDA AND TASKS TO COMPLETE}

\section{Agenda}

After the playback session, which you can find here: https://drive.google. com/drive/u/0/folders/1X3NcTMSjzo5GQzrDFG_Gt-vW8uKURITV

A meeting between the thought leaders and facilitators of the SDG Teams happen, where there was realization of the general direction of the project, since both teams had troubles reaching an end user:

The teams are not expected to develop a project for a research proposition for the ISS, instead we are asked to understand How does space based research on the ISS could address the SDGs? Deliver that information to those who are interested into knowing, so the questions started to happen:

1) Who can do something with the knowledge that the ISS can help address the SDGs?

2) Who is addressing the SDGs? 

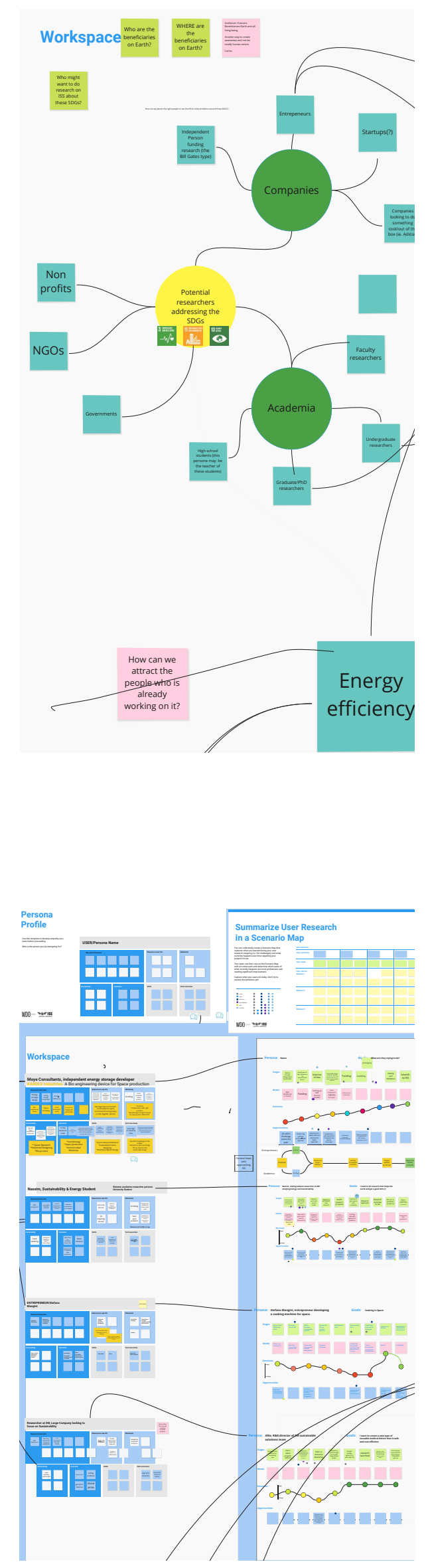

We are not expected to solve a particular or several SDG, but to help those who can. Our challenge is not about generating research for the ISS National Lab, it's about who would be doing the research that needs the ISSs' 3 benefits? And how can we make them know about the ISS and how can we make it accessible to them?

\section{Choosing a theme}

As having a conversation about the interests of the team it was suggested a common ground about focusing on ENERGY EFFICIENCY.

Researchers brainstorm.

So the team started working towards finding every kind of researcher who would be interested to work on a research with the ISS in the area about

\section{ENERGY EFFICIENCY.}

The potential researchers were grouped and two big categories were recognized Companies and Academia.

From that, the group selected those categories to develop a persona:

1) Companies: Entrepreneur

2) Academia: Graduate Student

3) Companies: Companies looking to do something cool (out of the box (ie. Adidas) with a large budget

\section{Homework}

1) Persona development

Fictional persona's were described based on the teammates experience so we could develop empathy and better understanding of their needs.

\section{OCTOBER 3}

\section{AGENDA AND TASKS TO COMPLETE}

\section{Agenda}

\section{1) Review}

A review was made to explain the progress and new direction for the team.

\section{2) Persona Scenario}

After finishing the persona profiles.

The team proceeded to build the persona scenarios. Thinking about the journey map of the persona from the moment they get to know the ISS possibilities, up until has access to participate along the ISS. Going through the stages, the needs during the stages, the emotions of the person, and the opportunity areas. 


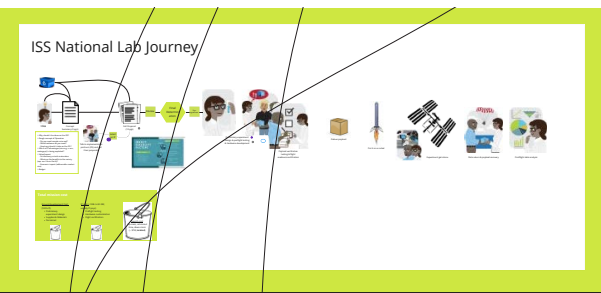

OCTOBER 4

\section{AGENDA AND TASKS TO COMPLETE}

\section{Agenda}

1) Review

A review persona

\section{2) ISS journey map}

Miki shared the journey map for the ISS common usual procedure to engage into new research.

\section{Homework}

1) The next steps/homework

Once the scenario maps are filled out, we will identify the stages or steps of their journey and the problems in those stages during the potential researcher experience.

2) Put a sticker on the stages that you find are more problematic for each

3) If you have an idea about how to solve a problem on the stages, put a sticky note on the corresponding brainstorm area.

\section{OCTOBER 5}

\section{AGENDA AND TASKS TO COMPLETE}

\section{Agenda}

1) Reviewing the opportunity areas

While evaluating the scenario maps the team was given 6 minutes to put 3 stickers for each map to identify the stages that it was considered to have a relevant opportunity area for the team to solve.

Each person had a color to add a sticker.

\section{Finding and defining the common areas}

After this exercise several common stages for the companies and academia with opportunity areas where found, so then it was categorized the problems to address in the team proposal.

Eliminating categories that were not feasible for the ISS to address. As going through the common stages problems, our thought leader Miki addresses the categories that the ISS can't get involved in or helped, since it is the researcher's responsibilities.

After a team discussion, the categories were narrowed down to 5 big areas,

Brainstorming - How

to reach the users?

A. Marketing - How to can we

generate awareness to the

sponsor and users?

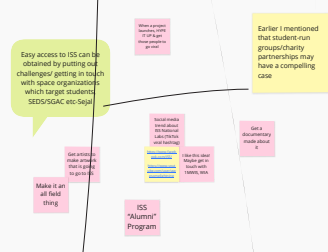

It was also addressed and emphasized to consider the big picture of it all for stages before using the ISS for space based research and after it.

DISCOVERY: A basic opportunity area for this challenge is to find ways for potential researchers to know the existent possibility to use the ISS National Lab in order to address the problem they want to solve regarding the SDGs, and in this case Energy Efficiency. 
Common opportunity areas
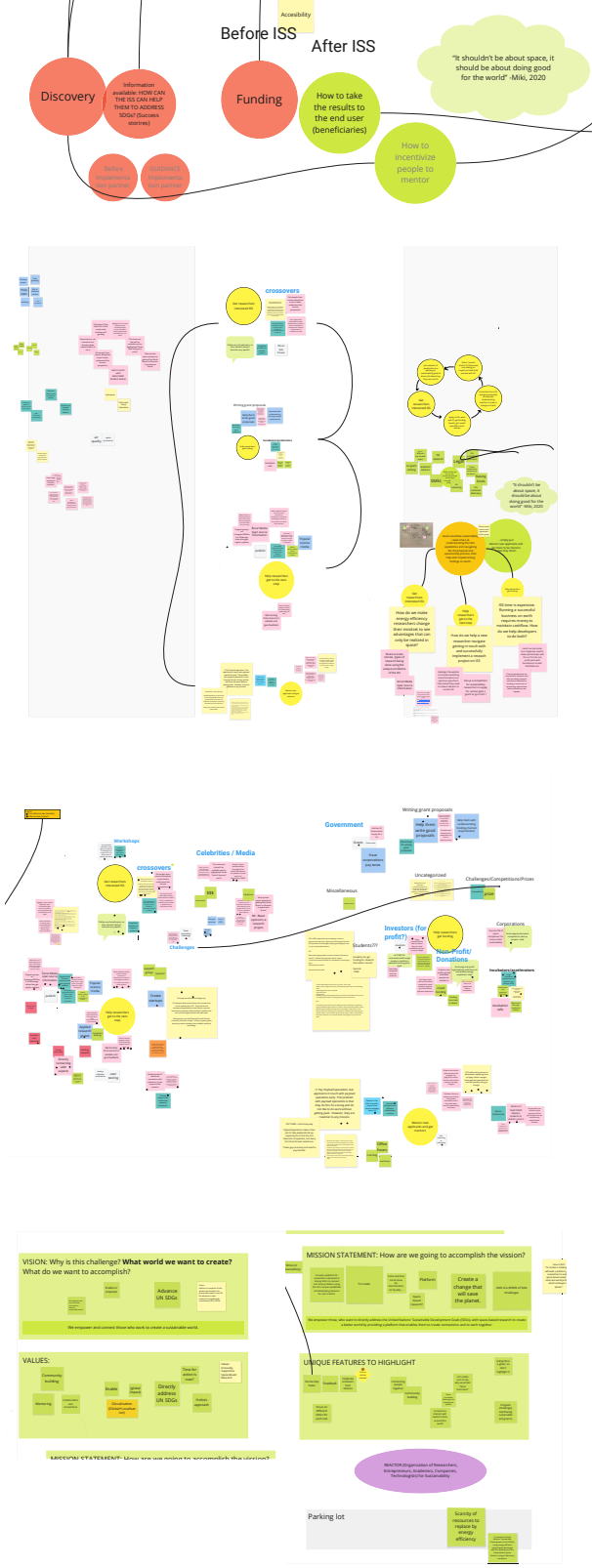

INFORMATION AVAILABLE (HOW CAN THE ISS HELP THEM TO ADDRESS SDGs?: Another big area to work on, and the basis for this challenge is to let the researchers know in what way the ISS can help their objectives. It was suggested to share and let them know how the ISS has already helped projects solving SDGs challenges. (Success stories). How are we going to deliver this information?

Along with the theme about information available it was talked during the discussion How to help or guide researchers applying for the use of ISS? How and who could mentor potential researchers through the ISS journey? Whether before or after an implementation partner is involved.

FUNDING: Big stone on the way is how can the researchers find the economical resources for implementing their experiment aboard the ISS?

After the use of the ISS National Lab facilities. What happened?

HOW TO TAKE THE RESULTS TO THE END USER (BENEFICIARIES) OF THEIR RESEARCH?: Find a way to help researchers achieve their goal in order to help others, the earth population that could benefit from their (in this case) energy efficiency projects.

HOW TO INCENTIVE PEOPLE TO MENTOR?: Thinking about the earlier problem for guidance, it was suggested a way for the people who already successfully applied and used the ISS to help new applicants. How do we convince them to help and keep them coming back.

\section{Homework}

1) While thinking about these problems, post on the brainstorming area on miro board, ideas that you come up with to solve them.

2) Build up upon the other team mates ideas already posted.

For the next session IT IS IMPORTANT THAT THE MAJORITY OF THE TEAM JOIN, TO WORK ON THE IDEATION SESSION.

\section{OCTOBER 6-7}

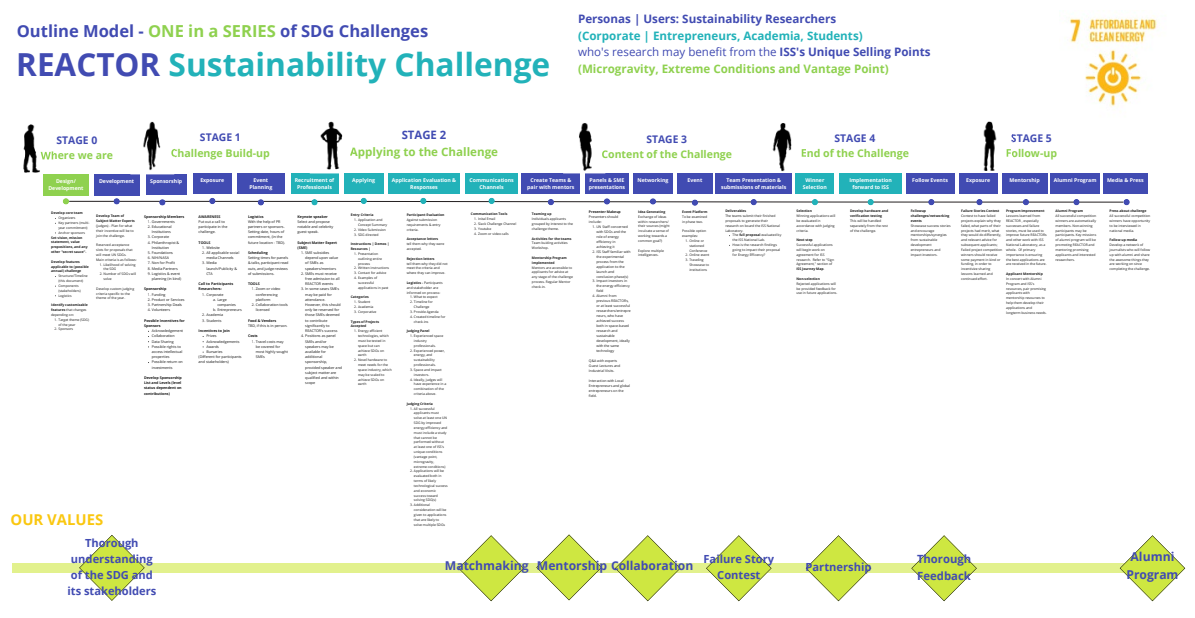

